Illinois State University

ISU ReD: Research and eData

Theses and Dissertations

$11-20-2018$

\title{
A Mixed Methods Study Of The Implementation Of Collaborative Technology Tools For Enhancing Collaboration And Student Engagement In Online Learning: Faculty Experiences And Student Perspectives
}

Ayshah Abdullah Alahmari

Illinois State University, ayshah.alahmari@gmail.com

Follow this and additional works at: https://ir.library.illinoisstate.edu/etd

Part of the Higher Education Administration Commons, Higher Education and Teaching Commons, and the Instructional Media Design Commons

\section{Recommended Citation}

Alahmari, Ayshah Abdullah, "A Mixed Methods Study Of The Implementation Of Collaborative Technology Tools For Enhancing Collaboration And Student Engagement In Online Learning: Faculty Experiences And Student Perspectives" (2018). Theses and Dissertations. 1034.

https://ir.library.illinoisstate.edu/etd/1034

This Dissertation is brought to you for free and open access by ISU ReD: Research and eData. It has been accepted for inclusion in Theses and Dissertations by an authorized administrator of ISU ReD: Research and eData. For more information, please contact ISUReD@ilstu.edu. 


\section{A MIXED METHODS STUDY OF THE IMPLEMENTATION OF COLLABORATIVE \\ TECHNOLOGY TOOLS FOR ENHANCING COLLABORATION AND \\ STUDENT ENGAGEMENT IN ONLINE LEARNING: \\ FACULTY EXPERIENCES AND \\ STUDENT PERSPECTIVES}

AYSHAH ABDULLAH ALAHMARI

220 Pages

The appropriate implementation of collaborative technology tools in online courses leads to a culture of social learning where technology empowers students to take central roles in their learning. Yet, critical questions still exist about how faculty design, develop, implement collaborative eLearning activities using technology tools that support collaboration and student engagement in online courses, and what perspectives students have toward their experiences while participating in these activities. The purpose of the study is to explore the experiences of faculty members implementing collaborative technology tools in online courses to support collaboration and student engagement, in addition, to obtain the perspectives of students toward their experiences while participating in these activities. The study attempts to better understand the potential and use of technology for enhancing collaboration and student engagement in online settings and the factors that influence the selection of collaborative technology tools for incorporating collaborative eLearning activities in online courses. An explanatory sequential mixed methods approach was utilized to collect data from a total of 210 faculty and student participants who met the participation criteria and volunteered to participate in the study at a 
large Midwestern state university. Out of the 210 participants, 29 faculty members and 181 students were surveyed, and after a review of the results, follow-up interviews were conducted with four faculty members and two students. The findings of this study confirmed that collaborative technology tools have the potential to create a virtual collaborative environment that enables instructors to establish a learning community within online courses where students can synchronously or asynchronously work together toward a common task, in which each student adds to an emerging pool of knowledge of the group. This study provides evidence that the use of collaborative technology tools positively affects students' experiences with collaborative eLearning activities in online learning. The instructor's ability to successfully select and implement collaborative technology tools that effectively support collaborative eLearning and student engagement in online courses is a primary concern. This concern raises the demand for online instructors who are well-prepared and fully-supported to integrate collaborative technology tools into online settings and design eLearning activities that engage students and foster interaction and collaboration. Possible implications of the study and practical recommendations drawn from the findings of the study for professional and meaningful practice are discussed.

KEYWORDS: collaborative eLearning; collaborative technology tools; online learning; social constructivism; transactional distance; social presence 


\section{A MIXED METHODS STUDY OF THE IMPLEMENTATION OF COLLABORATIVE TECHNOLOGY TOOLS FOR ENHANCING COLLABORATION AND STUDENT ENGAGEMENT IN ONLINE LEARNING: \\ FACULTY EXPERIENCES AND STUDENT PERSPECTIVES}

AYSHAH ABDULLAH ALAHMARI

A Dissertation Submitted in Partial

Fulfillment of the Requirements for the Degree of

DOCTOR OF EDUCATION

School of Teaching and Learning

ILLINOIS STATE UNIVERSITY 
(C) 2019 Ayshah Abdullah Alahmari 


\section{A MIXED METHODS STUDY OF THE IMPLEMENTATION OF COLLABORATIVE TECHNOLOGY TOOLS FOR ENHANCING COLLABORATION AND STUDENT ENGAGEMENT IN ONLINE LEARNING: \\ FACULTY EXPERIENCES AND STUDENT PERSPECTIVES}

AYSHAH ABDULLAH ALAHMARI

COMMITTEE MEMBERS:

Ryan A. Brown, Chair

Steve Mertens

Lydia Kyei-Blankson

Jay C. Percell 


\section{DEDICATION}

I dedicate this dissertation to my parents, my husband, and my children, who mean the world to me... 


\section{ACKNOWLEDGMENTS}

In the Name of Allah, the Beneficent, the Merciful. All praise and thanks are due to Allah, the Lord of the Universe for the blessing providing me the strength and patience to complete this dissertation. I pray that I utilize the knowledge Allah has provided me through this journey for good and to benefit others earnestly.

First and foremost, I would like to express my sincere appreciation to my dissertation committee chairperson, Dr. Ryan Brown, for the invaluable support, guidance, and encouragement throughout my journey. I would also like to acknowledge my dissertation committee members, Dr. Steve Mertens, Dr. Lydia Kyei-Blankson, and Dr. Jay Percell for their insightful comments and encouragemen. Their guidance, advice, and support have largely contributed to the successful completion of this dissertation.

I would like to express my great gratitude to my family for all of the spiritual support throughout this process. To my parents, thank you for your prayers, inspiration, and endless encouragement. Thank you for believing in me and I hope that I have made you proud. To my sisters and brothers, thank you for all the love, encouragement, and endless support. To my beloved husband, words cannot express my appreciation and gratitude to you for being always by my side to provide love and support. Without your care, patience, sacrifices, and endless support, I would not be where I am today. To my brilliant children, thank you for being my inspiration to achieve greatness and success. Thank you for all the love, joy, and happiness that you gave me. Thank you for coming into my life, you are my greatest accomplishment.

A. A. A. 


\section{CONTENTS}

Page

ACKNOWLEDGMENTS

TABLES vii

FIGURES Viii

CHAPTER I: INTRODUCTION 1

Background of the Study 1

$\begin{array}{ll}\text { The Purpose of the Study } & 4\end{array}$

$\begin{array}{ll}\text { Research Questions } & 4\end{array}$

$\begin{array}{ll}\text { Assumptions } & 5\end{array}$

$\begin{array}{ll}\text { Definition of Key Terms } & 6\end{array}$

$\begin{array}{ll}\text { Rationale } & 7\end{array}$

$\begin{array}{ll}\text { Significance of the Study } & 7\end{array}$

Limitations of the Study 99

Organization of the Dissertation $\quad 9$

CHAPTER II: LITERATURE REVIEW 11

$\begin{array}{ll}\text { Introduction } & 11\end{array}$

$\begin{array}{ll}\text { Online Education } & 12\end{array}$

$\begin{array}{ll}\text { Influence of Technology } & 16\end{array}$

$\begin{array}{ll}\text { Design and Development } & 18\end{array}$

$\begin{array}{ll}\text { Collaborative Learning } & 20\end{array}$

Effective Collaborative Learning $\quad 21$

Technology Tools for Collaborative Learning 26 
Theory of Social Constructivism

Theory of Transactional Distance

Theory of Social Presence

Conclusion

Introduction

Research Design

Research Setting \& Study Sample

Research Participants

Description of the faculty participants.

Description of the student participants.

Description of the interviewees.

Research Instruments

Survey Instrument

Interview Instrument

Pilot Study Procedures

Data Collection Techniques

Quantitative Data Collection

Qualitative Data Collection

Data Analysis Procedures 
$\begin{array}{ll}\text { Triangulation } & 72\end{array}$

$\begin{array}{ll}\text { Validity and Reliability } & 73\end{array}$

$\begin{array}{ll}\text { Positionality Statement } & 75\end{array}$

$\begin{array}{ll}\text { Ethical Assurances } & 79\end{array}$

$\begin{array}{ll}\text { CHAPTER IV: FINDINGS } & 81\end{array}$

$\begin{array}{ll}\text { Overview of the Study } & 81\end{array}$

$\begin{array}{ll}\text { Findings } & 83\end{array}$

$\begin{array}{ll}\text { Research Question } 1 & 83\end{array}$

Integration of collaborative technology tools. $\quad 88$

$\begin{array}{ll}\text { Preparedness and proactive thinking. } & 90\end{array}$

$\begin{array}{ll}\text { Creating a sense of instructor presence. } & 91\end{array}$

Establishing a sense of community. $\quad 94$

Engaging student collaboration. 95

$\begin{array}{ll}\text { Troubleshooting. } & 96\end{array}$

$\begin{array}{lr}\text { Practical guidelines and considerations. } & 100\end{array}$

Research Question $2 \quad 102$

$\begin{array}{ll}\text { Faculty-related factors. } & 104\end{array}$

$\begin{array}{ll}\text { Student-related factors. } & 109\end{array}$

Research Question $3 \quad 111$

$\begin{array}{ll}\text { Faculty perspectives. } & 111\end{array}$

$\begin{array}{ll}\text { Student perspectives. } & 116\end{array}$

CHAPTER V: DISCUSSION AND IMPLICATIONS 125

$\begin{array}{ll}\text { Overview of Study } & 125\end{array}$ 
$\begin{array}{ll}\text { Summary of Findings } & 126\end{array}$

$\begin{array}{ll}\text { Research Question } 1 & 126\end{array}$

$\begin{array}{ll}\text { Research Question } 2 & 128\end{array}$

$\begin{array}{ll}\text { Research Question } 3 & 130\end{array}$

$\begin{array}{ll}\text { Discussion } & 131\end{array}$

$\begin{array}{ll}\text { Collaboration Tools } & 132\end{array}$

Instructional Influence of Technology Integration 133

$\begin{array}{ll}\text { Fostering student engagement. } & 134\end{array}$

$\begin{array}{ll}\text { Demonstrating and building knowledge. } & 134\end{array}$

$\begin{array}{ll}\text { Promoting collaborative authoring. } & 135\end{array}$

$\begin{array}{ll}\text { Increasing online presence. } & 135\end{array}$

Establishing a sense of learning community. 136

$\begin{array}{ll}\text { Instructing 21st-century skills. } & 137\end{array}$

Factors Influence the Tool Selection Process 138

$\begin{array}{ll}\text { Faculty roles and responsibilities. } & 140\end{array}$

$\begin{array}{ll}\text { Faculty professional development. } & 141\end{array}$

$\begin{array}{lr}\text { Implications and Contributions } & 144\end{array}$

$\begin{array}{ll}\text { Recommendations for Future Practice } & 147\end{array}$

$\begin{array}{ll}\text { Practical Recommendation for Faculty } & 147\end{array}$

$\begin{array}{ll}\text { Practical Recommendation for Educational Institutions } & 149\end{array}$

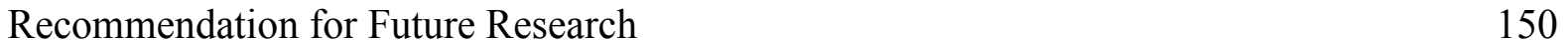

$\begin{array}{ll}\text { Conclusion } & 151\end{array}$

$\begin{array}{lr}\text { REFERENCES } & 153\end{array}$ 
APPENDIX F: E-MAIL INVITATION TO PARTICIPATE IN A FOLLOW-UP 


\section{TABLES}

Table

Page

1. Description of Faculty Participants

2. Description of Student Participants

3. Description of the Interviewees

4. Description of Study Variables

5. Data Sources for Research Questions

6. Cronbach's Alpha Reliability for the Survey Subscales

7. List of Collaborative Technology Tools Reported by Faculty Members

8. Faculty's Comfort Level Using Collaborative Technology Tools in

Online Course

9. Faculty Perceived Factors to Consider when Selecting Collaborative

Technology Tools

10. Faculty Perceived Influence of Using Collaborative Technology Tools for Online Learning

11. Student Perceived Influence of Using Collaborative Technology Tools on Online Learning

12. Student Perceived Impact of Collaborative Technology Tools in Collaborative Learning

13. Student Perceived Experiences in Online Collaborative Learning 


\section{FIGURES}

Figure

1. The Rate of Online Enrollments in U.S. Higher Education 14

2. Vygotsky’s Zone of Proximal Development Model 37

3. The Relationship between Structure, Dialogue, and Transactional Distance 41

4. The Relationship between Autonomy and Transactional Distance 42

5. Explanatory Sequential Mixed Method Design Diagram 49

6. The Perceived Most Commonly Used Technology Tools for Collaboration in Online Courses $\quad 84$ 


\section{CHAPTER I: INTRODUCTION}

This chapter provides background and explanation of the problem of the study. This chapter includes the following: (a) background of the study, (b) the purpose of the study, (c) research questions, (d) assumptions, (e) limitations of the study, (f) definition of key terms, (g) rationale, and (h) significance of the study.

\section{Background of the Study}

The new vision of education is to provide valuable and accessible education for all learners. Students who learn in different manners need various options and learning opportunities to succeed. Online education is seen to be a suitable educational trend to help achieve this vision. Online education is a form of education that provides resources and learning materials to learners and can give them options to study at a place and time that is feasible for them (Akhter, 2015). Thus, online learning is designed to provide students who may not be physically present on campus with a quality university education (Simonson, Smaldino, Albright, \& Zvacek, 2014). The primary aim of online education is to make learning accessible for students using various technological tools that are available and easy to use. This advantage of accessibility in online classrooms expands learning opportunities for many students, including those who work full time or who have special needs and are unable to physically attend regular classes at a specific time and place.

Online learning has become increasingly popular in higher education over the last decade due to its flexibility, accessibility, and affordability. Along with the continuous development of technology, the popularity of online education is destined to grow (Allen \& Seaman, 2014). Although online learning predominantly depends on student independence, collaboration can play a key role in student learning via interactions and construction of knowledge with other 
students. Collaborative learning is learning that occurs through a coordinated and shared environment where groups of students work together toward a common task, in which each student adds to an emerging pool of knowledge of the group while creating learning communities (Moore \& Kearsley, 2012; Tsai, 2013; Zygouris-Coe, 2012). Thus, collaborative learning is one of the key elements to the twenty-first century learning that aims to prepare students for life, work, and citizenship in the twenty-first century by exhibiting the ability to collaborate with others. Collaboration is one of the major skills that students need to survive as twenty-first century workers (Barry, 2012; Luna Scott, 2015). Perhaps as a consequence, Choi and Lee (2009) stated that the role of higher education is "helping college students develop as professionals who are able to deal with real-world problems in complex and dynamic situations, and who can make reasoned and reflective decisions" (p. 100). Therefore, higher education faculty are increasingly designing and implementing collaborative learning in their online courses. Thus, they are attempting to create a suitable environment for social interaction and collaboration in their online courses (Mashaw, 2012). Creating online collaborative activities and encouraging students to actively participate in discussion and group work are seen as essential to the success of online learning (Jacobs, 2013). However, it is a challenging task to establish and maintain an active collaborative environment, especially when group members are not active participants in their group work (Chiong, Jovanovic, \& Gill, 2012).

The development of technology has significantly impacted the implementation of collaborative learning in online courses. There are a growing number of technology tools that help facilitate collaborative learning where students work together toward a common task, in which each student adds to an emerging pool of knowledge. These tools can help drive online learning toward more learner-centered and interactive learning. These collaborative technologies 
excite a creative explosion of new ideas and opportunities for collaborative learning (Cheung \& Vogel, 2013). New technologies have expanded the opportunities for students to collaborate with others and to shift online learning toward more collaborative learning and interactive teaching and learning. The effective use of collaborative technology tools can foster student engagement and positively impact the outcomes of online learning (Revere \& Kovach, 2011). Online instructors must consider how to use collaborative technologies effectively for instructional purposes and how to ensure student engagement and interaction support collaborative learning. However, the choice of which technology tools to use should depend in part on students' needs and interests. Students must become familiar with the collaborative technology tools used in their courses, which can prevent them from being overwhelmed by the technologies themselves.

Successful collaborative learning experiences are mediated by collaborative technology tools that afford communication, sharing, and knowledge construction (Johnson, Adam, \& Cummins, 2012). Designing collaborative eLearning activities in online courses requires strategic use of these tools in order to enhance collaborative learning and student engagement. Despite considerable research in the literature exploring the values of online education and collaborative learning as standard practices in higher education, few studies have yet examined the potential and use of technology for enhancing collaborative learning in online education. There is a growing body of literature that examines designing and implementing collaborative eLearning activities to promote online learning. However, most of the studies in the current literature do not simultaneously examine the use of collaborative technologies to support collaborative eLearning and student engagement in online learning environments. Currently, critical questions still exist about how faculty design, develop, implement collaborative eLearning activities using technology tools that support collaboration and student engagement in 
online courses, and what perspectives students have toward their experiences while participating in these activities. The present study seeks to further investigate this area.

\section{The Purpose of the Study}

A broad goal of this study is to advance the understanding of how collaborative technologies are effectively implemented in online courses to enhance collaborative learning and student engagement. To achieve this goal, this study aims to explore the experiences of faculty members regarding using collaborative technology tools to design, develop, and implement collaborative eLearning activities in their online courses, in addition, to obtain the perspectives of students toward their experiences while participating in these activities. Accordingly, it is central to the study to identify the current use of collaborative technology tools to incorporate collaborative eLearning activities in online learning environments and to explore the perceived impact of such an approach on student learning. This study intends to gain a better understanding of how faculty integrate these technology tools into their online courses and how their choices of these tools affect collaborative learning and student engagement. Furthermore, this study seeks to understand the perspectives of students toward the implementation of collaborative technology tools for collaborative learning. Thus, this mixed method study seeks to better understand the potential and use of technology for enhancing collaboration and student engagement in online settings and the factors that influence the selection of collaborative technology tools for collaborative eLearning activities in online courses.

\section{Research Questions}

Determining research questions is a beneficial technique to narrow the purpose of a study into specific questions (Creswell \& Plano-Clark, 2011). The "research question drives the data collection, data analysis, and inference methods" (Dahlberg, Wittink, \& Gallo, 2010, p. 777). 
The goal of the study is to explore the experiences of faculty members regarding using collaborative technology tools to design, develop, and implement collaborative eLearning activities in their online courses, in addition, to obtain the perspectives of students toward their experiences while participating in these activities. Therefore, the primary research questions guiding the study are as follow:

1. What collaborative technology tools do faculty use and how do they incorporate collaborative eLearning activities in their online courses using those tools?

2. What are the factors that faculty may consider when selecting collaborative technology tools for collaborative eLearning activities?

3. How do faculty and students perceive the influence of collaborative technology tools on online collaborative learning?

\section{Assumptions}

According to Leedy and Ormrod (2010), "assumptions are so basic that, without them, the research problem itself could not exist" (p. 62). Thus, the following assumptions are made regarding this study. It was assumed that:

1. The participants of the study answered the survey and interview questions in an honest and candid manner since anonymity and confidentiality were preserved to maximize truthfulness.

2. The sample of participants is appropriate and representative of the population and therefore, assures that the participants have all experienced the same phenomenon of the study. 
3. All faculty members who participated in the study have had experience teaching online and integrating collaborative technology tools for collaborative eLearning activities.

4. All students who participated in the study have enrolled in at least one online course and use some collaborative technology tools for collaborative eLearning activities.

\section{Definition of Key Terms}

To increase accuracy in presenting this study and to minimize the possibility of misinterpretation, some terms that are used throughout the document are defined:

1. Collaborative learning: A learning that occurs through a coordinated and shared environment where groups of students work together toward a common task or goal, in which each student adds to an emerging pool of knowledge of the group (Moore \& Kearsley, 2012; Tsai, 2013; Zygouris-Coe, 2012);

2. Collaborative eLearning activity: An educational activity that allows a group of students to work together within the online environment where they can connect, interact, and collaborate for a common task.

3. Collaborative technology tools: The technology tools that enable individuals and groups to communicate, collaborate, and interact in online environments in order to accomplish a common task, share or exchange information, and construct knowledge;

4. Online Course: A courses where all or at least 80 percent of the content is delivered online (Allen \& Seaman, 2014); and

5. Online Collaborative Learning: A learning process where two or more people work together within the online environment to create meaning and construct knowledge. 
"Online collaborative learning comprises the same indispensable features as onsite collaborative learning" (Barkley, Major, \& Cross, 2014, p. 5)

6. Online Learning Environment: A learning environment that refers to the e-learning environment used asynchronously for knowledge acquisition within a Web-based platform.

\section{Rationale}

In online learning, educators need to know the educational technology tools that can be effectively used to facilitate student learning and the appropriate use of these tools to support eLearning activities. According to Paechter, Maier, and Macher (2010), "when designing an elearning course, instructors are faced with many considerations and decisions that consequently affect how students experience instruction, construct and process knowledge" (p. 223). This study aims to provide insights into the experiences of faculty implementing collaborative technology tools in online courses with the aim of improving collaboration and student engagement. The experiences of faculty members and the perceptions of students regarding the use of collaborative technology tools in online courses help recognize areas in need of improvement and factors that need to be taken into consideration when designing an online course and implementing collaborative activities to facilitate learning and increase student collaboration and communication. The findings of this study provide insights into the practical implications for designing online courses and developing collaborative eLearning activities.

\section{Significance of the Study}

Recently, a considerable literature has grown up around the theme of collaboration, collaborative learning, and student engagement in online learning environments. However, this study provides new insights into the experiences of faculty members regarding the 
implementation of collaborative technologies to design, develop, and implement collaborative eLearning activities in their online courses. Insights gained from this study may be of assistance to online instructors who are seeking methods and instructional strategies to engage students and provide opportunities for interaction and collaboration in online courses. The findings of the study provide insights into the practical implications for implementing collaborative technology tools to design and facilitate collaborative eLearning activities by informing instructors and instructional designers of the perceptions of both students and instructors. The study provides guidance and practical suggestions for online instructors as they make informed decisions in the development of collaborative learning in their online courses. Knowing the ideal implementation of the advanced collaborative technology tools to promote interaction and collaboration in online courses is of great significance to online instructors who are concerned about designing effective collaborative eLearning activities.

The study offers more important insights into students' perspectives toward their experiences while participating in collaborative eLearning activities using collaborative technology tools. It is hoped that this research will contribute to a deeper understanding of the perspectives of students regarding the technology used for collaborative eLearning activities, which is influential and critical to the success of the integration of collaborative technology tools in higher education settings. More broadly, the findings should make an important contribution to the field of online education in higher education by enabling online instructors and institutions to better design their online courses to meet students' learning needs, resulting in increasing student enrollment and retention. Therefore, this study makes a major contribution to the body of knowledge regarding collaboration, collaborative learning, technology integration, student engagement and online education in general. 


\section{Limitations of the Study}

This study has several limitations. The first limitation is that this study only included faculty members who teach at least one online course and students who are enrolled in at least one online course at the Midwestern state university. Therefore, the responses cannot be assumed to represent a larger population of online faculty who teach online or students who enroll in online courses. Another limitation is that the data collected is self-reported and dependent on the understandings and emotional aspects of the participants. Thus, the study was limited to the beliefs of the faculty and students, their technical knowledge and skills, and their willingness to express their feelings and perceptions.

\section{Organization of the Dissertation}

Chapter I presents an introduction to the study, including the background of the problem, the purpose of the study, research questions, rationale, definition of key terms, and significance of the study.

Chapter II provides a review of the existing literature in the areas related to online learning, collaborative learning, and collaborative technology tools. The literature review discusses the potential and use of technology for enhancing collaboration and student engagement in online settings and the factors that influence the selection of collaborative technology tools for collaborative eLearning activities in online courses. The chapter concludes with definitions and synthesis of the learning theories that guided the processes of the study.

Chapter III provides details of the research methodology utilized to address the research questions. This chapter clearly describes the process by which data were generated, gathered, and analyzed. Accordingly, the chapter is organized into nine sections as follows: (a) Research design, (b) Research setting and study sample, (c) Research instruments, (d) Pilot study 
procedures, (e) Data collection techniques, (f) Data analysis procedures, (g) Validity and reliability, (h) Positionality statement, and (i) Ethical Assurances.

Chapter IV began with a very brief review of the overall research design. The chapter presents, in detail, the research findings of the study in a manner that addresses the research questions. Thus, the experiences and perspectives of faculty regarding the integration of collaborative technology tools into online courses for collaborative eLearning activities were revealed, along with students' perspectives toward their experiences while participating in these activities. These findings provide the foundation for the conclusions and implications outlined in the following chapter.

Chapter V begins with a summary of the research findings in light of the research questions and the purpose of the study. The chapter provides a discussion on the findings of the study, accompanied by the conclusions and the possible implications of the study, along with practical recommendations drawn from the findings of the study for professional and meaningful practice. The chapter concludes by recommendations for future research. 


\section{CHAPTER II: LITERATURE REVIEW}

This chapter begins by reviewing the appeal and nature of online learning as a standard practice in higher education followed by the influence of technology on the design and development of online learning. Next, the focus turns to the collaborative learning as an approach that is commonly implemented to support student learning, reviewing the effective practices of collaborative learning in higher education. Then, the review narrows to consider the collaborative benefits of some technology tools that have been used to support collaborative learning in online settings. This chapter provides a discussion of three learning theories that best suit the current study, serving as the theoretical grounding for the study.

\section{Introduction}

The purpose of this study is to explore the experiences of faculty members implementing collaborative technology tools in online courses to support collaboration and student engagement, in addition, to obtain the perspectives of students toward their experiences while participating in these activities. This study attempts to better understand the potential and use of technology for enhancing collaboration and student engagement in online settings and the factors that influence the selection of collaborative technology tools for collaborative eLearning activities in online courses. Findings of the current study provide insights into the practical implications for implementing collaborative technology tools to design and facilitate collaborative eLearning activities by informing instructors and instructional designer of the perceptions of both students and instructors. The implementation of advanced technology tools that support collaborative learning in online settings constitutes the basis for the review of the literature. Numerous scholarly databases were used to find most of the relevant research, using 
keywords that include online learning, collaboration, collaborative eLearning, collaborative technologies, collaborative technology tools, and student engagement.

\section{Online Education}

Online education has developed from the concept of distance education that is designed for learners who are unable to attend regular classes due to personal or geographical reasons (Lei \& Gupta, 2010). In the first American study to define distance education, Moore (1973) challenged the prevalent perspective toward distance education at that time and stated:

Learning and instruction to take place in other situations. Millions of learners, particularly adults, do not learn in classrooms, never meet or speak directly to their teachers and learn from teachers with whom they have no personal acquaintance at all as contrasted to contiguous teaching-learning, theirs is a distant learning and teaching situation (p.664).

Later, Schlosser and Simonson (2009) defined distance education as an "institution-based, formal education where the learning group is separated, and where interactive telecommunications systems are used to connect learners, resources, and instructors” (p. 1). However, the definition of distance education has evolved over time due to the development of online learning as it has become the primary form of distance education. Notably, online education is variously termed, and the terms are sufficiently synonymous; some of these terms include distance education, e-learning, online learning, blended learning, computer-based learning, Internet-based learning, web-based instruction, and virtual learning (Milman, 2010; Sun \& Chen, 2016).

Advancements in information and technology have created formal online learning environments in which online learning can be delivered asynchronously or synchronously or a 
combination of both. Synchronous learning is a form of online education that refers to teaching and learning that occur at a specific time where all students are expected to be available to participate such as participating in live lectures, discussions, and video conferencing while asynchronous learning is teaching and learning that do not occur at the same time such as reflecting on recorded lectures and asynchronously participating in discussions (Moore \& Kearsley, 2012; Sun \& Chen, 2016).

Sun and Chen (2016) categorized online education into two models; one is a UniversityBased Online Education to obtain degrees and diplomas, and the other is the Massive Open Online Course (MOOC). The MOOC is a recent development in online learning that focuses on increasing the accessibility to higher education by the public. Most of the MOOCs are exclusively offered by Ivy-league institutions in addition to organizations, corporations, and individuals. These groups provide a range of online courses that are free and widely available to the public (Daniel, 2012; Sun \& Chen, 2016). These online education initiatives are booming exponentially by offering ongoing open learning opportunities to self-motivated individuals. University-based online education provides the opportunity and accessibility for learners to upgrade their educational status without attending institution campuses regularly and leaving their jobs or business. It makes a university degree more accessible and, potentially, less expensive.

In the United States, online education has rapidly grown and became standard practice and in some cases a preferred option of higher education (Carrol \& Burke, 2010; Caruth \& Caruth, 2013). Advances in the Internet and technology have made online education the fastest growing sector of higher education (Carol \& Burke, 2010; Sun \& Chen, 2016). Therefore, the number of students enrolled in online courses has significantly increased and "online courses are 
becoming a more widely popular and viable option for many adult learners” (Lee, 2016, p.81). According to the report series that originated in 2002 to investigate the state of online learning at 2,800 institutions in the United States, online enrollments have continued to grow at rates that far exceed the growth rate the total higher education student population (Allen \& Seaman, 2010). The number of students taking online courses has increasingly grown from 3.9 million in 2007 to 6.7 million in 2013 (Allen \& Seaman, 2013). In the $11^{\text {th }}$ annual report, Allen and Seaman (2014) tracked online education in the United States since 2002 until 2012 and found that the growth rate of online enrollments has ranged between $9.6 \%$ in 2002 and 33.5\% in 2012 (see Figure 1). In the latest report, Allen and Seaman (2017) reported that the rate of online learning enrollment continues the previous steady growth (Allen \& Seaman, 2017). The 15 annual reports showed a steep rise of online learning enrollments over time and the overall number of students who are taking at least one online course have continued to grow. Thus, online learning has become a common learning option for millions of U.S. students (Zygouris-Coe, 2012).

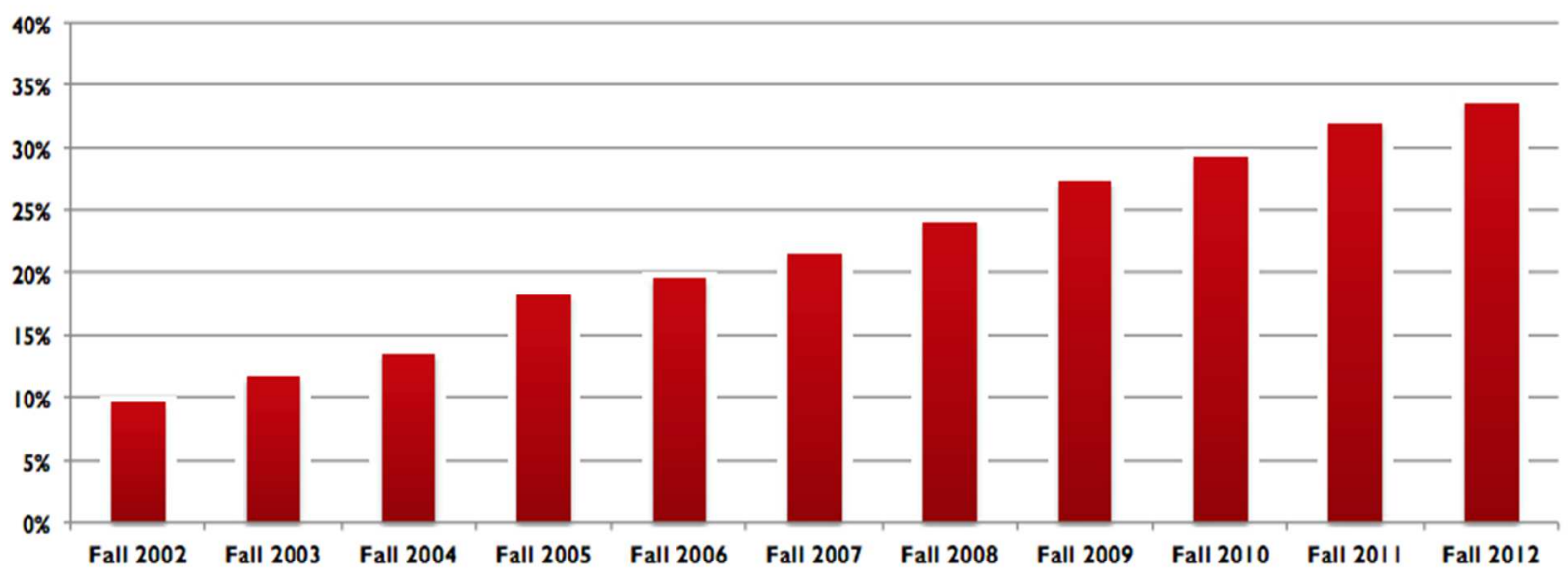

Figure 1. The rate of online enrollments in U.S. higher education (Allen \& Seaman, 2014) 
On an international scale, some U.S. institutions have started intentional marketing of their online courses to international students (Rovai \& Downey, 2010). Offering online courses overseas meets the needs of students in developing countries who are unable to attend colleges due to the limited number of higher education institutions (Oteng-Ababio, 2011). Thus, the potential for strong growth of online learning is not limited inside the United States, but also in other parts of the world. In this sense, So and Bonk (2010) claimed that "the vast majority of formal as well as informal learning experiences in the future will be blended ones" (p. 198).

Regarding the quality of online learning, Ward, Peters, and Shelley (2010) asserted that the quality of learning achieved by students in a face-to-face environment can be achieved in an online format. In this regard, U. S. Department of Education (2009) commissioned a metaanalysis of studies that compared fully online courses to face-to-face courses and concluded that student-learning outcomes in online conditions were equal to or better than those in traditional face-to-face conditions. It was found that there are additional learning time and other instructional elements in the online learning environments that are not received by students in face-to-face learning conditions (U.S. Department of Education, 2009). Online learning is an alternative and unique method of learning that addresses many of the issues that instructors and students face in traditional education. While it is often difficult for instructors to interact with all students in a traditional classroom, online learning provides opportunities to increase the interactions, which is considered the key to successful online education (Rao \& Tanners, 2011). The use of asynchronous discussion board in online courses facilitates student-student interaction where students can post timely, reflect, respond, and reply to their peers' postings (Chou, 2012). In most online environments, students are allowed to complete discussions and assignments on their own time and instructors have a flexible time to interact with the students. Mbuva (2015) 
determines the advantages of online education to include: convenience, time efficiency, accessibility, dynamic interactions, and creativity. Furthermore, online education permits the opportunity to facilitate collaboration and take full advantage of new technologies (Johnson, 2013).

\section{Influence of Technology}

The 21 st-century students, who have been raised and socialized by exploring and using advanced technological innovations in all aspects of their lives, may no longer benefit from traditional education where students are expected to learn in a certain place and time using traditional strategies of learning (Blair, 2012). In learning theory, technology is considered an effective way to support learning and behaviorist learning approaches; and technology is effective in facilitating constructivist theories of learning (Tamin, Bernard, Borokhovski, Abrami, \& Schmid, 2011). Therefore, technology has become increasingly integrated into instruction and considered an essential component of education around the world. Technology has created new and powerful learning tools that aim to improve instruction and make learning

more accessible for twenty-first century students. It is acknowledged that technology plays a key role in delivering instruction at distance. Simonson et al. (2014) indicate that program administrators are able to bridge the transactional distance between students and instructors through the use of technology. Technology is seen as an essential tool to reduce the transactional distance that exists in online learning between student and instructor, student and peers, student and the institution (Mafenya, 2014). Therefore, online courses are commonly dictated by technology (Cole, Shelley, \& Swartz, 2014)

The role of technology in online learning significantly increased due to the rapid change of the nature of the information age and communication were technologies that were previously 
considered advanced are becoming more familiar and new technologies are still being developed. However, since the invention of the Internet in 1983 and the World Wide Web (WWW) in 1989, they were and still the primary means of delivering distance learning and advancing online learning. Later, widespread technological innovations provide diverse tools of delivery that can be used in online education (Al Ghamdi, 2017). The use of online education platform comes as a powerful alternative to face to face education (Mbuva, 2015). Other effective technologies that can be used to deliver online education include (a) interactive audio or video conferencing that provide real-time interaction, (b) pre-recorded audio or video that can be used to present class lectures and visually oriented content and allow students to watch/ listen at their own pace, (c) discussion forums and threads that allow students to interact with their instructor and with each other, and (d) electronic mail that can be used to send messages and assignment feedback (Al Ghamdi, 2017; Bell \& Fedeman, 2013; Simonson et al., 2014, Yates, Thorn, Han, \& Deacon, 2018).

Typically, online learning has been offered through Learning Management Systems (LMS) which are learning platforms that are widely adopted by educational institutions to assist instructors in structuring online courses and arranging learning materials. The widespread adoption of LMSs in schools and universities is undoubtedly related to their features that allow instructors to replicate most of the traditional classroom activities into an online format. Some of the LMSs which have proven effective in enhancing effective teaching and learning include the Blackboard, eCollege - ClassLive Pro, Moodle, Desire2Learn, ANGEL, WebCT, Edmodo, Schoology, and Canvas (Mbuva, 2015). There are many other LMSs, with rapid growth and competition to best deliver educational programs (Mbuva, 2015). 
The continued proliferation of new digital tools has a great impact on online education in higher education, especially with the new capabilities, such as automated online grading with real-time feedback, course discussion boards, and blogs. In addition, some interactive multimedia components, such as video and audio clips, animation have been used to effectively deliver distance education. Many colleges and universities around the world made the decision to adopt online learning because of technological advances that made distance learning options more robust while less costly (Simonson et al., 2014). Most observers regard online learning technologies as the best hope for cost-saving innovations in higher education by reducing labor costs by increasing class size and reducing face-to-face interaction (Bowen, 2012). Certainly, "the unbundling capacity of new cloud capabilities will make it possible for academics to assemble just-in-time collaborative environments and to assemble an infrastructure and open source tools that might be needed to facilitate a learning encounter or research effort" (Katz, 2010, p. 28).

\section{Design and Development}

With the significant increase in online enrollment in the past decade, higher education faculty have been increasingly required to teach online (Allen \& Seaman, 2015). One of the strongest motivations for faculty to teach online is the flexible schedule (Chapman, 2011; Wingo, Ivankova, \& Moss, 2017). However, the standard of designing online classes is often to take the curriculum from traditional classrooms and to force it into an online format, without taking full advantage of the affordances of technology. Meier (2015) described this approach as "codifying past educational practice in a digital form - merely digitizing the status quo" (p. 5). Yet, designing learning activities that engage students and foster interaction and collaboration is still one of the many challenges that instructors face while creating online courses. Nayan, 
Shafie, Mansor, Maesin and Osman (2010) argued that some instructors are reluctant to implement collaborative learning activities because of the "fear or the loss of content coverage and lack of teacher training in collaborative learning methods" (p. 116). As a matter of fact, many faculty had little or no experience or background in instructional design which resulted in poorly designed online courses and even entire online programs. Mbuva (2015) reported the lack of adequate training for faculty and online administrators as one of the current and foreseeable challenges of online education.

In online learning, several challenges appear such as lack of interaction, lack of sense of community, and lack of collaboration with peers that may lead some students to drop the online courses. That being the case, more colleges and universities have incorporated instructional designers to assist faculty with the design of online courses. Online instructors have been assisted in developing new approaches to teach online taking advantage of the capabilities of elearning rather than transferring their in-class pedagogy to an online format (Jaggars \& Bailey, 2010). Lalonde (2011) indicates that online instructors must "foster flexibility in their teaching practices - a central theme in using these approaches in online teaching environments—which involves consistently updating their approaches and curricula in response to their students and social environment" (p. 408). It became a necessity for online instructors to design instructional tools that allow effective online interaction and collaboration. Instructors can appropriately use technology tools to build a learner-centered environment and foster student engagement (Revere \& Kovach, 2011).

Sun and Chen (2016) reviewed 47 research studies of online learning since 2008 and concluded that "effective online instruction is dependent upon 1) well-designed course content, motivated interaction between the instructor and learners, well-prepared and fully-supported 
instructors; 2) creation of a sense of online learning community; and 3) rapid advancement of technology" (p. 157). Online instructors need to consider how to adapt technologies applicable to online teaching for achieving the course objectives (Rao \& Tanners, 2011). Technology can provide a wide range of options to present material in various formats, such as videos, audios, narrated presentations, animated videos, and others, which can make online courses more interesting.

Indeed, having faculty members who are well-prepared and fully-supported is crucial for effective online education (Sun \& Chen, 2016). The success of online education depends largely on a high-quality faculty and a well-designed online course (Brannagan, 2012). Therefore, more emphasis should be placed on the need for specific training to help online instructors update their teaching practices and navigate the technological aspects of teaching in a new format that enhances their teaching practices, not just learning how to manage the learning management system (Crawford-Ferre \& Wiest, 2012). Consequently, instructors need sufficient professional development and training related to the instructional design to use proper online teaching strategies and promote effective online collaboration for students (Crawford-Ferre \& Wiest, 2012). It is essential to find a balance between pedagogy and technology when designing and delivering online course content (Keengwe \& Kid, 2010).

\section{Collaborative Learning}

Moore and Kearsley (2011) define collaborative learning as "a learning environment in which individual learners support and add to an emerging pool of knowledge of a group; emphasizes peer relationships as learners work together creating learning communities” (p. 305). According to Deejring (2015), online education provides "space for learners to share experiences and knowledge as well as corporate with peers without the limitations of time and without 
boundary" (p.35). Therefore, collaborative learning has become a well-established instructional method used in online courses. Razali, Shahbodin, Hussin, and Bakar (2015) identified some advantages of collaborative learning such as improving academic performance, increasing satisfaction in the learning experience, enhancing creativity, and promoting soft skills development including communication, collaboration, problem-solving and critical thinking skills. Commenting on the potential of collaborative learning in developing soft skills, Panitz (1996) argued that "collaborative learning is a personal philosophy, not just a classroom technique. In all situations where people come together in groups, it suggests a way of dealing with people, which respects and highlights individual group members' abilities and contributions. There is a sharing of authority and acceptance of responsibility among group members for the groups actions" (p. 3). Collaborative learning contributes to better learning outcomes by providing opportunities for students to engage in interactive and collaborative activities with their peers in quality learning environments (Brindley, Walti, \& Blaschke, 2009). Such environments enhance collaborative learning and have a positive effect on student development and success. Nowadays, collaborative learning has become of vital importance in higher education due to the significant increase in online enrollments compared to on-campus enrollment (Allen \& Seaman, 2010; Ku, Tseng, \& Akarasriworn, 2013).

\section{Effective Collaborative Learning}

Numerous studies have attempted to highlight the factors that influence student collaboration experiences whether online or offline. For instance, Brindley, Walti, and Blaschke (2009) conducted a study to explore factors impact creating effective collaborative learning groups. The data collected from the Foundations course in the Master of Distance Education (MDE) program offered jointly by the University of Maryland University College (UMUC) and 
the University of Oldenburg for over a three-year period. The findings of this study suggested that instructors need to incorporate a variety of instructional strategies in order to improve the quality of group collaboration such as: facilitating learner readiness for group work, establishing a sense of community within groups, monitoring group activities, providing clear instructions and feedback, and allowing sufficient time for collaborative learning activities. Razali et al. (2015) identified that some other strategies including creating a learning environment, learning interaction, and learning design that impact effective collaboration in online learning environments.

In a significant study, Swan, Day, Bogle, and Matthews (2014) examined the effects of a collaborative, design-based approach to improving teaching and learning in four core courses in a fully online graduate program in Teacher Leadership. The researchers redesigned their core courses using two measures specific to online learning to improve their core courses; (a) the Quality Matters (QM) rubric which is a faculty-oriented instrument designed based on instructional design principles to assure quality design in online; and (b) the Community of Inquiry (CoI) framework that represents online learning as supported by three presences - social presence, teaching presence, and cognitive presence. The results of this study showed significant increases in student learning outcomes in most core courses where the positive changes in outcomes resulting from the combination of the two-step process (Swan et al., 2014). The researchers recommended using the QM framework to guide initial course redesign and $\mathrm{CoI}$ framework to building communities of inquiry in online courses. Furthermore, they suggested creating "a collaborative community of educators to share responsibility for ongoing course improvement and redesign" (p.79). 
Another significant study conducted by Jain and Jain (2015) examined the relationship between the instructional design elements and the overall meaningful interactions among eighteen online graduate students using bivariate and multivariate analysis techniques. The results of this study suggested that the quantity of meaningful interaction among learners can be improved by some instructional design elements in online courses. These elements include dividing the students into smaller groups, using introduction sections, increasing social interaction among students, and limiting participation from the instructor. Likewise, student assessment is a key element of the online course built based on the social constructivist theory to effectively improve collaborative learning. Online instructors need to carefully design the assessments that allow students to freely demonstrate what they have learned in forms of "portfolios, projects, and performances" and not only to answer what instructors want to hear from them (Fennema, 2010, p. 34).

Effective feedback is another technique for effective collaborative learning. Guasch, Espasa, Alvarez, and Kirschner (2013) conducted a quasi-experimental study within the virtual campus (VC) of the Open University of Catalonia (UOC) to examine the effects of feedback on writing quality and student learning in an environment based on asynchronous written communication. Guasch et al (2013) identified four types of feedback for writing assignments; (a) corrective feedback, (b) epistemic feedback, (c) suggestive feedback, and (d) epistemic plus suggestive feedback. The results of this study showed a significant impact of the epistemic and suggestive feedback on improving the quality of collaborative writing performance in online learning environments. Taken together, the results suggest that the epistemic and suggestive feedback given by instructors and peers have positive effects on the quality of collaborative writing performance. 
One technique commonly used to overcome the difficulties in collaboration is a collaborative learning script where learners are expected to follow the steps to engage in collaborative learning. In this regard, Handayani (2012) examined the impact of using collaboration scripts as a pedagogical method to facilitate collaborative learning for graduate students at the University of Sydney. Using a multiple case study design, Handayani (2012) divided student participants to three groups as writers, editors, and reviewers in online collaborative writing to explore the impact of these roles on the group's collaboration. The results showed that each group developed unique emerging roles. It was found that the collaboration scripts enhanced group collaboration and ensured that the task given was completed within the framework. However, the results reported, "unequal participation in collaboration, especially free riding, ghosting, and ghostwrite as recognized both by some active members of the group and by some less active members themselves" (Handayani, 2012, p. 378). To overcome this challenge, Handayani (2012) suggested designing a script that can engage students equally in collaborative writing and increase the instructor's role during collaboration.

Another technique to improve collaborative learning is the use of peer evaluation which is an effective strategy that allows students to evaluate the performance of their peers during group work and to reflect on their own work (Wang, 2011; Wever, Keer, Schellens, \& Valcke, 2011). Peer evaluation, however, has also been criticized with respect to credibility and differences in the evaluations between teachers and students. Considering the fact that instructors and students evaluate different aspects of the learning process, Lee and Lim (2012) investigated the important components of peer interaction in team project-based learning using the message analysis of a total of 773 messages posted by 32 students. The results of this study showed that students evaluate their peers on managerial, procedural, and social contributions as being more 
important components of peer interaction. These results imply that students valued social and managerial contributions more significantly than cognitive contributions in peer evaluations. Students regard managerial, procedural, and social contributions to be more influential in collaborative learning. Lee and Lim (2011) recommended using a peer evaluation "as a useful strategy to encourage and support social competencies, especially in higher education" to prepare students for the work phase where "employers consider social abilities to be of critical importance" (p. 222).

According to Wever, Keer, Schellens, and Valcke (2011), peer evaluation is as valid as instructor evaluation. Substantially, peer evaluation is considered fair and can be employed as a complementary strategy for group work because students can perceive each of the different types of contributions while instructors are unable to access the process of team collaboration. Instructors are not able to assume that all students make equal contributions to the group work and then allocate the same marks to all group members (Wang, 2010). More specifically, Brutus and Donia (2010) stated that "peer evaluation processes are relatively simple to develop, and their use follows an important trend in higher education of relying on peer relationships to support educational objectives" (p. 653).

In an investigation into the use of an online community, Dorner \& Kumar (2016) examined the implementation of an online collaborative mentoring model, the Mentored Innovation Model (MIM), in a teacher education program where pre-service Hungarian teachers learn to effectively integrate technology into their classrooms. This model combines a formal online pedagogical ICT training with an informal online community. In the online community, pre-service teachers had the opportunity to share, develop, and critique shared learning resources to help them integrate technology in their classroom. The researchers used two online 
questionnaires to collect data from 116 pre-service teachers. One questionnaire explored their self-efficacy with technology before the mentoring began and the other surveyed their satisfaction with the mentoring experience once it was over. The results of this investigation showed that MIM served as a useful platform to support pre-service teachers with technology integration in their teaching, leveraging expertise with the active online collaboration between pre-service teachers and educational researchers, subject-specific mentors, and others. Dorner \& Kumar (2016) recommended this model to build a community of multiple teachers, educators, and stakeholders.

The previous research determined some instructional strategies and techniques to create an effective online collaborative learning environment such as the use of collaborative learning script, student assessment, epistemic and suggestive feedback, and peer evaluation. When used appropriately, these strategies and techniques can positively impact collaboration experiences in online learning environments. Additionally, technology fosters interaction and collaboration by providing innovative and collaborative tools in the learning environment. The significant increase of technology tools allows individuals to share content and commentary using "wikis, discussion forums, and through various file formats that can be shared or edited online" (Cheung \& Vogel, 2013, p. 160).

\section{Technology Tools for Collaborative Learning}

The current and continuous development of technology has produced new technology tools that provide significant opportunities for collaborative learning. These collaborative technology tools have greatly created opportunities for collaboration in online learning environment. According to Cheung and Vogel (2013), “collaborative learning technologies refer to a set of tools for task-specific collaborations and are associated with goal and work-oriented 
activities" (p.161). The collaborative technologies can be employed to support faculty members in designing collaborative eLearning activities in their online courses. The online collaboration is fostered by the availability of synchronous and asynchronous communication and collaborative tools in the online learning environment. Based on the idea of 'tool mediation' that stems from Vygotsky's work, using collaborative technology tools as a source of mediation for learning can accomplish the goals of a social constructivist learning (Cheung \& Vogel, 2013). Integrating collaborative technology tools in online courses encourage interaction between students at convenient times. Online collaboration can be easily designed through the use of technology via Wikis, Blogs, and other web-based technology. Such tools that provide collaborative document development opportunities help instructors to develop collaborative eLearning activities in their online courses.

Collaboration in online courses is influenced by the types of technology tools that instructors use to design collaborative activities. Thus, it is increasingly necessary to determine the best and most effective technology tools that faculty can use to create activities that enhance interaction and collaboration in an online learning environment. One of the common technology tools that instructors can incorporate into online courses to enhance student interaction and collaboration is the discussion board which is included as a learning tool in most online course systems (Crawford-Ferre \& Wiest, 2012; Lalonde, 2011). As students learn best when they are able to interact with other students, instructors need to carefully design discussion forums that allow students to share their knowledge, experiences, and understandings to learn from each other in a safe environment. In a small study, Weidman and Bishop (2009) examined the impact of technology support on the implementation of cooperative learning in an online post-secondary English course that utilized discussion boards. The findings of this study revealed that 
communication through discussion boards encouraged students to be more eager to form groups for learning projects.

The newer collaborative tools that have become more popular in fostering student learning are Web 2.0 tools (Hew \& Cheung, 2013). Web 2.0 tools are web-based applications that "allow collaboration and information sharing" (Moore \& Kearsley, 2012, p. 313). Web 2.0 applications have emerged in recent years and have been utilized to support student interaction and collaboration. In this regard, Capo and Orellana (2011) conducted survey research to examine the factors that contribute to use Web 2.0 technologies for classroom instruction. The findings revealed that online instructors who incorporated social media tools in their courses reported the improvement of student interaction and learning due to the students' use of social media in carefully designed activities. The findings also reported some of the factors contributed to the use of Web 2.0 for student interaction include teachers' behavioral intention to use Web 2.0 technologies, perceived usefulness, and compatibility. Social media has become a sociotechnical phenomenon that has the potential to become a valuable resource to improve the quality of educational communications and collaborations in online learning environments. Social media tools that emerged in recent years with benefits to online collaboration, communication, and interaction include Facebook, Linked-in, Skype, Google Plus, and Twitter (Jacobs, 2013; Leafman, 2015).

Facebook is a social networking site that has been widely used all over the world. It is the most popular global social networking site among university or college students for social interaction and has been largely used for educational communications and collaborations (Roblyer, McDaniel, Webb, Herman \& Witty, 2010). Facebook “allows the users to keep up-todate on their friends, depending, of course, on the information provided by them. This feature 
can be very useful in an e-learning environment, allowing students to keep updated on a particular course" (Rodrigues, Sabino, \& Zhou, 2010, p.1148). Results from earlier studies that examined Facebook adoption and usage for educational purposes demonstrate that Facebook is currently considered as the most popular platform for communications and collaboration among students who reported a positive feedback for supporting their learning and academic engagement (Roblyer et al., 2010; McCarthy, 2010; Wise, Skues \& Williams, 2011). Although Facebook is seen as an effective educational tool with its features such as peer feedback and interaction tools, the use of Facebook in the field of education is very limited (Hew, 2011).

Wikis are social media tools that have been used in educational settings to facilitate online collaborative learning. They allow students to create a website with editable pages, which other students can make changes. In an experimental study, Kimmerle, Moskaliuk, and Cress (20111) examined the impact of using Wikis on the processes of learning and knowledge building. The results revealed that "wikis seem to be suitable instruments to encourage and facilitate processes of individual learning and collaborative knowledge building at the same time" (Kimmerle et al., 2011, p. 146). Another study conducted by Popescu (2014) reported the successful experiences of 215 post-secondary students over a period of 4 years when using Wiki to support project-based learning. The findings of this study provided evidence that the use of Wikis can promote collaborative learning and support student engagement.

With the aim of enhancing problem-solving skills and ICT literacy within undergraduate students, Nookhong, and Wannapiroon (2015) developed a collaborative learning model using case-based learning via cloud technology and social media. The collaborative learning model consisted of four components as follows: (1) The principles of instruction model, (2) The objective of instruction model, (3) The instruction process, and (4) Assessment and examination. 
Then, the researchers proposed the developed model to five experts in the field of curriculum design, information and communication technology (ICT), and undergraduate-level instruction selected by purposive sampling. The results of the evaluation indicated that the collaborative learning model was beneficial and effective for enhancing problem-solving skills, accessing information, and presenting interaction and collaboration.

Other technology tools that can enhance collaborative learning are Google applications which are a suite of cloud-based tools that can be used for real-time collaboration. The collaborative features embedded in these applications include "synchronous group composing and commenting, capabilities that are not offered by other word processors or file sharing services" (Hocutt \& Brown, 2018, p.52). In particular, Google Drive applications provide students with opportunities to share documents and work collaboratively to brainstorm ideas and build knowledge. Google Drive is a cloud storage and synchronization service that includes: (1) Google Docs, (2) Google Sheets, (3) Google Slides, (4) Google Sites, and others. Many schools and educational institutions are currently subscribed to Google for Education, recently named G Suite for Education (Ventayen, Estira, De Guzman, Cabaluna, \& Espinosa, 2018).

Cheung and Vogel (2013) examined the factors that influence the acceptance of Google Applications for collaborative learning by extending the technology acceptance model and the theory of planned behavior to develop a research model. Using a structured questionnaire, data were collected from 136 students enrolled in an advanced marketing research course at the Hong Kong Polytechnic University. In this study, a project Web site was used for supporting an advanced marketing research project where students were required to work collaboratively in groups to complete the project using Google Applications to facilitate collaborations including Google's share spaces, Forms, Google Docs, discussion forums, and Sites. According to the 
results of the study, Google Applications have significant contributions in enhancing collaborative learning environments. The ease of use and usefulness were major factors influencing the acceptance of collaborative technologies.

In a recent study, Hocutt and Brown (2018) conducted a multi-year study exploring student attitudes toward the use of Google Apps for Education, renamed G Suite for Education, for collaborative composing in two first-year composition environments. The data were collected between 2013 and 2015 using mixed methods to capture students' reflections on the effectiveness of Google applications for composing including invention, drafting, revising, finalizing, submitting, and reviewing. The results of this study suggested that "the remediation of the composing process as collaborative, convenient, and cloud-based in Google Docs via Google Drive resulted in remediation through reform of traditional composition pedagogy" (Hocutt \& Brown, 2018, p.52). It was also found that the use of Google Drive for collaboration and composing contributed to the perception of equality through the remediated roles of writer, reviewer, and instructor.

Google Docs is a great educational tool that is commonly used for collaborative writing, editing, and peer reviewing where students can share, write, comment, and edit collaboratively. To assess the effectiveness of using Google Docs in a collaborative writing activity, Zhou, Simpson, and Domizi (2012) compared students' collaborative performance and learning across two out-of-class assignments. In this study, 35 students at the University of Georgia were required to complete two assignments over a six-week period, the first assignment was completed without Google Docs, and the second assignment was completed with Google Docs. The results of the study showed that Google Docs was a useful tool for collaborative writing and influenced student learning. 
Liu and Lan (2016) investigated the differences in motivation, vocabulary gain, and perceptions between individual and collaborative learning at a tertiary level using the Google Docs. Involving 65 English-as-a-Foreign Language (EFL) students, the results of the study indicated that collaborators performed better than the individuals regarding vocabulary gain. The collaborators were motivated to acquire knowledge and to perceive the learning experience more positively. The researchers concluded that "students will be more capable of thinking critically if they work collaboratively rather than working individually" (p.181). Regarding the usage of the web-based applications, it was found that the collaborators had high levels of motivation and self-efficacy, a lower level of test anxiety, and a more positive perception towards learning on Google Docs. Liu and Lan (2016) asserted that "Google Docs plays a pivotal role in enhancing students' motivation and involvement" (p.171).

Another significant Google application for collaborative learning is Google Sites, which is a structured web page-creation tool. Google Sites provides opportunities to promote $21^{\text {st }}$ century learning enabling instructors to create a collaborative learning environment. For the same purpose, Gan, Menkhoff \& Smith (2015) used Google Sites to help students stay organized and on track in a resource-rich project-based course. They found that Google Sites not only enabled easy access to course content, discussion forums, and class sharing and collaboration but also enabled students to embrace the new challenges in their future careers, such as lack of collaboration skills.

In sum, successful online collaborative learning needs to be mediated by some forms of technology that affords communication, interaction, knowledge building such as Wikis, Skype, Dropbox (Kelly \& Thorn, 2013). Other technology tools that provide collaborative learning opportunities in online learning include the synchronous, Web 2.0, and cloud-based applications 
that "allow collaboration and information sharing" and expand the options for developing collaborative eLearning activities (Moore \& Kearsley, 2012, p. 313). The cloud-based applications such as Google Applications, allow students from varied locations to collaborate on one document where they can view, edit, track changes, and communicate in real-time. Instructors and students use these applications to write collaboratively as common use of these applications. These applications work as a collaborative platform where students brainstorm ideas and document their work.

Learning how to use collaborative technology tools to collaborate with others is a unique skill for today's students preparing them to be digital citizens and more importantly, to be able to collaborate with people across the world as one of the soft skills that they need to demonstrate in a professional career. The online instructor's responsibility is to incorporate these technology tools into online courses and provide students with the guidance and resources needed to facilitate and enhance collaboration in the online environment (Johnson, 2013).

\section{Theoretical Framework}

According to Marshall and Rossman (2011), the theoretical framework is a significant structure of the study that provides a broader context of the study by connecting the research to the theoretical constructs. As a consequence, the theoretical framework for this study is drawn primarily from three learning theories namely: (a) social constructivism, (b) transactional distance, and (c) social presence.

\section{Theory of Social Constructivism}

A large and growing body of literature and instructional strategies on collaborative learning stemmed from the precedents set by the theory of constructivism and social constructivism. In the 1970s and 1980s, the theory of constructivism emerged from the work of 
some of the most recognized cognitive psychologists such as John Dewey, Jerome Bruner, Jean Piaget, and Lev Vygotsky. The idea of constructivism is that learners are not passive recipients of information; instead, they actively construct their knowledge based on their own prior experiences and in interaction with the environment (Piaget, 1971). Dewey (1916) viewed the teacher's role as a facilitator and guide of learning rather than a director of learning or a knowledge transmitter. According to Bruner (1961), the purpose of education is not only to impart knowledge to learners but instead to develop learner's thinking and problem-solving skills.

From a constructivist perspective, "knowledge is assumed to be constructed, rather than acquired" (Driscoll, 2005, p. 386). Effective constructivist learning environments occur when knowledge is not handed over to students, but created by students (Lee \& Spires, 2009). In this environment, learners actively construct knowledge through their own experiences while the teacher serves as a facilitator, not a disseminator of knowledge. Learners, through constructing knowledge, are motivated to recall their prior experiences and the "prerequisite skills or entry learning goals, then, are not necessarily ignored by constructivist, but they are attended to largely in the context of higher-order goals" (Driscoll, 2005, p. 393). In constructive learning, learners gain a rich and relevant understanding of classroom information, providing motivation and practical application (Fox-Turnbull \& Snape, 2011).

In the late 20th century, the constructivist view of learning was further developed by Vygotsky's perspective of the fundamental role of social context in the development of cognition. He placed great emphasis on the social context of learning and the importance of interaction with peers and teachers. Vygotsky (1978) emphasized the role of social interaction in the process of constructing knowledge and understanding (Pritchard \& Woollard, 2010). 
Vygotsky believed that learning cannot be separated from its social context. Vygotsky (1978) clarified that "every function in the child's cultural development appears twice: first, on the social level, and later, on the individual level; first, between people (interpsychological) and then inside the child (intrapsychological)" (p. 57).

Thus, the theory of social constructivism was one of the learning theories that guided the processes of the study. Social constructivism is often used as the foundational basis for pedagogical and curricula decision-making among educators. According to Powell and Kalina (2009), "social constructivism is a highly effective method of teaching that all students can benefit from since collaboration and social interaction are incorporated" (p. 242). Vygotsky (1978) asserted that "learning is a necessary and universal aspect of the process of developing culturally organized, specifically human psychological function" (p. 90). Social constructivism is a learner-centered theory in which learners have the opportunity to engage in social activities to construct their knowledge (Vygotsky, 1978). In essence, social interaction is a critical element of cognitive development.

Hoic-Bozic (2009) argued that it is important to include "elements of behaviorism, cognitivism, and constructivism," but "constructivism is the most widely accepted model of learning in education today" (p. 21). Constructivism and social constructivism have been applied in the traditional face-to-face classroom to improve student learning. In an online learning environment, learners have the opportunity to experience a variety of online resources interacting with other students and constructing their new knowledge with prior knowledge. Bowers and Kumar (2015) indicated that social interaction in an online course is greater than a face-to-face course. In this vein, social constructivism seems to be suited to improve the quality of online learning environments. 
Designing online courses based on the theory of social constructivism in the form of collaborative learning enables students to work in groups to construct their understanding of a given concept build upon their ideas and prior knowledge. More specifically, using social constructivism theory as a referent for teaching approach is needed to improve collaboration and student engagement in online learning. Students need to possess the ability to interact and collaborate with others in group work, especially higher education students as a preparation for the future professional career where they need to demonstrate the ability to work in a team-based work environment (Luna Scott, 2015).

Collaborative learning is grounded in Vygotsky's theory of learning, specifically the “zone of proximal development." Vygotsky (1978) developed and defined the concept of the zone of proximal development as "the distance between the actual development level as determined by independent problem-solving and the level of potential development as determined through problem-solving under adult guidance or in collaboration with more capable peers" (p. 86). In other words, the zone of proximal development is the area between what learners can do independently without guidance and what they can do through social activities with peer collaboration (see Figure 2). 


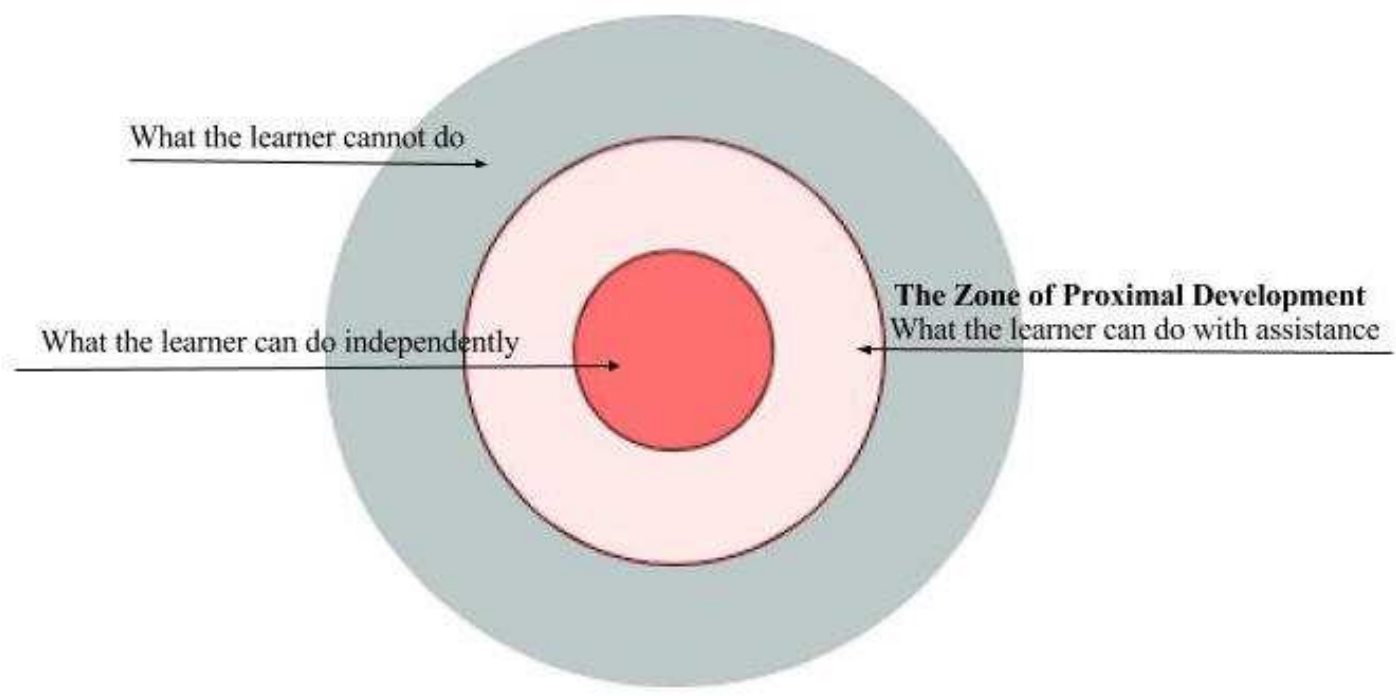

Figure 2. Vygotsky's (1978) zone of the proximal development model.

According to Janssen, Kirschner, Erkens, Kirschner, and Paas (2010), the "concept of the zone of proximal development is often used to explain that collaborative learning is beneficial for learners because the more capable learner can help and scaffold, the less capable learner to accomplish a task he or she could not accomplish while working individually" (p. 140). Vygotsky (1978) opined that the zone of proximal development, the current or actual level of development of the learner and the next level, can be achieved through the facilitation by teacher or peers and the use of mediating semiotic and environmental tools.

The second important principle of Vygotsky's (1978) work is the More Knowledgeable Other (MKO) which refers to someone who has a better understanding and more knowledge than the learner in which learner advance his/her knowledge by participating in activities with more knowledgeable other (Vygotsky, 1978). Collaborative learning helps establish active interaction between the student and the MKOs. In collaborative learning, students can learn to trust each other, construct knowledge, share information, and establish connections while they set up 
common objectives for learning (Yuan \& Kim, 2014). Collaborative learning is a social interaction between students to acquire and share experiences or build knowledge (Zhu, 2012). In the online environments, the roles for both the instructor and the learners require a redefinition (Johnson, 2013; Keengwe \& Georgina, 2012). The role of the online instructor has to be a facilitator who designs a constructivist-based learning environment where learners are required to be self-directed in order to play an active role in their learning. One instructor can create a powerful learning environment where students work together to accomplish a task which leads to the theory of social constructivism by facilitating the active construction of knowledge. Learners need to learn in a social setting and the function of the instructor is to create collaborative eLearning activities and encourage their participation to accomplish learning objectives. Some collaborative eLearning activities that can enhance the construction of knowledge include collaborative written assignments, group discussions, and critical reflection (Zhu, 2012). According to Cicconi (2014), the appropriate use of collaborative technology tools leads to a culture of social learning where technology tools empower students to take the role of Vygotsky's MKO.

In sum, it is essential to design online courses based on social constructivism as a way to build an online learning environment where students have the opportunities to interact with each other in order to construct their new understanding and knowledge. Several studies have documented that limited interaction is one of the greatest challenges in online education courses that may in turn decrease students' course satisfaction (Hew \& Cheung, 2013; Jaggars, 2014; Kuo, Walker, Schroder, \& Belland, 2014). Therefore, it is essential to create an online learning environment based on social constructivism where social interactions and collaboration help students actively and effectively learn. One benefit of using a social constructivist framework 
when developing online course is to offer opportunities for learning beyond traditional pedagogy where the online course can serve simply as the venue for social interaction with the benefit of the development of the online interactive technologies.

\section{Theory of Transactional Distance}

The theory of transactional distance, developed by Michael G. Moore, serves as the theoretical grounding for the current study. The tenets of Moore's theory of transactional distance has been used extensively in research investigating distance education and online learning. The theory provides a useful theoretical "lens" through which to analyze online teaching and learning practices (Falloon, 2011). Moore (1973) identified distance education as a system that consists of three sub-systems namely; (a) "autonomous learners engaged in learning events"; (b) "distance teachers preparing programs of instruction for transmission through communication media"; and (c) "communication media systems to bring teaching programs to learners in response to learners' demands" (p.672). Moore (1997) asserted that "distance education is not simply a geographic separation of learners and teachers, but, more importantly, is a pedagogical concept" (p.22). According to Moore's theory, the physical separation between teacher and learners in distance education can lead to communication and psychological space, known as transactional distance. Moore (1997) defined transactional distance as "the psychological and communications space" between learners and teachers (p.22). Thus, the emphasis in Moore's theory is on the pedagogical concept, not simply the geographical separation of teachers and students who are physically separated by space and/or by time.

The separation between the instructor and students can "lead to communication gaps, a psychological space of potential misunderstandings between the behaviors of instructors and those of the learners" (Moore and Kearsley, 2011, p. 200). This transactional distance 
accordingly needs to be bridged for an effective learning. According to Moore's theory, three interrelated factors influence the degree of transactional distance namely: (a) the structure of the learning environment, (b) the dialogue that exists between learner and others, and (c) the level of learner autonomy. The relationship between the three factors determines the degree of transactional distance. Moore (1997) clarified that

Structure expresses the rigidity or flexibility of the programme's educational objectives, teaching strategies, and evaluation methods. It describes the extent to which an education programme can accommodate or be responsive to each learner's individual needs (p. 26). Thus, the structural factors include the educational objectives, learning content, assessment activities, delivery method, media, pace of content delivery, communication channels, and syllabus design (Horzum, 2015). Moore (1997) mentioned that the term 'dialogue' can be used to describe the interactions that have positive qualities, considering that "dialogue is purposeful, constructive and valued by each party" (p.24). Falloon (2011) pointed out that "dialogue refers to more than simply two-way communication, but takes into account all forms of interaction" (p.189). The learning environments that encourage a purposeful dialogue between the learner and others are associated with low transactional distance. The two factors, structure and dialogue, are inversely related in which the highly structured learning environments are associated with low dialogue opportunities and vice versa. Figure 3 provides an illustration of the relationship which exists between the variables, structure and dialogue, and how these variables interact to determine the degree of transactional distance in a simple graph developed by Moore (2006). 


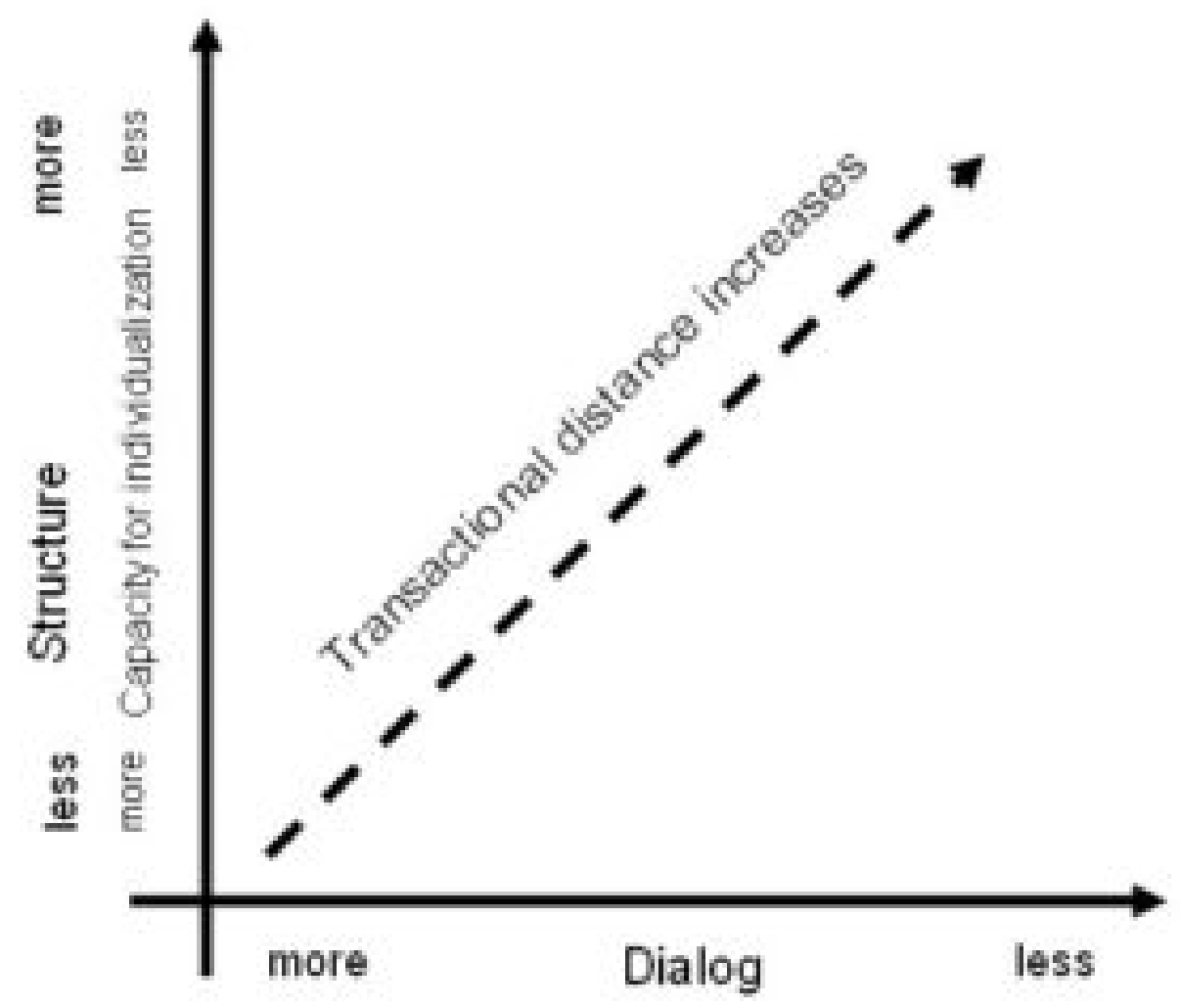

Figure 3: The relationship between structure, dialogue, and transactional distance.

The third factor that influences the degree of transactional distance is autonomy that is contingent upon the previous two factors, structure and dialogue. Autonomy is the learner's ability to define learning objectives, identify sources of information, and accomplish goals (Moore, 1997). This factor "describes the roles of the learners, in terms of the extent to which they exercise degrees of "autonomy" in deciding what to learn, how to learn, and how much to learn" (Moore, 2007, p.90). More specifically, Moore (1997) clarified that an autonomous learner is the independent individual who is able to act, solve problems, start and complete tasks, and "achieve goals of their own, in their own ways, under their own control", without asking teachers to assist them to acquire these skills (p. 31). In this meaning, the learner's ability to demonstrate high autonomy is determined by being a self-directed learner who has the 
motivation, and willingness to study independently. This independence in learning makes an autonomous learner appeared to be quite comfortable with little structure and with less dialogue (Moore, 1997). In a program with little structure and with less dialogue, the transactional distance increases and learner will need to demonstrate a high level of autonomy. In other words, the level of learner autonomy increases as the degree of transactional distance increases. Figure 4 presents a graph developed by Moore (2006), illustrating the relationship between learner autonomy and transactional distance.

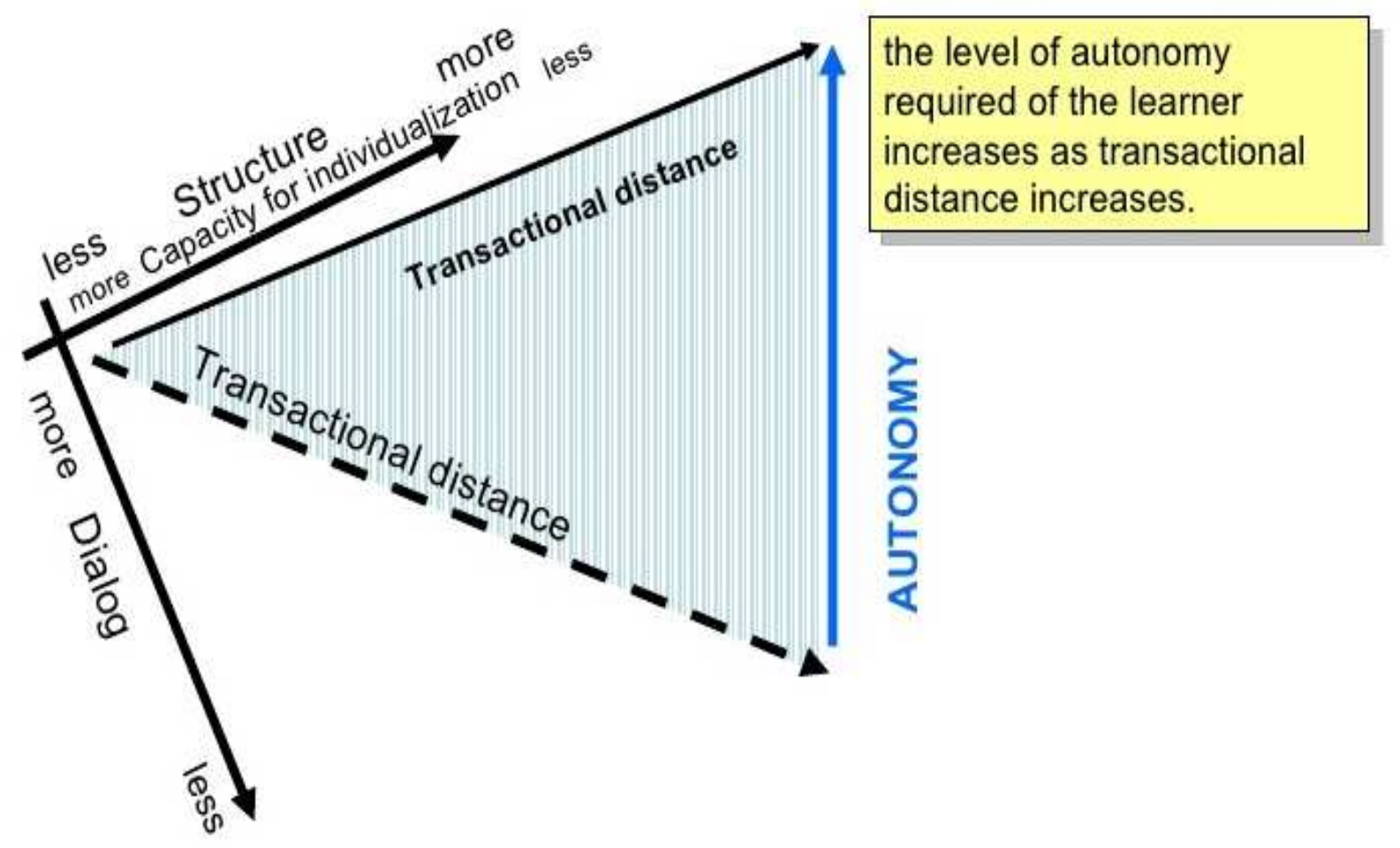

Figure 4. The relationship between autonomy and transactional distance.

In sum, the relationship between the three factors, structure, dialogue, and autonomy determines the degree of transactional distance. This transactional distance can be bridged 
through making a balance of these three factors. Bridging or at least minimizing the transitional distance largely depends on the structure of the course and how it is delivered. It is the instructor's responsibility to apply different learning techniques and strategies to best facilitate online learning (Anderson \& Dron, 2011). Moore (1997) pointed out that there is a direct impact of the features of each communication medium on the extent and quality of dialogue between instructors and learners. In this regard, media that have the capacity to increase dialogue between learners and teachers can minimize the degree of transactional distance (Moore, 1997). Accordingly, collaborative technology tools are seen to be effective communication mediums that can potentially contribute to the development of the quality of dialogue in online courses and minimize the degree of transactional distance. Instructors need to take full advantage of the capabilities of such communication media to design an online course where dialogue can be increased and as a result, the transactional distance can be decreased.

\section{Theory of Social Presence}

The theory of social presence initially came from the collective work of Short, Williams, and Christie (1976) to describe the effect of a communication medium on communication and interaction between people. Short et al. (1976) originally defined social presence as "the degree of salience of the other person in the interaction and the consequent salience of the interpersonal relationships" (p. 65). The social presence was re-defined by other researchers. For instance, Gunawardena (1995) defined the social presence as "the degree to which a person is perceived as a "real person" in mediated communication" (p. 151). Another modern definition of social presence theory was provided by Picciano (2002) as "a student's sense of being in and belonging in a course and the ability to interact with other students and an instructor" (p. 22). Further, Tu 
and McIsaac (2002) defined social presence as "a measure of the feeling of community that a learner experiences in an online environment" (p. 131).

The theory of social presence is largely applied in research and other educational purposes to describe and understand social interaction in online learning environments. According to Lowenthal (2010), it is the most often referenced theory explaining the social nature of communication mediums used in online educational environments. This theory is often used to determine the quality of a communication medium based on the degree of social presence since communication mediums differ in their degree of social presence. Some communication mediums have a higher degree of a social presence than others. For instance, the video has a higher degree of a social presence than audio. Short et al. (1976) argued that mediums with high social presence are sociable, warm, and personal, whereas mediums with low social presence are less personal.

This theory articulates the idea that education is a social process that involves a high level of interpersonal communication and interaction through a communication medium. The quality of a communication medium determines the way that people interact and communicate. Therefore, learning that occurs in online environments requires communication mediums that have high degrees of social presence "to create a mutual sense of interaction that is essential to the feeling that others are there" (Cutler, 1995, p. 18). It is critical to establish and maintain a social presence throughout the duration of a course. Online instructors should plan on enhancing social presence using communication tools that provide a high degree of salience. With the advancement of technology, most of the new technologies, especially collaborative technology tools, are designed to improve social presence and collaborative work environments. In this regard, the present study is focused on exploring the impact of the implementation of 
collaborative technology tools on enhancing the quality of collaborative learning and student engagement through improving social presence in online courses.

\section{Conclusion}

Considering all of this evidence, it seems that learning occurs through effective interaction and working collaboratively with peers. The evidence presented in this section suggests that students need teacher assistance and peer collaboration to absorb concepts and ideas that are difficult to understand on their own. According to Hämäläinen, \& Vähäsantanen (2011), "the potential of technology for future learning relies first on designing new ways to support teachers in orchestrating collaborative learning and creativity, and second, in developing technological environments which require and support definite collaboration in problem-solving" (p. 17). With the advancement of technology tools that support interaction and collaboration, there is a need to investigate how to promote effective social interaction and collaboration using the various technological tools that support collaborative learning (Sun \& Chen, 2016). The existing literature provided little information about the potential and use of technology tools to support collaborative eLearning and student engagement in online learning. Additional research could expand the knowledge base about how faculty design, develop, implement collaborative eLearning activities using technology tools that support collaboration and student engagement in online courses, and what perspectives students have toward their experiences while participating in these activities. In the current study, the implementation of collaborative technology tools in online courses to support collaboration and student engagement was investigated through the theoretical lenses of three learning theories; (a) social constructivism, (b) transactional distance, and (c) social presence. 


\section{CHAPTER III: METHODOLOGY}

This chapter provides an explanation of the research methodology utilized to address the research questions. This chapter begins by describing the research method and design, followed by a description of research participants. The research instruments, pilot study, data collection techniques, and data analysis procedures are described in detail. This chapter then concludes with a discussion of validity and reliability, researcher positionality, ethical assurances, and a chapter summary.

\section{Introduction}

The primary purpose of this study is to explore the experiences of faculty members implementing collaborative technology tools in online courses to support collaboration and student engagement, in addition to obtain the perspectives of students about their experiences while participating in these activities. Through an explanatory sequential mixed methods approach, the study attempts to better understand the potential and use of technology for enhancing collaboration and student engagement in online settings and the factors that influence the selection of collaborative technology tools for incorporating collaborative eLearning activities in online courses. The primary research questions guiding the study are as follow:

1. What collaborative technology tools do faculty use and how do they incorporate collaborative eLearning activities in their online courses using those tools?

2. What are the factors that faculty may consider when selecting collaborative technology tools for collaborative eLearning activities?

3. How do faculty and students perceive the influence of collaborative technology tools on online collaborative learning? 


\section{Research Design}

The research design section establishes what method of research is used in the study and the rationale for the design selection and the variables identified (Roberts, 2010). In the current study, a mixed-method design was utilized to achieve the purpose of this study and to address the research questions. Creswell and Plano Clark (2011) defined the mixed methods approach as a procedure utilized to collect, analyze and mix both quantitative and qualitative data of the research process within one study. Describing the value of mixed methods approach, Johnson and Onwuegbuzie (2004) stated,

Today's research world is becoming increasingly interdisciplinary, complex, and dynamic; therefore, many researchers need to complement one method with another, and all researchers need a solid understanding of multiple methods used by other scholars to facilitate communication, to promote collaboration, and to provide superior research. Taking a non-purist or compatibilist or mixed position allows researchers to mix and match design components that offer the best chance of answering their specific research questions (p. 15)

A major advantage of the combination of both qualitative and quantitative approaches in mixed methods design is that it helps gain better understanding of the research problem than either approach alone (Plano Clark \& Creswell, 2015). Since both quantitative and qualitative methods have biases and weaknesses when used separately, the use of mixed methods approach neutralizes the weaknesses and overcomes limitations of a single design while giving priority to one method enhanced by the second method (Creswell \& Plano Clark, 2011). In the present study, the mixed method design allows for a thorough investigation of the research topic from 
multiple perspectives in a combined format where the qualitative phase was used to further explain and interpret the findings from the quantitative phase.

According to Molina-Azorín \& Font (2016), "the mixed method approach challenges the researcher to move beyond the agreed conventions of quantitative research for a given topic by asking broader questions on the validity of such approach and gaining meaningful insights" (p. 16). The primary rationale for using the mixed methods approach was to gain a greater insight into the experiences of faculty using collaborative technology tools to design, develop, and implement collaborative eLearning activities to enhance collaboration and student engagement in their online courses, along with the perspectives of students toward their experiences while participating in these activities. The mixed method research design seems to be the most appropriate method to understand more about the practical implications for selecting and implementing collaborative technology tools to design online courses that incorporate collaborative eLearning activities. The limitation associated with mixed methods design is that it requires the researcher to have a good experience in both qualitative and quantitative research as well as to be able to effectively mix both methods and interpret results. Another limitation is that this design is more time-consuming as it requires to collect and analyze both quantitative and qualitative data.

More specifically, an explanatory sequential mixed method approach was utilized in this study for data collection and analysis. Consequently, the study involved two phases: (a) an initial quantitative data collecting and analyzing phase, followed by (b) a qualitative data collecting and analyzing phase to provide a richer explanation of the data that has been collected and analyzed in the quantitative phase. In this way, the quantitative results were explained in more detail through the use of qualitative data. According to Creswell (2013), the explanatory sequential 
mixed method "is one in which the researcher first conducts quantitative research, analyzes the results and then builds on the results to explain them in more detail with qualitative research" ( $p$. 15). Figure 5 shows the explanatory methods research design diagram which is adapted from the work of Creswell and Plano Clark (2011) who suggests the creation of a diagram to visualize all of the components of the study.

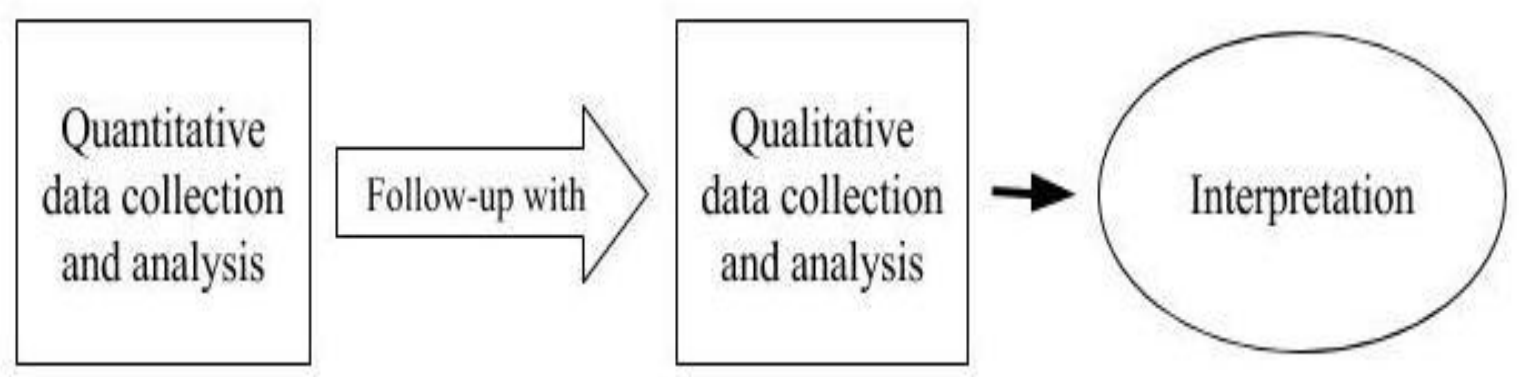

Figure 5. Explanatory sequential mixed method design diagram.

For the initial quantitative data collection phase, two online surveys were developed to collect data from faculty and students who are involved in online courses at a Midwestern state university. The survey focused on the experiences and perspectives of faculty and students regarding the implementation of collaborative technology tools to incorporate collaborative eLearning activities and the perceived impact of these tools on collaboration and student engagement in online courses. In this vein, the survey is a useful instrument for gathering information from a large population, especially when they are dispersed across many geographic areas. It utilizes numerical data to examine relationships between research variables through statistical analysis of data (Creswell, 2013). Using an online survey allowed for the rapid 
development of the instrument and provided participants with a greater level of convenience (Sills \& Song, 2002). It was also a great way to collect information from a wider audience with a greater diversity of participants, which increases the reliability of the study. This instrument allowed the researcher to obtain information from a large number of faculty and students regarding the implementation of collaborative technology tools for collaborative eLearning activities in an online learning environment. In sum, the use of the initial quantitative phase was intended to provide a breadth of numerical data from faculty and students representing a wide array of programs, departments, schools, and centers within the institution targeted for the study.

For the qualitative data collection phase, a set of semi-structured interviews were conducted in-person with faculty and students who met the participation criteria and volunteered to participate in the qualitative phase of the study. The use of a qualitative approach is beneficial "to understand the world from the subjects' points of view, to unfold the meaning of their experiences, to uncover their lived world" (Brinkmann \& Kvale, 2015, p. 3). The use of the qualitative phase expanded upon and elucidates the quantitative outcomes. The use of qualitative phase was intended to probe the perspectives of faculty and students further in order to generate more in-depth responses regarding their perceptions toward the implementation of collaborative technology tools to support collaboration and student engagement in online learning. The objective of conducting the semi-structured interviews was to allow participants to elaborate on their responses to the survey questions. In this sense, the core rationale of using the explanatory sequential mixed-methods design was to provide a better understanding of the research problem than either qualitative or quantitative approaches alone could fully address. This design served to explore the experiences, perceptions of faculty and students regarding the benefits and 
challenges associated with the implementation of collaborative technology tools for collaborative eLearning activities in their online courses.

\section{Research Setting \& Study Sample}

The target population for this study consisted of all tenure and non-tenure track faculty who have taught at least one online course in the past five years and students enrolled in at least one online course at a large Midwestern state university. The online teaching experiences were limited to the past five years due to the fact that most technology tools that support collaboration have launched nearly in 2012. This study was conducted at a large Midwestern state university that offers both online and traditional courses. The university's total enrollment is approximately 21,000 students in a diverse selection of undergraduate and graduate programs that offer a variety of undergraduate and graduate level online courses.

The institution's mass electronic communications system was used to elicit participation from a wide population of students and faculty members with greater diversity in an attempt to increase the quality of the study. Consequently, a total of 210 participants volunteered to participate in the study. More specifically, 29 faculty members and 181 students were surveyed in the study, and after a review of the results, follow-up interviews were conducted with four faculty members and two students who met the participation criteria and volunteered to participate in the study. Taken together, these two sources of data produce insight into the potential of collaborative technology tools for enhancing collaboration and student engagement in online settings and the factors that influence the selection of these tools to incorporate collaborative eLearning activities in online courses.

The participants of this study were selected on the basis of convenience sampling. According to Roberts (2010), "sampling is the process of selecting a number of individuals for a 
study in such a way that the individuals represent the larger group from which they were selected" (p. 149). Etikan, Musa, and Alkassim (2016) defined convenience sampling as a type of non-probability or non-random sampling where participants meet certain practical criteria such as proximity, ease of access, availability, and willingness to participate. Thus, convenience sampling was used in this study to collect information from faculty and students who are readily available and easily accessible to the researcher. Although this technique is likely to be biased and subjective, it is useful for this study due to the limitations in resources, time and workforce.

\section{Research Participants}

The online surveys were completed by a total of 210 participants who met the participation criteria and volunteered to participate in the study. Out of the 210 participants, 29 were faculty members and 181 were undergraduate and graduate students. The criteria for faculty members to participate in the study were: (a) teaching or have taught at least one online course in the past five years and (b) employing or have employed one or more collaborative technology tools for collaborative learning in their online courses. The criteria for students to participate in the study were: (a) currently enrolled or have enrolled in at least one online course in the past five years and (b) utilizing or have utilized one or more collaborative technology tools for collaborative activities in their online courses. At the outset of the survey, participants were asked to provide some demographic information. The faculty demographic data collected included gender, age, years of teaching experience, current title, years of online teaching experience, online course level taught, and technology-related training received. The student demographic data collected included gender, age, education level, and degree. 


\section{Description of the faculty participants.}

There were twenty-nine faculty members completed the online survey. A detailed overview of the survey faculty participants is provided in Table 1 . Of the 29 faculty members participated in the study, 18 participants were females and 11 were males. The age of faculty respondents ranged from 25 to 46 years, with a median score of 45 . An examination of the number of years of teaching experiences shows that more than half of faculty participants had been teaching for 11 years and above and reported their current title as assistant professors. Table 2 shows that $45 \%$ of the faculty participants reported that they taught undergraduate online courses and $22 \%$ of them taught graduate online courses while $33 \%$ of them reported that they have been teaching online courses for 1- 5 years for both graduate and undergraduate online courses. Sixty-four percent of faculty participants reported that they have received technologyrelated training.

Table 1

Description of Faculty Participants

\begin{tabular}{llcc}
\hline Demographic Variables & & Number & Percent \\
\hline Gender & Male & 11 & 38 \\
& Female & 18 & 62 \\
& & & 0 \\
Age & 25 and below & 0 & 21 \\
& $26-35$ & 6 & 41 \\
& $36-45$ & 12 & 38
\end{tabular}




\begin{tabular}{|c|c|c|c|}
\hline \multicolumn{2}{|l|}{ Demographic Variables } & \multirow{2}{*}{$\begin{array}{c}\text { Number } \\
2\end{array}$} & \multirow{2}{*}{$\begin{array}{c}\text { Percent } \\
7\end{array}$} \\
\hline Years of teaching & Less than 1 year & & \\
\hline \multirow[t]{3}{*}{ experience } & $1-5$ years & 6 & 21 \\
\hline & $6-10$ years & 4 & 14 \\
\hline & 11 or more years & 17 & 58 \\
\hline \multirow[t]{5}{*}{ Current position/title } & Professor & 0 & 0 \\
\hline & Associate Professor & 6 & 20 \\
\hline & Assistant Professor & 15 & 52 \\
\hline & Instructional Assistant Professor & 4 & 14 \\
\hline & Other & 4 & 14 \\
\hline Years of online teaching & Less than a year & 8 & 27 \\
\hline \multirow[t]{3}{*}{ experience } & $1-5$ years & 13 & 45 \\
\hline & $6-10$ years & 6 & 21 \\
\hline & 11 or more years & 2 & 7 \\
\hline \multirow[t]{3}{*}{ Online course level taught } & Undergraduate & 12 & 45 \\
\hline & Graduate & 6 & 22 \\
\hline & Both & 9 & 33 \\
\hline Technology-related training & Yes & 18 & 64 \\
\hline received. & No & 10 & 36 \\
\hline
\end{tabular}

\section{Description of the student participants.}

There were 181 students who completed and returned the online survey. A detailed overview of the survey student participants is provided in Table 2. As shown in Table 2, the 
majority of student participants were female students $(83 \%, \mathrm{n}=151)$ with ages ranged from 20 to 31. Most student participants were undergraduate students $(72 \%, \mathrm{n}=131)$ seeking a bachelor's degree $(67 \%, \mathrm{n}=120)$. The table shows that the highest percentage of student participants $(12 \%$, $\mathrm{n}=21$ ) were from the School of Teaching and Learning and the item Other had a similar percentage $(12 \%, \mathrm{n}=21)$. The second high percentage of student participants were from the Department of Psychology $(11 \%, \mathrm{n}=20)$. Interestingly, the data provided a great diversity of students from different departments and schools.

Table 2

Description of Student Participants

Demographic Variables

Number Percent

Gender

Male

30

17

Female

151

83

Age

20 and below

63

35

$21-25$

71

39

26-30

12

7

31 and above

19

Education level Undergraduate

$131 \quad 72$

Graduate

$50 \quad 28$

Degree type

Associates

$10 \quad 5$

Bachelors

120

67

Masters

$34 \quad 19$

Doctorate

$13 \quad 7$

Non-degree courses

3

2

Table Continues 
Department of Chemistry

Department of Communication Sciences and

Disorder

Department of Criminal Justice Sciences

Department of Economics

Department of Educational Administration and

Foundation

Department of English

Department of Family and Consumer Sciences

Department of Geography-Geology

21

Department of History

Department of Languages, Literatures and Cultures

$1 \quad .5$

Department of Mathematics

Mennonite College of Nursing

$14 \quad 8$

Department of Politics and Government

1

.5

Department of Psychology

20

11

Department of Sociology and Anthropology

2

Department of Special Education 
Department of Technology

School of Art

School of Biological Sciences

School of Communication

School of Information Technology

School of Kinesiology and Recreation

School of Music

School of Social Work

School of Teaching and Learning

School of Theatre and Dance

Other

95

2

1

8

4

8

4

$2 \quad 1$

10

6

10

6

6

3

3

2

21

12

3

5


collaborative technology tools, and the experience in online learning. Likewise, the identified students were contacted via email to schedule the follow-up interviews. In the end, a total of six participants were interviewed in-person. Four of the participants were faculty members that included one male and three females that were given pseudonyms, Jack, Laura, Samantha, and Tracy. The remaining two participants were one male and one female graduate students given the pseudonyms of, Patrick and Abby. Table 3 provides demographic information on each of the six interviewees who volunteered to participate in the qualitative phase of the study.

Table 3

Description of the Interviewees

\begin{tabular}{|c|c|c|c|c|c|}
\hline Pseudonym & & Position & Gender & Age & Department/School \\
\hline \multirow[t]{6}{*}{ Faculty } & Laura & Assistant Professor & Female & $46+$ & Department of Technology \\
\hline & Tracy & Assistant Professor & Female & $36-45$ & Department of Special \\
\hline & & & & & Education \\
\hline & Samantha & Assistant Professor & Female & $46+$ & Department of Chemistry \\
\hline & Jack & Assistant Professor & Male & $36-45$ & School of Teaching \& \\
\hline & & & & & Learning \\
\hline \multirow[t]{4}{*}{ Students } & Patrick & Graduate Student & Male & $36-45$ & School of Communication \\
\hline & Abby & Graduate Student & Female & $26-30$ & Department of Educational \\
\hline & & & & & Administration and \\
\hline & & & & & Foundation \\
\hline
\end{tabular}




\section{Research Instruments}

This section includes a description of all instruments used to collect data for this explanatory sequential mixed methods design research that involved two phases: (a) an initial quantitative data collecting and analyzing phase, followed by (b) a qualitative data collecting and analyzing phase to provide a richer explanation of the data that has been collected and analyzed in the quantitative phase. Initially, two online surveys were developed to collect quantitative data from students and faculty members. Afterward, semi-structured interviews were conducted to follow up on the quantitative data in more depth. The survey and follow-up interview questions were informed by a review of the literature on online learning, collaborative learning, collaborative eLearning, and the implantation of collaborative technology tools in online courses.

\section{Survey Instrument}

Surveying is one of the most used research tools to obtain large information from participants in a timely fashion (Vogt, Gardner, \& Haeffele, 2012). The survey is seen as a very valuable approach providing "a quantitative or numeric description of trends, attitudes, or opinions of a population by studying a sample of that population" (Creswell, 2013, p.13). For the current study, two closely related surveys were developed by the researcher using the survey platform, Qualtrics, to gather data from faculty members who have taught at least one online course and employed collaborative learning techniques in their online courses and students who were enrolled in at least one online course. The first survey was developed for the faculty (see Appendix D). The second survey was developed for students (see Appendix E). The two surveys were related but distinctly different. The survey questions were research-based that were developed by the researcher after conducting a careful literature review, including demographic 
information, and Likert-type questions. Though the surveys differ slightly in the form of questions, they were generally divided into five major sections:

1. Participants' demographic information:

a. Faculty participants' demographic information include gender, age, years of teaching experience, current title, years of online teaching experience, online course level taught, and technology-related training.

b. Student participants' demographic information include gender, age, education level, and degree type.

2. Participants' experiences using collaborative technology tools.

a. Participants' selections of the most commonly used technology tools for collaboration in online courses.

b. Faculty participants' levels of comfort using technology tools for student collaboration in online courses, using a 5-point Likert scale with the following response metric: very uncomfortable, uncomfortable, neither comfortable nor uncomfortable, comfortable, and very comfortable.

c. Student participants' views of the impact of collaborative technology tools to improve their group work, using a 5-point Likert scale with the following response metric: definitely no, probably no, might yes or might no, probably yes, and definitely yes.

d. Student experiences using collaborative technology tools for collaborative eLearning activities using a 5-point Likert scale with the following response metric: extremely negative, negative, neither positive nor negative, positive, and extremely positive. 
3. Factors contributing to the successful selection of collaborative technology tools. Faculty participants were asked to indicate their level of endorsement with 10 items on a 5-point Likert scale with the following response metric: strongly disagree, disagree, neutral, agree, and strongly agree.

4. The influence of collaborative technology tools on online learning:

a. Faculty participants' levels of endorsement with 32 items, using a 5-point Likert scale with the following response metric: strongly disagree, disagree, neutral, agree, and strongly agree.

b. Student participants' levels of endorsement with twenty-one items, using a 5point Likert scale with the following response metric: strongly disagree, disagree, neutral, agree, and strongly agree.

In addition, the survey included a question at the end to inquire if the participant is interested in participating in a follow-up interview by providing their email address. The variables of the study are presented in Table 4 . 
Table 4

Description of Study Variables

\begin{tabular}{|c|c|c|}
\hline Variables & Variable Code & Measurement Level \\
\hline \multirow[t]{3}{*}{ Gender } & $1=$ Male & Nominal \\
\hline & $2=$ Female & \\
\hline & $3=$ Other & \\
\hline \multirow[t]{4}{*}{ Faculty Age } & $1=25$ and below & Ordinal \\
\hline & $2=26-35$ & \\
\hline & $3=36-45$ & \\
\hline & $4=46$ and above & \\
\hline \multirow[t]{4}{*}{ Years of teaching experience } & $1=$ Less than a year & Ordinal \\
\hline & $2=1-5$ years & \\
\hline & $3=6-10$ years & \\
\hline & $4=11+$ years & \\
\hline \multirow[t]{6}{*}{ Current Title } & $1=$ Professor & Ordinal \\
\hline & $2=$ Associate Professor & \\
\hline & $3=$ Assistant Professor & \\
\hline & $4=$ Instructional Assistant & \\
\hline & $5=$ Professor & \\
\hline & $6=$ Other & \\
\hline
\end{tabular}

Table Continues 


\begin{tabular}{|c|c|c|}
\hline Variables & Variable Code & Measurement Level \\
\hline Years of online teaching experience & $\begin{array}{l}1=\text { Less than a year } \\
2=1-5 \text { years } \\
3=6-10 \text { years } \\
4=11+\text { years }\end{array}$ & Ordinal \\
\hline Online Course Level taught & $\begin{array}{l}1=\text { Undergraduate } \\
2=\text { Graduate } \\
3=\text { Both }\end{array}$ & Ordinal \\
\hline Receiving technology-related training & $\begin{array}{l}1=\text { Yes } \\
2=\mathrm{No}\end{array}$ & Nominal \\
\hline Student-Age & $\begin{array}{l}1=20 \text { and below } \\
2=21-25 \\
3=26-30 \\
4=31 \text { and above }\end{array}$ & Ordinal \\
\hline Education Level & $\begin{array}{l}1=\text { Undergraduate } \\
2=\text { Graduate }\end{array}$ & Ordinal \\
\hline Degree Type & $\begin{array}{l}1=\text { Associates } \\
2=\text { Bachelors } \\
3=\text { Masters } \\
4=\text { Doctorate } \\
5=\text { Non-Degree Courses }\end{array}$ & Ordinal \\
\hline
\end{tabular}




\begin{tabular}{lll}
\hline Variables & Variable Code & Measurement Level \\
\hline The perspectives of faculty toward the & 1 = Strongly Disagree & Ordinal \\
factors that instructors may consider & $2=$ Disagree & \\
when selecting collaborative technology & $3=$ Neutral & \\
tools for collaborative eLearning & $4=$ Agree & Ordinal \\
activities & $5=$ Strongly Agree & \\
The perspectives of faculty about the & $1=$ Strongly Disagree & \\
influence of using collaborative & $2=$ Disagree & \\
technology tools on online learning. & $3=$ Neutral & \\
& $4=$ Agree & \\
The perspectives of students about the & $1=$ Strongly Disagree & \\
influence of using collaborative & $2=$ Disagree & \\
technology tools on online learning. & $3=$ Neutral & \\
& $4=$ Agree & \\
\hline
\end{tabular}

\section{Interview Instrument}

The semi-structured interviews were conducted to follow-up on the quantitative survey results in more depth. This kind of interview protocol is suited and useful for exploring participants' perspectives due to the flexibility on how to ask questions in order to probe and expand responses of the interviewee. Thus, the semi-structured interviews were beneficial to develop a deeper understanding and a more thorough analysis of the overall participants' 
perceptions and experiences using collaborative technology tools to provide collaborative

learning opportunities. According to Alshenqeeti (2014), the semi-structured interview is a more flexible version of the structured interview. The reason for the explanatory follow-up interviews is to examine an in-depth understanding of the survey results with a representative sample of the participants and to build on the initial quantitative results. Thus, the interview questions were developed in response to the results of the quantitative data analysis from the survey. Conducting interviews is intended to focus on the experiences of participants and the meaning they make of that experience. Although it is a semi-structured, the interviews were structured into three sections as follows:

1. Interviewee demographic information;

2. Interviewee perspective about collaborative eLearning; and

3. Interviewee perspective about the use of collaborative technology tools.

Interviews were conducted at a convenient location and remained under 45 minutes in length. Interviews were digitally recorded and transcribed for accurate evaluation and analyzing (see Appendix H \& I).

\section{Pilot Study Procedures}

A pilot study is a small study that is often conducted to assist in designing a large and more comprehensive study and generally used to demonstrate "the feasibility, reliability, and validity of the proposed study design" (Thabane et al., 2010, p. 2). In the current study, a pilot study was used to test the effectiveness of the survey instruments. Pilot participants were contacted via email with an invitation to participate in the pilot study that included an overview of the study and embedded a web link to the online survey (see Appendix A). Thus, the study instruments were pilot-tested with a convenience sample of faculty members and students. The 
pilot study consisted of two phases. The first phase focused on testing the survey questions to further refine question wording and appropriateness. Six students and seven faculty members completed the pilot survey and provided feedback and recommendations on how the survey could be improved. The second phase of the pilot study focused on testing the interview questions. Some of the participants who are knowledgeable in the area of the study furthered refining question wording and appropriateness. The comments of the pilot participants were incorporated into the final instrument revisions. Conducting a pilot study was beneficial to provide initial indications of results and the potential complications that can be addressed to best conduct the study. Consequently, the pilot study furthered the development and design of the survey by addressing a number of logistical issues including the clarity of the instructions, the wording of a survey, and the reliability and validity of results (Simon, 2011).

\section{Data Collection Techniques}

Prior to conducting this study, the approval of the Institutional Review Board (IRB) at the Midwestern state university was sought and obtained. The specific objective of this study was to explore the experiences of faculty members implementing collaborative technology tools in online courses to support collaboration and student engagement, in addition, to obtain the perspectives of students toward their experiences while participating in these activities. A mixedmethods sequential explanatory design was utilized to achieve the objective of this study. Thus, this study involved two phases: (a) an initial quantitative data collecting and analyzing phase, followed by (b) a qualitative data collecting and analyzing phase to provide a richer explanation of the data that has been collected and analyzed in the quantitative phase. In this way, the quantitative results were explained in more detail through the use of qualitative data. For the initial quantitative data collection phase, two online surveys were developed to collect data from 
faculty and students who are involved in online courses at a Midwestern state university. For the qualitative data collection phase, a set of semi-structured interviews were conducted in-person with faculty and students who met the participation criteria and volunteered to participate in the qualitative phase of the study. Table 5 represents the questions of this study and the different data collection techniques that were used to address each of the questions. The procedures for collecting quantitative and qualitative data are described in detail below.

Table 5

Data Sources for Research Questions

\section{Data Sources}

Research Questions

Online Survey Interview

RQ 1 What collaborative technology tools do Faculty survey Faculty interview faculty use and how do they incorporate

Student survey collaborative eLearning activities in their online courses using those tools?

RQ 2 What are the factors that faculty may Faculty survey Faculty interview consider when selecting collaborative technology tools for collaborative eLearning activities?

RQ 3 How do faculty and students perceive the Faculty survey Faculty interview influence of collaborative technology tools Student survey Student interview on online collaborative learning? 


\section{Quantitative Data Collection}

After receiving the approval from the IRB, a request was sent to the Office of the Registrar at the university to contact the potential participants with a recruitment email using the institution's mass electronic communications system. The recruitment email included an invitation to participate in the study with an overview of the research and embedded a web link to the online survey (see Appendix B). The online survey contained a consent form that details the purpose of the study, the importance of participation, the steps for participation, their rights as participants, and the contact information for the researcher, the adviser, and the Institutional Review Board at the university (see Appendix C). The participants were informed about the likely risks involved in the research and of potential consequences for participants. Each participant was given the opportunity to agree/disagree to participate. However, it was a requirement that each participant completed the online informed consent form before taking part in the study.

The survey platform, Qualtrics, was used to develop two closely related surveys that were used to collect data from faculty members and students who were involved in online learning. Links to the online surveys were distributed to the faculty members and students in the spring 2018 semester in the month of March and were available for a period of two weeks. In the final bulk of the online surveys, participants were asked to provide their contact information if they were willing to participate in the qualitative section of the study. A reminder email was sent to the faculty and students after one week of administration of the survey. After collecting the quantitative data using Qualtrics, the data was extracted in a Microsoft Excel file, cleaned, coded, and analyzed with SPSS statistical software. 


\section{Qualitative Data Collection}

The qualitative data of this study was collected primarily utilizing a semi-structured interview protocol. The semi-structured format was used to develop the interviews and gather more in-depth information. This allowed to ask additional questions to the respondents as well as to delve into some of the respondents' answers more in-depth. The interviews were conducted as a follow-up to the quantitative results to help expound upon the data collected from the online surveys for further understanding of their experiences and perspectives toward the utilization of collaboration technology tools for collaborative eLearning activities in online courses. Thus, the semi-structured interview protocol was utilized to ensure coverage of all relevant areas related to the research questions.

After collecting and analyzing the quantitative data from the online surveys, the participants who voluntarily committed to participate in the qualitative section of the study and provided their contact information in the survey were contacted via e-mail to accommodate their preferences and availability for a follow-up interview (see Appendix F). During the initial phase of each interview, participants were asked to sign the informed consent form that outlined their rights (see Appendix G). The participants were informed that the information collected remained confidential. A copy of the main questions or topics was emailed to the respondents prior to the interview for preparation. Those questions were the foundation for each interview. The interviews took place at mutually convenient times and locations. The interviews lasted between 20 to 40 minutes in length. Upon completion of the semi-structured interviews, the audio recordings were transcribed in order to carefully evaluate and analyze the interviews. The qualitative results were used to assist in interpreting the findings of the quantitative phase. The 
level of interaction between the quantitative and the qualitative strands is an important consideration in the procedures of a mixed methods design (Creswell \& Plano Clark, 2011).

\section{Data Analysis Procedures}

An explanatory sequential mixed methods design was utilized in the current study in which the quantitative and qualitative data were collected and analyzed separately (Creswell, 2013). The study started with initial online surveys to collect data from faculty and students who are involved in online courses at a Midwestern state university, followed by a set of interviews with faculty and students who met the participation criteria and volunteered to participate in the qualitative phase of the study. In this way, the quantitative results were explained in more detail through the qualitative inquiry. The qualitative data obtained from the online surveys were analyzed using the SPSS software program to provide descriptive statistics include frequencies, percentages, means, and standard deviations. The qualitative data obtained from the semistructured interviews were analyzed using a thematic analysis technique to identify themes generated from the data. The analysis procedures of both quantitative and qualitative data are described in detail below.

\section{Quantitative Data Analysis}

The online surveys were completed by a total of 210 participants who met the participation criteria and volunteered to participate in the study. Out of the 210 participants, 29 were faculty members and 181 were students. The quantitative data obtained from the online surveys were analyzed using SPSS to provide descriptive statistics include frequencies and percentages for categorical data and means and standard deviations for continuous data. According to Gravetter and Wallnau (2012), descriptive statistics "are statistical procedures used 
to summarize, organize, and simplify data" (p. 7). Thus, descriptive statistics were calculated to interpret the data for the purpose of the study.

More specifically, the survey questions that identify demographic information about the faculty respondents included gender, age, years of teaching experience, current title, years of online teaching experience, online course level taught, and technology-related training received and were analyzed using frequencies and percentages. Similarly, the survey questions that identify demographic information about the student respondents included gender, age, education level, and degree and were analyzed using frequencies and percentages. On the other hand, the survey questions that seek to explore the perspectives of respondents towards the implantation of collaborative technology tools for collaborative eLearning activities in their online courses and the factors that influence the selection of these tools were analyzed using means and standard deviations.

\section{Qualitative Data Analysis}

After conducting the follow-up interviews, the audio records of the interviews were transcribed and carefully reviewed to develop a preliminary list of categories and themes using a thematic analysis method. Consequently, the qualitative data analysis process for the current study included the following steps: (a) writing interview transcripts, (b) identifying participants' characteristics related to their experiences of online learning and collaborative technology tools (c) reviewing interview transcripts, (d) organizing and preparing the data for analysis, (e) generating initial codes from the data, (f) collecting and connecting the codes into broader themes, (g) reviewing and refining themes, (h) representing the themes in a qualitative narrative in the final report. 
Following the previous steps, the interview transcripts were organized, highlighted, coded, and analyzed for themes development. The researcher created a set of codes which were short descriptive words to be easily organized and grouped into themes. An open coding process was used for theme and category development. According to Creswell (2013), coding is the process of taking text data gathered during data collection, segmenting sentences into categories, and labeling those categories with a term. Thus, the qualitative data obtained from the interviews were analyzed using a thematic analysis technique to identify themes generated from the data. The goal of thematic analysis is to identify themes that aid in presenting the data in a qualitative narrative.

Using a thematic analysis method, general themes for this study were developed by narrowing and grouping initial codes generated from the data through an open coding process. "As a popular form of analysis, classification involves identifying five to seven general themes" (Creswell, 2013, p. 186). Consequently, six general themes emerged from the qualitative data analysis as follows: (a) preparedness and proactive thinking, (b) creating a sense of instructor presence, (c) establishing a sense of community, (d) engaging student collaboration, (e) troubleshooting, and (f) practical guidelines and considerations. Meaningful and important passages and quotations were presented using pseudonyms for participants and references to their institution to protect their identities

\section{Triangulation}

The mixed methods approach used in this study is particularly useful in neutralizing the weaknesses of a single design where it is offset by the strengths of another. Both quantitative and qualitative methods have different weaknesses and strengths and therefore, the triangulation can help overcome the weaknesses of any single method (Molina-Azorín \& Font, 2016). Tashakkori 
and Teddlie (1998) referred to the concept of triangulation as "multilevel research" which refers to the use of multiple methods to develop a comprehensive understanding of phenomena and can be accomplished by either quantifying qualitative findings or qualifying quantitative results ( $\mathrm{p}$. 48). Onwuegbuzie and Combs (2010) illustrated that "mixed analysis involves the use of both quantitative and qualitative analytical techniques within the same framework" (p. 425). The level of integration and interaction between the quantitative and the qualitative results is an essential consideration in the procedures of a mixed methods design (Creswell \& Plano Clark, 2011).

In this study, the explanatory sequential mixed method approach was utilized in which data was collected and analyzed sequentially. The results of quantitative data were used to guide and inform the qualitative data collection (Onwuegbuzie \& Teddlie, 2003). In other words, the quantitative analysis phase preceded the qualitative analysis phase. Then, the data obtained from both the qualitative and quantitative phases was integrated to obtain comprehensive data in accordance with the purpose of the study. The combination and integration of the mixed data draw more comprehensive conclusions from the present study regarding the influence of the implementation of collaborative technology tools to facilitate collaborative eLearning activities and enhance collaboration and student engagement in online learning. The mixed methods approach used in this study offer an effective way of the interpretation and explanation of the findings to successfully organize and consolidate the final report with a clear formulation of the conclusion and recommendations.

\section{Validity and Reliability}

Validity is defined as "the degree to which the instrument truly measures what it purports to measure" where the reliability is defined as "the degree to which the instrument consistently measures something from one time to another" (Roberts, 2010, p. 151). To address content 
validity, survey items were developed based on a careful literature review associated with collaborative learning in online learning environments. The word choice, answer choices, and construction of each item in the surveys were reviewed to determine whether each item measured what it intended to measure. Furthermore, the study instruments were pilot-tested with a convenience sample of faculty members and students to ensure reliability by improving questions, format, and scales. For qualitative data validation purposes, participants were informed that only the researcher will be privy to the tape which will be eventually destroyed after it is transcribed. They were required to sign informed consent for the interview which indicated that all information will be held confidential and their participation was voluntary and that they may stop at any time if they felt uncomfortable. Moreover, the transcriptions of the interviews were sent to the participants for any comments and clarifications. Additionally, data was collected from two different points of view to reduce possible validity threats. It was collected from both students and faculty members.

Furthermore, advanced statistical techniques were used to determine survey reliability. To assess internal-consistency reliability, a Cronbach's alpha was computed to verify the consistency of survey items. Table 6 shows that the Cronbach's alpha reliability for the survey subscales was found to be 0.70 and above. Theoretically, all reliability estimates should meet the desired standard level of 0.70 or above as suggested by Green and Salkind (2014). According to Mohsen and Reg (2011), the higher the Cronbach Alpha, the more reliable the test results. 
Table 6

Cronbach's Alpha Reliability for the Survey Subscales

Subscales

Number of Items

Alpha

Faculty perceived factors to consider when selecting

10

.70

collaborative technology tools

Faculty perceived influence of using collaborative technology

32

.95

tools in an online course

Student perceived influence of using collaborative technology

21

.95

tools on group work

\section{Positionality Statement}

The researcher is the primary instrument of data collection and analysis as well as the interpretation of the findings. This critical role requires clear identification of personal values and cultural norms that may influence the interpretation of the research findings. According to Foote and Bartell (2011), "the positionality that researchers bring to their work, and the personal experiences through which positionality is shaped, may influence what researchers may bring to research encounters, their choice of processes, and their interpretation of outcomes" (p. 46). Therefore, Creswell (2013) recommended including a statement that describes the researcher's background and experience which help explain how the study is shaped by the research positionality. 
For the present study, the primary researcher is a Saudi female student who is working toward a doctorate degree in Teaching and Learning from a state university with a research emphasis in educational technology, e-learning, and online education. My experience within this graduate program inspired me to examine the best practices of online education in U.S. schools and gain insights into the experiences and perspectives of faculty and students towards the implementation of advanced technology tools into online courses with the aim of improving online learning.

Online learning is an attempt initially to meet the unique learning needs of students who cannot attend school for various geographic or personal reasons. This trend of education supports the idea that learning does not take place only in a school building, but rather at home, library, or wherever an Internet connection can be found. However, when I examined the state of online learning in Saudi Arabia, I have found that it is being adopted at a relatively slow pace and continue to remain of minor interest in Saudi universities. While universities worldwide have taken advantage of the benefits of online education by offering at least some coursework online, many universities in Saudi Arabia are still reluctant to offer online courses. The study concluded that the effective adoption and implementation of online learning in Saudi Arabia can help address many issues such as the educational overcrowding and the steady increase of the demand of Saudi students for higher education credentials. Online education has the potential to offer great opportunities for Saudis to upgrade their educational status without attending the institution regularly and leaving their jobs or business, especially those who have a demanding work schedule and family responsibilities. Another important finding was that online education has the potential to empower Saudi female students to overcome social and cultural obstacles (Alahmari, 2017). 
Unlike most Western universities, public universities in Saudi Arabia consist of two geographically separated campuses: one campus for male students, and the other for female students. This separation is due to religious and cultural norms of the society that are upheld by governmental laws and policies. Due to the shortage in the number of available female faculty, male instructors are authorized only to teach female students indirectly using courses that are remotely delivered by means of closed-circuit television, one-way video and two-way audio, or broadcast audio. Female students view lectures in real-time via a TV monitor and use a microphone system to ask questions and give feedback. Such a reality would appear tailor-made for the online learning approach. For this purpose, I worked with Dr. Amirault to examine the general perceptions of Saudi Arabian faculty members and Saudi female students toward online learning and potentially replacing the current closed-circuit distance technology in use for female students studying at Princess Nourah Bint Abdulrahman University (PNU) in Riyadh, Saudi Arabia, with online courses. The results of this study revealed high levels of support within these groups for the implementation of online course delivery in the case when male instructors teach and interact with female students. The results also revealed that most faculty reacted very favorably to the online course as a replacement for closed-circuit television modality. Consequently, the study concluded that there is an urgent need to actively and reflectively consider online learning in Saudi higher education, particularly for the special situation when female students are taught by male instructors (Alahmari \& Amirault, 2017).

Though I have never taught an online course, I have facilitated a short- scale online professional development, titled Teaching with Technology, which was an open online course to support Saudi teachers in the integration of technology in Saudi schools. This initiative was a response to the previous two studies that Dr. Kyei-Blankson and I conducted to examine 
technology integration in teaching and learning in Saudi K-12 schools. The results reveal that many Saudi teachers grapple with the demands of integrating technology into their teaching practices reporting their needs for technology-related professional development (Alahmari \& Kyei-Blankson, 2016; Alahmari \& Kyei-Blankson, 2018). One of the more significant results to emerge from this study is that most current teachers have not been taught by using technology nor on how to use technology in teaching. Findings identified technical barriers to effective technology integration in teaching and learning in Saudi K-12 schools and the need to create a supportive technology-related professional development program that has the potential to expand access to reach a large number of Saudi teachers (Alahmari \& Kyei-Blankson, 2016; Alahmari \& Kyei-Blankson, 2018).

For this purpose, I have developed Teaching with Technology as a technology-related teacher professional development program that aims to exclusively enhance teacher technology knowledge and skills, providing them with more accessible and high-quality resources while promoting active engagement and sustained learning. Teaching with Technology was designed to take place in an ongoing, online, collaborative working environment using Open Learning website. With a great support from IVORY Training \& Consulting in Saudi Arabia, I provided ten professional development webinars during the 2016-2017 school year to introduce this program to teachers and help them learn how to use the program and collaborate with other teachers in active learning to exploit the provided technology tools and the effective use of these technologies to improve their teaching practices. With the aim to improve this initiative, I worked with Dr. Rugutt and Dr. Banicki to examine the preliminary outcomes of the Teaching with Technology initiative as a short- scale online professional development provided during the 2016-2017 school year. The findings reveal that this short-scale initiative had a significant 
positive effect on improving teachers' knowledge and teaching practices. The evidence from this study suggests that online professional development has the potential to develop an online learning community that facilitates the transfer of knowledge to teaching practices and allows teachers to collaborate with other teachers nationwide. Online professional development has the potential to improve teacher quality and thus ultimately, effective technology integration in Saudi schools. However, Teaching with Technology initiative is still an experiential program and with more improvement, it could become a large-scale online professional development for teachers across Saudi Arabia and other Arab countries. It was an attempt to design a model for sustained and continuing learning that provides interactive, self-paced, and collaborative professional development to improve teacher technology knowledge and skills in the applications of educational technology into their teaching practices.

\section{Ethical Assurances}

This study was conducted with the approval of the IRB. The researcher completed the Collaborative Institutional Training Initiative (CITI) training and hold a completion certificate. The appropriate ethical procedures were followed for this research. Creswell (2013) illustrates some ethical issues to be considered when conducting research that includes obtaining appropriate consent, respecting the rights of participants, avoiding collecting harmful information, and reporting research honestly. For this purpose, the researcher took specific measures to protect the identities of those who participate in the study. An informed consent process was used to emphasize that participant engagement in the study was voluntary and they have the right to withdraw from the study at any time without penalty. The informed consent will also describe the nature and purpose of the study, the scope of the study, and the use of the results (Appendix A). 
The anonymity and confidentiality of participants will be maintained at all times throughout the study. All information provided from the web-based survey will remain anonymous and will only be reported as group data with no identifying information. The names and e-mail addresses of the participants will remain confidential. All surveys, interview recordings, transcripts, and other data were secured on a password-protected computer. Data was presented with no identifiers and the participants were assured that any information they provided during this study was used only for the purpose of improving collaborative learning in online environments. Overall, the risk associated with the proposed study was very minimal and did not extend beyond normal everyday risks. The participants of this study were informed that they may contact the Research Ethics \& Compliance Office at the university if they have any questions or concerns about their rights in this research. No participant received an incentive or compensation for their participation. After writing and reviewing interview transcripts, a copy of the interview transcript was emailed to each participant to review for accuracy and consistency of the transcription. 


\section{CHAPTER IV: FINDINGS}

This chapter details the research findings of the current explanatory sequential mixed method study used to answer the following research questions:

1. What collaborative technology tools do faculty use and how do they incorporate collaborative eLearning activities in their online courses using those tools?

2. What are the factors that faculty may consider when selecting collaborative technology tools for collaborative eLearning activities?

3. How do faculty and students perceive the influence of collaborative technology tools on online collaborative learning?

The explanatory sequential mixed methods design used in this study involved two phases: (a) an initial quantitative data collecting and analyzing phase, followed by (b) a qualitative data collecting and analyzing phase. The data obtained from both quantitative and qualitative data were integrated to address the research questions more comprehensively. Quantitative data were presented in tables and figures. Furthermore, numerous quotes, from the follow-up interviews with faculty and students, were included to support the findings. The findings reported in this chapter were organized and presented in light of the research questions.

\section{Overview of the Study}

The purpose of the current study was to better understand the potential and use of technology for enhancing collaboration and student engagement in online settings and the factors that influence the selection of collaborative technology tools for collaborative eLearning activities in online courses. Therefore, the study aims to explore the experiences of faculty members integrating collaborative technology tools into online courses to support collaboration and student engagement. In addition, the perspectives of students were gathered to know more 
about their experiences while participating in these activities. The target population for this study consisted of faculty members who have taught at least one online course and employ collaborative learning techniques in their online courses and students who were enrolled in at least one online course. This study was conducted at a large Midwestern state university during the spring of 2018 semester.

An explanatory sequential mixed methods design was utilized to achieve the purpose of this study and to address the research questions. The study involved two phases: (a) an initial quantitative data collecting and analyzing phase, followed by (b) a qualitative data collecting and analyzing phase to provide a richer explanation of the data that has been collected and analyzed in the quantitative phase. In this way, the quantitative results were explained in more detail through the use of qualitative data. Initially, the researcher developed two closely related surveys that were developed using the survey platform, Qualtrics to collect data from faculty members and students. The online surveys were distributed during the spring of 2018 semester via a recruitment email using the institution's mass electronic communications system.

The online surveys were completed by a total of 210 participants who met the participation criteria and volunteered to participate in the study. Out of the 210 participants, 29 were faculty members and 181 were students. The quantitative data gathered from both surveys were analyzed using SPSS software, version 25 for descriptive statistical analysis. The quantitative survey data supplied demographic information along with descriptive information about experiences and perspectives of faculty integrating collaborative technology tools into their online courses for collaborative eLearning activities and perspectives of students toward their experiences while participating in these activities. 
After a review of the results obtained from the surveys, follow-up interviews with four faculty members and two students were conducted to gather qualitative data. The qualitative data obtained from the follow-up interviews supported and expanded the results found in the quantitative phase. In other words, the qualitative data provided a more descriptive picture of faculty members' experiences concerning the use of collaborative technology tools in their online courses for collaborative activities, as well as of the students' perceptions toward their experiences of participating in these activities. The interviews were audio recorded and transcribed for data analysis. An open coding process was used to analyze participants' responses for contributing factors of their experiences and perspectives. Subsequently, the data obtained from both quantitative and qualitative data were integrated, organized, and presented in light of the research questions.

\section{Findings}

\section{Research Question 1}

What collaborative technology tools do faculty use and how do they incorporate collaborative eLearning activities in their online courses using those tools?

The findings of this question come from responses from faculty and students on the survey questions and are supported by their responses to the follow-up interviews. The survey sought to determine what collaborative technology tools were most commonly used to support collaboration and student engagement in online courses. The findings are shown in detail in

Figure 4. The survey included the following collaborative technology tools: Google Applications (Google Drive: Docs, Sheets, Slides, Draw), Microsoft Applications/Microsoft Office 365 (OneNote Class Notebook), Social Networking Tools (Facebook, Linked-in, Skype, Twitter, 
WhatsApp, SnapChat), Wikis, Blogs, Microblogging, Web Conferencing, Presentation \& Slide Sharing, Blackboard Collaborate, and Discussion Forums.

Figure 6 shows that Google applications are the most commonly used collaborative tools as reported by the highest percentages of both faculty $(82 \%)$ and students $(78 \%)$. The second most commonly used collaborative tools were Discussion Forums as reported by 61 percent of faculty and 60 percent of students. The less commonly used tool was Microblogging where only 14 percent of faculty and 5 percent of students reported using Microblogging for collaborative learning. Closer inspection of the figure shows that Wikis and Blogs were seen as less commonly used tools, as compared to Google applications and Discussion Forums. Figure 6 shows that 25 percent of faculty reported using Wikis and Blogs for collaborative learning. For students, Blogs were reported by 16 percent of student participants whereas Wikies were reported by only 13 percent of them.

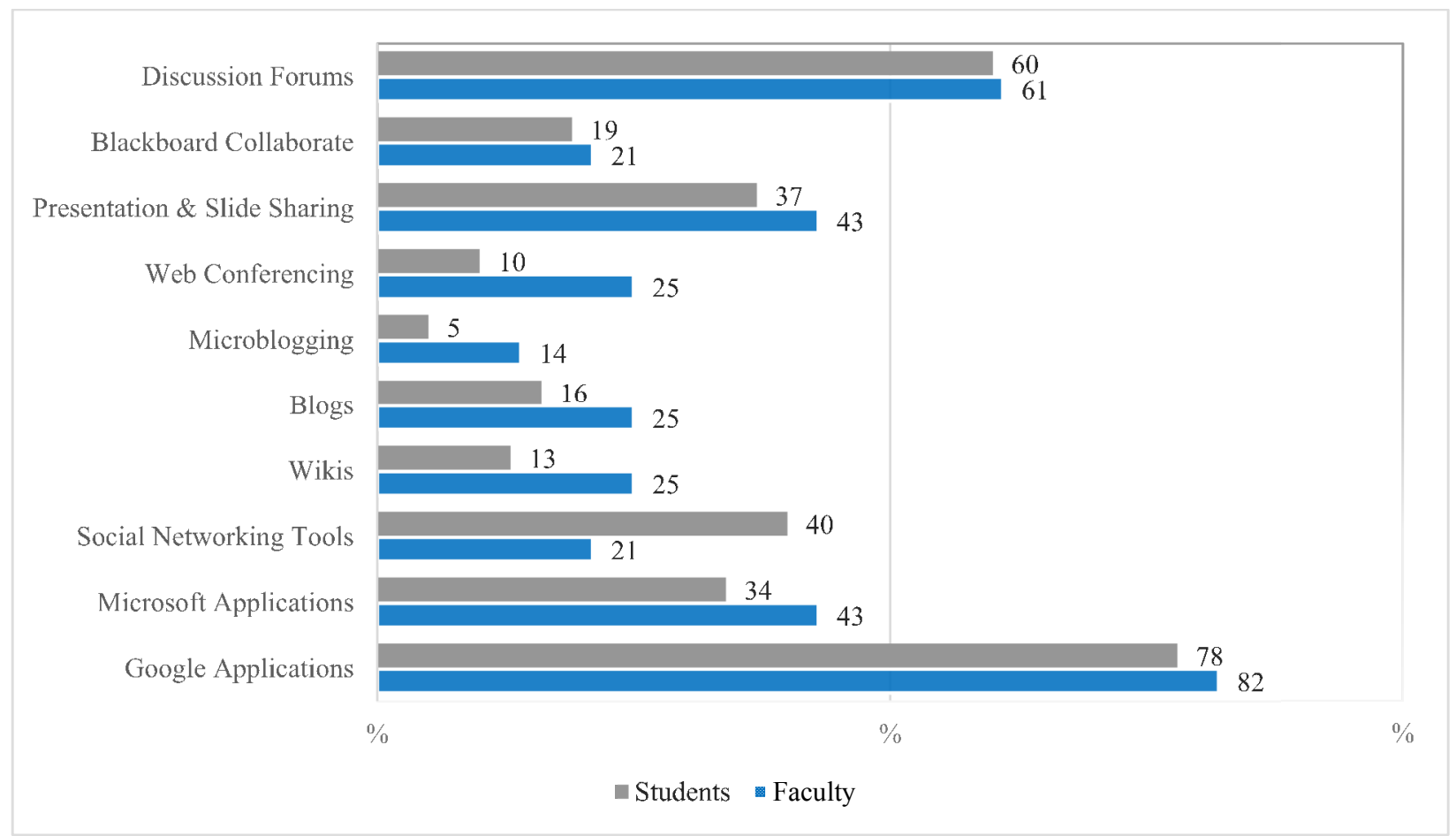

Figure 6. The perceived most commonly used technology tools for collaboration. 
Interview data resonates with survey data in that both faculty and students frequently use Google applications for collaborative eLearning activities in online courses. The two students interviewed in the study, Patrick and Abby, perceived Google Docs as an excellent tool for collaborative eLearning activities, especially collaborative writing and co-authoring, due to the collaboration features of Google Docs. Abby mentioned the collaboration features of Google Docs and how these features support collaboration and student engagement in an online course. She said:

Google Doc was actually very, very helpful; Google Doc was used for one of the group activities in one of the online courses that we did, we were doing group-- Zoom video and audio also because we didn't sit together. So, we would upload our themes, our parts in the Google Doc. And then, everybody would look, would comment, and everybody had a different color that they use, so it was color-coded, and you don't have to do that, and Google Doc does it automatically. So, we could see, like A, B, C, A has said this about this and then we were making real-time changes...I mean, that was a wonderful collaboration.

Abby explained how the use of Google Documents enabled her to engage in online collaborative eLearning activities with the other parties who were spread geographically, which is seen to be an excellent example of effective use of collaborative technology tools:

I was in India. The other person in the group was in Africa. I mean, he was in Ghana or somewhere, and the other person was here in the United States. So, we did a group project like that. So, it was completely like an online group project, like, we had to read everybody's work and then comment, and then rewrite. It was a good collaboration... 
Abby indicated the essential role of technology to facilitate collaborative learning in online courses

It [technology] does facilitate. I mean, without the technology, without Google Doc, and all of that, three of us couldn't have done that group work. So, I think this is an excellent example of how technology can help your real-time issues.

In addition, data from the follow-up interview included additional collaborative technology tools such as FlipGrid, Adobe Connect, Padlet, and Canva. The faculty interviewed in the study explained how they utilize collaborative technology tools to incorporate collaborative eLearning activities into their online courses. The collaborative technology tools mentioned by faculty interviewed in the study are presented in Table 7 with a description for each tool, together with collaborative learning opportunities hosted by each tool as reported by faculty members interviewed in the study.

Table 7

List of Collaborative Technology Tools Reported by Faculty Members

Tool Description Collaborative Learning Opportunities

\begin{tabular}{lll}
\hline Google Docs & An online word processing & Online collaborative writing \\
& application within Google Drive & Peer review \\
& service. It is the keystone of Google & \\
& Applications
\end{tabular}

Google Slides A Google application within Google Group presentation

Drive service An encyclopedia of terminology

Table Continues 


\begin{tabular}{|c|c|c|}
\hline Tool & Description & Collaborative Learning Opportunities \\
\hline FlipGrid & $\begin{array}{l}\text { An online, asynchronous video } \\
\text { discussion application }\end{array}$ & $\begin{array}{l}\text { A threaded video response discussion } \\
\text { for sharing and negotiating an } \\
\text { understanding }\end{array}$ \\
\hline Office Online & $\begin{array}{l}\text { An online version of Microsoft } \\
\text { Office. It is included in the } \\
\text { subscription-based Office } 365 \text { within } \\
\text { OneDrive }\end{array}$ & $\begin{array}{l}\text { Online collaborative writing } \\
\text { (WordOnline) } \\
\text { Co-authoring }\end{array}$ \\
\hline OneNote & $\begin{array}{l}\text { An application included in the } \\
\text { subscription-based Office } 365 \text { within } \\
\text { OneDrive }\end{array}$ & $\begin{array}{l}\text { A class online notebook where each } \\
\text { student can add notes }\end{array}$ \\
\hline Discussion & A web application that provides & A threaded text response discussion \\
\hline forum & $\begin{array}{l}\text { workspaces for asynchronous } \\
\text { discussion }\end{array}$ & (asynchronous discussion) \\
\hline VoiceThread & A web-based platform & A threaded audio response discussion \\
\hline Zoom & A web conferencing program & $\begin{array}{l}\text { Synchronous discussion or meeting } \\
\text { Book club meetings to discuss an } \\
\text { assigned book. }\end{array}$ \\
\hline Adobe & A collaborative conferencing & Synchronous discussion or meeting \\
\hline Connect & software & \\
\hline
\end{tabular}

Table Continues 


\begin{tabular}{lll}
\hline Tool & Description & Collaborative Learning Opportunities \\
\hline Google & A collaborative conferencing & Synchronous meetings \\
Hangout & software & Book club meetings to discuss an \\
& & assigned book \\
Padlet & An application to create an online & Sharing ideas. \\
& bulletin board & An online post-it board \\
Canva & A graphic-design website & Collaborative work on posters or \\
& & presentations \\
Wiki & A website or platform for & Group projects \\
& collaborative learning & \\
\hline
\end{tabular}

\section{Integration of collaborative technology tools.}

In order to gather more data about faculty comfort using collaborative technology tools, faculty participants were asked to rate their comfort levels using such tools in their online courses. Survey items used for this question were formatted using a 5-point Likert scale with the following response metric: very uncomfortable, uncomfortable, neither comfortable nor uncomfortable, comfortable, and very comfortable. The total number of responses for this question was 28 out of 29 faculty participants and the overall response to this question showed high levels of comfort. As shown in Table 8, one-half of the faculty participants (50\%) who responded to this item reported that they were very comfortable using collaborative technology tools in their online courses. Additionally, $39 \%$ of faculty participants reported that they were comfortable and a minority of participants (11\%) reported neither comfortable nor uncomfortable. Interestingly, none of the faculty participants reported that they were 
uncomfortable or very uncomfortable using collaborative technology tools in their online courses.

Table 8

Faculty's Comfort Level Using Collaborative Technology Tools in Online Course

Please rate your comfort/confidence in implementing new

Number Percent

collaborative technology tools to support collaborative learning into

your online course.

Very uncomfortable

0

0

Uncomfortable

0

0

Neither comfortable nor uncomfortable

3

11

Comfortable

11

39

Very comfortable

14

50

This result was supported by the data from the follow-up interviews whereby all faculty members interviewed in the study expressed being comfortable integrating collaborative technology tools into their online courses to support collaborative learning. They demonstrated their awareness of the benefits of integrating these tools in their online courses, along with the challenges that they may face. They also discussed some strategies for successful integration. Their responses were grouped into six themes: (a) preparedness and proactive thinking, (b) creating a sense of instructor presence, (c) establishing a sense of community, (d) engaging 
student collaboration, (e) troubleshooting, and (f) practical guidelines and considerations. Meaningful and important passages and quotations were presented using pseudonyms for participants and references to their institution to protect their identities.

\section{Preparedness and proactive thinking.}

The integration of collaborative technology tools into online learning is critical and requires proactive thinking, as explained by the faculty members interviewed in the study. They explained that it is essential to have an initial plan before the integration of any technology tool for a collaborative learning activity. They clarified that the initial plan is needed for: (a) to identify the appropriate tool that supports the assigned collaborative activity, (b) to create students' groups based on their interests and schedules, and (c) to assign their roles in the groups on a rotating basis. For instance, Tracy explained the need for proactive thinking before using technology tools for incorporating collaborative activities into online learning, using Google Forms to survey students and assign them in groups based on their availability and time preference. She said:

Using technology especially for collaboration in an online class requires very proactive thinking. If you try to do something in the last minute without planning how those interactions are going to go... that may not work out so well because you don't know who's in the group, what time they have free... You have to plan a lot up front.....I usually start by using Google Forms and surveys to try to work my way through that. I ask them about what time they tend to work on their schoolwork, and I put them in small groups based on that.. you can't put... If you're trying to do a big discussion, 30 students in one discussion forum is not going to create meaningful discourse. So, I put them in smaller groups and then have subpages in their assigned groups. You have to assign them 
roles. I find that if you just let them go and say, “Okay, you have a discussion," they don't really meaningfully engage in it. But when I assign on a rotating basis who's the discussion leader, who's the discussion summarizer for me, because grading discussions that way is also difficult. How do I monitor students from afar?

Laura also discussed the necessity of proactive thinking to create collaborative activities, which requires the knowledge of a wide range of available tools that can effectively facilitate these activities. She stated "there's a lot of upfront thinking that requires the knowledge of a lot of different tools. So, I think that's a big challenge, just finding new tools that will do that". Samantha also perceived finding the appropriate technology tool that supports collaboration as the central aspect of the successful integration of collaborative technology into online courses. She said:

I think my point always is, if I was going to do it in person, I can do it online. You just gotta figure out the technology. There likely is a piece of technology out there at this point that will help you do that. Some better than others. But that you can make it work if you structure it correctly. And so I guess for me it's always like, Okay, if this is what you think your students should do, then you should let them do that and go find the technology.

\section{Creating a sense of instructor presence.}

A few faculty interviewed in the study discussed the importance of creating a sense of instructor presence in online courses, raising some challenges related to interaction and student engagement in online environments. For instance, Jack explained the nature of online learning and the associated challenges. He said: 
Teaching online presents a certain set of challenges that I think a lot of people either don't consider, or don't realize until they're in an online classroom, and having to liaison with students only online, and in online settings that are one-on-one and personalized for an entire class. And so, I think the scope of that is something that a lot of people don't really realize until they're there... It feels very individualized and siloed, where I'm just interacting with each one of my students individually, 25 different times, or however many students I might have in a class, over and over.

Tracy also described the nature of online teaching before the use of collaborative technology tools for facilitating collaborative learning and student engagement. She said:

Honestly, online education before some of these tools [collaborative technology tools], everything was really siloed. So, students really... You'd work by yourself. I do the work, take the test at the end of the week, and it became this checklist of things to do and not really learning. And so much of learning especially in the field of education. When I'm teaching people to be teachers, I mean, the communication and social interactions are the critical components of a lot of our instruction. So, without these tools, I'd rather not teach some of those courses online at all if I couldn't have some kind of discourse between the students.

Certainly, the faculty interviewed in the study shared similar concerns regarding student engagement in online courses, explaining the need for creating instructor presence and its positive consequences in fostering student engagement. In this respect, Jack shared his ways to build a solid online presence by embedding demonstrative videos into his online course. He said: I rely on the videos, and I try and make my face shown as much as possible I would also encourage instructors to be as visible as possible, to use video, and to allow students to 
see your face as the instructor. Because I think there's just a personal touch that allows those students to know...Hey, I'm here and I'm with you, and even though you're looking at me through a computer screen, I'm on the other end of this. And I'm with you.

Tracy also indicated that she utilizes videos as weekly introductions to establish her presence in her online course for student engagement. She said:

In any online class, I video record an intro video every week of the course. So, they [students] see my face, they see me talking to them.

Additionally, some of the collaborative technology tools mentioned in the study offer great opportunities to provide synchronous collaborative activities, which is seen as excellent opportunities to increase online presence in their online courses. However, some faculty interviewed in the study demonstrated a reluctance to provide synchronous activities in their online courses because some students may be more comfortable working at their own pace, especially those who are full-time employees. Jack commented:

I wonder if that's kind of what they [students] want, signing up for an online class. Maybe sometimes they want to just do the work, and not really interface with others.

In this case, Tracy illustrated that she tries to balance the use of synchronous and asynchronous activities in their online course in a way that is suitable for students. She clarified that she provides clear instructions for students about these activities from the beginning of the semester, allowing them to schedule times during the semester that are appropriate for them to collaborate synchronously. She uses FlipGrid for asynchronous video discussions and Zoom or Google Hangouts to hold synchronous meetings. She said:

I try to balance the synchronous and asynchronous pieces because I know that our students who are taking online classes are working and they can't always get together. 
But I do let them know up front that there's always going to be both kinds, So, FlipGrid is still asynchronous but it's video-based. So, it's asynchronous, but they still are seeing their faces and talking back and forth. So, we use that. And then they also might use something like Zoom or Google Hangouts to have book club meetings. They are synchronous meetings. They have to get together and schedule a few times a semester where they talk about the book that we're reading in the class.

\section{Establishing a sense of community.}

The sense of isolation felt by students in online learning was one of the common challenges in online learning. Abby described her sense of isolation in one of her online courses and how that was her biggest challenge. She said:

The difficulty was that I didn’t know anyone. That was my first experience of being in a class where I haven't seen anybody. I was just looking at their names. So, it was like talking to a blind wall. It was very vague and blurry. I mean, that was my biggest challenge.

The faculty members interviewed in this study discussed the importance of establishing a sense of community to reduce the sense of isolation felt by students in online courses. Jack said:

In my experience, classrooms, whether online or face-to-face, they're always better when you can establish a sense of community. Ideally, a sense of family where they're all in this together. I think that just creates a better classroom environment. And so, in online environments, that's a real challenge, but it's not impossible. Under the right structure and the right planning, I think it can be achieved.

Jack also clarified using discussion forums and Wiki to establish a sense of community in his online course. He said: 
I try and establish a sense of community and engagement for my students. So, I try and do whatever I can to bring that out. Certainly, with discussion threads, I think that's an attempt at collaboration, and putting students into groups, then they're required to discuss and collaborate back and forth. I tried those early on. And, I have a lot of good experience with Wikis that are very collaborative in nature, where students can literally see the work that other people were doing. And that sort of gave them a sense that there are other people in the course, besides just them, and they can see the work of their peers and realize that there are others out there that are working along, at the same time that they are. So, that has been good for me

Samantha expressed the positive consequences of establishing a sense of community in fostering student engagement. She noted, "the ones [students] that participate I think feel more in the community."

The students interviewed in this study also discussed the impact of interaction and collaboration on their online learning. Patrick said: "In most of them [online courses], the ones I did better in, there were collaborative opportunities." Abby also expressed her feelings working with her peers on online courses, she said:

It makes a lot of difference to me when I see my classmates, and I love-- because I learn as much from my classmates and I learn from the teacher. But I would say, like for me, it's important. I really connect to the energy level of my classmates. And, I mean, the classmates are very engaged, then I am engaged, and it really affects my learning.

\section{Engaging student collaboration.}

Another reported challenge was student unwillingness to participate in collaborative eLearning activities. For instance, Tracy mentioned students who show reluctance to participate 
in a group project, which is an essential component in her online course as a challenge. She stated:

I'm teaching an online class. The course is about community and collaboration, and it's online. So, they have to be able to collaborate online. I use a couple of different tools to do that. They use sometimes online bulletin boards like Padlet to share ideas. We use a video tool called FlipGrid where instead of the discussion forum, I find that students don't love the discussion forum. It does create discourse, but they're usually really cookiecutter answers... They always hate working on group projects especially online. But I try to facilitate in a way that's reasonable for them to accomplish and scaffold it enough that they can take it step by step and be successful with it.

In this regard, Laura observed that adding "a positive pressure" in student discussion encourages students to effectively participate in online collaborative activities. She said:

I think that had added that positive pressure. That, if I respond well to my peers, then they will respond well to mine... We didn't even tell them they had to respond to each other. To the initial, they had to respond to the initial prompt. But, we didn't tell them they had to reply to the responses. But they did. We had, like, 60 plus in every single forum, and there were 15 students in the class.

\section{Troubleshooting.}

Faculty members interviewed in the study discussed some challenges they encounter when integrating collaborative technology tools into their online courses for collaborative eLearning activities, and stated several approaches they use to overcome these challenges. 
The follow-up interviews also revealed some challenges associated with technology. Jack pointed out that students who lack technology skills can pose a noteworthy challenge for instructors who integrate technology into their online courses,

Another challenge with the technology is students.... I don't know how many times I've heard students say, "I'm technologically illiterate," "I'm no good with technology.” And, that's just a barrier that instructors will have to overcome.

He made a connection between this challenge and the challenge he faced as an English teacher with students who do not enjoy reading,

I think of it in the same way when I taught English in the high school classroom, I would have students come to me and say, "You know, I hate to read." Or, "I'm no good at reading." And so, I always felt like it was my mission to show them that not only can you improve in whatever reading ability you have, but I'm here to show you that you're going to also like reading, once you figure out that you're reading things that you're interested in, and that appeal to you, and that you can connect with. Like, you'll find that you really do enjoy reading. It's just that you haven't been reading the right things, or you haven't been reading those things that are interesting to you. And wherever you're at, I maintain the belief that you can improve. I see this, like the students that come to me and say, "Oh, I'm no good at technology,"

He discussed his effort to entirely overcome this challenge,

I see it as the same kind of challenge, where it's like, “Okay. Well, wherever you're at in your level of technology, you can improve upon it. And I'm going to provide you with some of the tools, and also the support to show you that you can do this. And I always 
ask my students, how did that go for you? Did you enjoy that? And they say, "Yeah, I liked it a lot.” Well, good. There you go.”

Tracy also mentioned student resistance to technology and her approaches to address this issue: Students are resistant. Every age. So, I usually start off the semester letting them know that this is a learning curve for everybody, where some people are going to latch on, some people aren't. I try to make personal connections to students early on. I think they have more buy-in to trying new things when you show them that you care and that you also problem-solve... Anytime I use a new tool, I make screenshots of me doing the use of the tool for the assignments. And I give them some tips and resources of where to go if they get stuck.

In this regard, Samantha claimed using built-in links in the online course platform to direct students who need help with technological issues, besides having a technology person who can help those students. She said:

I usually have some already built into the course like, "Hey, if you need help with this technology, here's this link." Already built into the resources of the class like extra information. I have a few links to, depending on what it is, a video or just sometimes the university made. When we used Adobe Connect, we had a good support system for people to get in and on, there was a technology person that could help students when they were getting on to do the synchronous part, where we were all talking. We had a technology person that would come in and sit in the class at the beginning and would help people that were having trouble early." 
However, other faculty members stated that they don't intervene in this process, allowing students to explore the tools at their own. For instance, Jack explained his role in students' use of collaborative technology tools for online collaborative activities:

I do a lot of modeling. But then I will also allow them to create it on their own. I don't do a lot of sort of step-by-step instruction with, "First do this, and then do this, and then do this." I sort of just say, "Here's the tool. This is what I did with it. See what you can do with it."

In the same manner, Laura clarified her role in implementing collaborative learning activities using a video discussion platform, FlipGrid, providing students with general instructions and allowing them to explore the tool and how to use it to create a prompt in the video discussion forum. She said:

The way we did it, sometimes we were just a week ahead of them [students]. So, we would get the next unit, the next lesson up. And we would let them know, "Go and look at that. And create a prompt in the video forum for the rest of the class to respond to." We never told them how to create it because we knew they were teachers. And they could come up with something really good.

Laura argued that the online instructor should not do more than facilitating students' learning referring to the $80 / 20$ rule. She said:

I think a lot of faculty members do far more than they should. The $80 / 20$ rule is what I go by; the students do $80 \% \ldots$ and we, as the faculty member, we just design the course. But we should only do $20 \%$. We're here to be a guide. You know, and a mentor for somebody who's learning and growing. Hopefully at a really strong, robust rate. 


\section{Practical guidelines and considerations.}

The faculty interviewed in the study provided practical guidelines and considerations for successful integrating collaborative technology tools into online courses to better support collaboration and student engagement. For instance, Jack encouraged faculty who have some fears of technology and hesitate to integrate collaborative technology tools into their online courses to take the risk. He said:

I would encourage you to take that risk, and put yourself out there and try a technology, regardless of whether you've used it before, or whether you are sure it's going to work or not. And just, give it a try and see how it goes. Maybe it does end up not working the way that you imagined it would. Or maybe it works in a way that you never dreamed it was possible. So, you never really know unless you try. So, I'll encourage you to take those risks, not be afraid to fail.

Tracy also encouraged instructors to change their habits first, regularly explore tools, and carefully incorporate new collaborative tools. She said:

I usually tell people to change their own habits first and explore regularly. And also baby steps. Don't try to put everything into your course at once. If you don't currently use any collaborative technology, don't try three new tools this semester. Pick one and learn how to use it well, learn how to troubleshoot it, and try it out from the teacher and the student's standpoint. Make multiple accounts so that you can see what it looks like from both ends before you try to put it in your class. Students get frustrated with technology when the instructor doesn't know how to use technology. It's very obvious to students when the instructor's like, "I heard about this tool. I should use it," but they didn't spend 
time with it. So, I would rather see one done really well than try to use multiple things and have everyone confused.

Laura also recommended using a few tools that are well-known to the instructor to be able to support students using those tools:

Keep them [collaborative technology tools] to a minimum. And only use the ones you need. Keep your course really simple. Keep a consistent. Use tools you know really well because you're going to need to support those tools for your students. They're going to have questions. So, it's best to not use more than three new ones at a time. Once you learn those three new ones, you can add some more. I've learned that from other people who taught online too.

Laura responded:

You need to be vividly clear on the expectations in an almost higher archival linear way. So that they know, just to set the structure. But then keep it loose enough where they have some flexibility in how they apply it. And how they act upon it. Additionally, one of the students interviewed provides a recommendation for faculty regarding the technology integration for collaborative learning.

Think of it whichever direction you want to think of it, but understand technology changes. Technology improves. Technology's gonna continue to improve. If an instructor believes that the techniques and methods that they used, even 5 years ago, are still effective today, $100 \%$ they're wrong. Faculty especially, if they're wanting to teach and instruct, they have to be willing to learn new technologies. And they have to be willing to explain those technologies or have somebody explain those technologies to the 
current and modern students. Know your tools. Be willing to learn those tools yourself.

Or at least understand how they operate.

\section{Research Question 2}

What are the factors that faculty may consider when selecting collaborative technology tools for collaborative eLearning activities?

The findings presented for this question are from responses from faculty on the survey questions and supported and expanded by their responses to the follow-up interviews. Data from the survey are shown with the descriptive statistics associated with the factors that faculty may consider when selecting collaborative technology tools for online collaborative activities are reported in Table 9. The survey included the following described factors: (a) user-friendliness (ease of use), (b) effectiveness, (c) sustainability, (d) ability to integrate with the platform used, (e) security features, (f) features that support collaborative learning (communication-interactioncollaboration), (g) availability of technical assistance with active customer forums, (h) previous experience of using the same tool, (i) being adopted by several instructors (user community), and (j) receiving adequate training. The response metric for these 10 items was a 5-point Likert scale: strongly disagree, disagree, neutral, agree, and strongly agree. Examining the mean score of the responses, the majority of faculty members "agreed" or "strongly agreed" with the 10 factors with the mean score ranging between (3.45) to (4.86). As evidenced in Table 9, the factor userfriendliness/ease of use had the highest mean score (4.86), followed by the factor effectiveness that had a mean score of 4.83. The factor that had the lowest mean score (3.45) was being adopted by several instructors (user community). 
Table 9

Faculty Perceived Factors to Consider when Selecting Collaborative Technology Tools (n=29)

\begin{tabular}{|c|c|c|}
\hline Item & $M$ & $S D$ \\
\hline User-friendliness (Ease of use) & 4.86 & .35 \\
\hline Effectiveness & 4.83 & .38 \\
\hline Sustainability & 4.41 & .73 \\
\hline Ability to integration with the platform used. & 4.62 & .62 \\
\hline Security features & 3.90 & .94 \\
\hline $\begin{array}{l}\text { Features that support collaborative learning (communication-interaction- } \\
\text { collaboration) }\end{array}$ & 4.59 & .57 \\
\hline Availability of technical assistance with active customer forums & 4.03 & .94 \\
\hline My previous experience of using the same tool. & 4.41 & .68 \\
\hline Being adopted by several instructors (User community) & 3.45 & 1.05 \\
\hline Receiving adequate training & 3.66 & 1.17 \\
\hline
\end{tabular}

The follow-up interviews explore further factors that faculty may consider when selecting collaborative technology tools for online collaborative eLearning activities and also help to 
clarify the essential factors that may affect the tool selection process. These factors can be classified into faculty-related factors and student-related factors.

\section{Faculty-related factors.}

Some of the faculty members interviewed in the study asserted that faculty ability to identify the purpose for using the collaborative tools is a central factor that must be considered in the tool selection process to ensure the successful integration of these tools in online courses. For instance, Laura commented that it is important to classify the kind of collaboration that is needed in order to select the proper and best tool that can support it. She said:

I think that's central to its success is the purpose of it. It needs to be clear what the purpose is. So, the big ones that we used depending on the kind of collaboration we're doing. For instance, if you're teaching an, um, biology class, how is this tool and this activity relevant... to what I'm going to be doing in the field? If you can point out that relevance...the authenticity component ...I had disciplinary faculty say, "I'm not sure how I will use this with my students." The ones who do see how, they're still in there, and they're still active, they're still involved in using it. So, I think that's central to any tool that you would use. In any collaborative activity actually. A skill that they need to develop.

Tracy also perceived identifying the purpose of the use of collaborative tools as an initial step for the tool selection process. She said:

To me, technology needs to be... Whether you're using an online learning or face-to-face learning that you need to be thinking of it from the purpose first before picking a tool. Like, what are you struggling with in your class and how can technology help problemsolve? Because then you can really weigh your choices and pick the best tool for the task 
as opposed to "Oh, I like that she's using that. That looks so fun. Let me use it." And then that retroactive fitting of technology...It's great that you know a lot about those tools, but it's also important that you know a wide range, and you know where to go to find tools, and you know what the purpose is for looking for them in the first place. You want to pick the best tool for the task.

The follow-up interviews revealed some factors that affect the tool selection process. A few faculty perceived faculty confidence in their technological abilities as a significant factor affects faculty ability to select the appropriate tool for collaborative eLearning activities in their online courses. For instance, Jack described the inherent risk with technology, "there's always associated challenges and risks anytime that you use technology.... what if it crashes? Or what if it goes down?" He expressed that the fear of technology and the inherent risk with technology may prevent the effective use of collaborative technology, "there's that inherent risk that is there with technology, is enough to drive a lot of educators, maybe, away from even using it. Because they'll think, "I'm not going to use it, because what if it crashes?" He claimed, "I've always been an educator that will take the risk. And I'll be willing to risk Plan B because if it works like it's supposed to, I think the reward is worth it".

Knowing that technology rapidly and increasingly grows, some faculty believe that faculty knowledge of tools available is another factor that affects the tool selection process, for instance, Jack said:

They [technology tools] are moving so fast. I mean, they change, and they evolve, and they grow, or they just come out of nowhere, too. They just appear. And you really have to stay on top of it. So, that's challenging. 
Tracy also expressed this challenge and shared her way to keep up with new technology trends and update her digital knowledge continuously. She recommended using the EDShelf website to search for suitable tools because this website allows educators to search by the purpose and provides a variety of tools that can be used for the same purpose, which helps the instructor find the appropriate tool that can effectively facilitate online collaborative activities. She said:

Technology never stops. It changes all the time. To overcome some of the challenges and to figure out what to use, it's about a change in the way I approach teaching every day. I get up in the morning, grab a cup of coffee, and I like to go to different technology websites. EDShelf is my big-go-to website because you can search by purpose. So, if I'm looking for writing tools. I just flip through some...

In this regard, faculty members discussed the support and professional development needed to enhance their technology skills and to better integrate technology into their online course. Tracy demonstrated the support she received from her department. She said:

My department is really supportive of this. When I'm showing them what I'm doing in some of the classes, they're willing to spend money to buy some of these tools so that other professors can try it, too. So, I feel there's a variety of ways I can get access to these tools that are not breaking my own bank. Because sometimes some of these tools, they start out free. But to use all the features, they're not free anymore. So, there are a variety of funding sources that help me

Jack also clarified the support provided by his institution and welcomed learning opportunities:

Our department has been very supportive in wanting to make sure that teachers and instructors who are teaching in online environments have the requisite training. And so, they've been willing to support us in pursuing that kind of professional development. And 
also, putting on the inter-departmental development courses. I think, the department's stands that they support this. So, I've taken professional development and I've been through training just offered within my department. And so, I'm always learning. So, I'm a big proponent of professional development. I think it's just one step in always trying to maintain, to be current in the field of these technology tools that are out there.

However, other faculty discussed their concerns about the quality of the support needed to take advantage of these emerging technologies and how best to support student collaboration and engagement in their online courses. Tracy discussed the quality of the provided training sessions, she commented:

It was never really pedagogically focused. It was always focused on, like, "This is how the tool works." As opposed to, "How do I use this tool to facilitate learning?" Laura illustrated that the focus of these sessions should be on how to meet students' needs. She commented:

It's what will be good for faculty to have the opportunity to use for their students. And again, what skills do our students need to be ready for that contemporary professional life? It's what will be best for our students where they're going after school. Samantha particularly emphasized that most of the training sessions were provided in a more general manner, informing faculty about new technology tools, and faculty still need to know how to integrate these tools into their courses. She said:

It was just like, "Hey, these are the things to do," and then they just ran through the technologies that they had licenses for that you could potentially use. So, it was like, "Hey, we have Adobe Connect. You can use it if you want". So right, they just kind of checkbox through that. It wasn't really how to use the technology, it was more like, 
"Hey, think about this." Because it was for people teaching large different kinds of courses, so they kind of gave you the overview and what kind of seems good. But you have to make it your own.

Furthermore, most faculty interviewed in the study discussed the importance of and need for a professional learning community, whereby they pursue professional development through exchanging ideas, expressing opinions, sharing concerns, and benefiting from each other's expertise. Jack commented:

This past entire year, I've been involved in a group where many faculty members have been talking about various technology tools that they use online. I gain so much from those sessions, just seeing what my colleagues were doing with... You know, maybe I knew the tool, or had used it before, but maybe not to its fullest capacity, or not in a way that someone else might have chosen to use it, and I never would have thought of. Samantha explained that she gained professional development through discussion with other educators sharing best practices and insights. She said:

In terms of professional development. It's mostly been discussions with other people that I know that taught online and professional conferences. Just hearing about other people teaching online and that kind of stuff, too. With Adobe Connect, it was like they had the technology and the person there. So they did a quick, "Hey, this is how you use this," and I talked to other teachers, other people that had used it before. Like, "How do you do it?" and, "What do you do with it?" and so we kind of mutually developed ourselves with that one. So it's always been kind of collaborative and like, "Hey, you're teaching online. What do you do online?" and stuff like that. 
Samantha stated, "I work with teachers, so sometimes they're like, "Hey, have you seen this?" And I go and look and I would work it out".

Laura commented, "I'm constantly doing research. I'm constantly working with other online teachers. So, it's just a constant, we're at the unknown edge that no one has yet has written, which is the place I love. I love the unknowns."

Tracy explained:

I tend to be a self-supporter. I tend to just go online and dig through forums and figure it out on my own. Then, ... I started creating a close cohort with the rest of the people in the program. We all just shared ideas. We met weekly to talk about those ideas...I've heard talk that we're trying to create a technology, pedagogy-focused committee that's university-wide or at least College of Ed-wide to start with....There is a need at the university level, they say, that we should look at technology. Not just what the tools are, but that pedagogy focus.

\section{Student-related factors.}

The follow-up through interviews revealed other factors related to students which faculty may consider selecting collaborative technology tools for collaborative eLearning activities. Students' familiarity with the selected tool is seen as an essential factor that some faculty consider when selecting tools for online collaborative activities. For instance, Samantha mentioned encouraging students to use tools that students are familiar with. She said: I encourage them to use Google Docs to collaborate on a research project for the Capstone and maybe work it together. A lot of them are more familiar with Google because their schools have Google, they used the Google classroom stuff and so a lot of them go in that direction. 
However, Samantha also acknowledged that she forces students to use the tool offered by the institution for data security. She said:

With the research course, I do force them into OneDrive, at least for their data. Because they have to share their data with me and with each other sometimes. And so on that one, because it does have student data and we need to lock it appropriately, I do force them to share documents through OneDrive and collaborate that way.

In this sense, the institution's technology license is perceived as another factor that some faculty may consider when selecting tools for online collaborative activities. One of the students interviewed in the study, Patrick, claimed that faculty usually suggest using some tools that have the institution's technology licenses, but the collaborative features of these tools are limited or not accurate. He said:

In all of the collaborative settings I've put in from day 1 , in the syllabus, the instructor explained there was going to be a group project. And we've had tools suggested to us, Because of the license and everything like that. But the collaborative prospects in Office, in my opinion, are limited. There are better tools out there.

Patrick explained that the instructor may know the tool, but do not perceive or understand the use of the tool from the students' standpoint. He stated,

There's a lot of instructors who are familiar with it [collaborative technology tool], but they don't have correct information on the collaborative features and exactly how they work.

In this vein, Tracy declared considering student's standpoint when selecting collaborative technology tools for collaborative eLearning activities. She illustrated that she creates multiple accounts to test the tool from both the instructor's and the student's standpoint before integrating 
the tool in her online course. She noted, "I try it out from the teacher's standpoint and from the students' standpoint before I would ever try using it in my class."

\section{Research Question 3}

How do faculty and students perceive the influence of using collaborative technology tools on online learning?

The findings for this question come from responses from faculty and students on multiple survey questions and are supported by their responses to the follow-up interviews. Overall, faculty and students perceived the positive influence of using collaborative technology tools on online learning.

\section{Faculty perspectives.}

Faculty participants were asked to rate their levels of the purpose of 32 relevant statements in the survey, using a 5-point Likert scale with the following response metric: strongly disagree, disagree, neutral, agree, and strongly agree. As reported in Table 10, most faculty participants either agreed or strongly agreed with the importance of the 32 items by mean ranging between 3.83 and 4.59 , reflecting that they felt that these statements actually represented the impact of collaborative technology tools on online learning. The highest scoring item was promoting interactive and engaging learning, with a mean score of 4.59. Other items with a mean score over 4.50 included: facilitating collaborative learning to become easier, making communication easier and more productive, increasing interaction and connection, allowing students to communicate and network, linking students to help one another learn, and enhancing the collaborative learning experience. The item that had the lowest mean score (3.83) was minimizing, if not eliminating, travel costs for group work. 
Table 10

Faculty Perceived Influence of Using Collaborative Technology Tools for Online Learning $(n=29)$.

\begin{tabular}{lll}
\hline Item & M & SD
\end{tabular}

Facilitating collaborative learning to become easier.

4.52

.57

Promoting collaboration and team work.

Making communication easier and more productive.

Helping students obtain a deeper understanding of the material.

Decreasing student resistance to group work

Increasing group performance.

Monitoring the progress of group work.

Building necessary collaboration and communication skills

Developing higher level thinking skills

Fostering critical thinking.

Developing 21st-century skills

Training for post-educational work.

Preparing students for the real world and workplace

Increasing interaction and connection

Allowing students to communicate and network.

linking students to help one another learn 


\begin{tabular}{|c|c|c|}
\hline Item & $\mathrm{M}$ & $\mathrm{SD}$ \\
\hline Enhancing the collaborative learning experience & 4.55 & .63 \\
\hline Expanding educational options for students & 4.41 & .78 \\
\hline Promoting interactive and engaging learning & 4.59 & .57 \\
\hline Creating an online learning community. & 4.48 & .69 \\
\hline Decreasing the sense of isolation in an online course & 4.45 & .69 \\
\hline Increasing student productivity in group work. & 4.24 & .83 \\
\hline Increasing student learning responsibility & 4.21 & .77 \\
\hline Being effective in giving timely feedback. & 4.21 & .86 \\
\hline $\begin{array}{l}\text { Improving the quality of student-student interaction and student- } \\
\text { teacher interaction. }\end{array}$ & 4.34 & .67 \\
\hline Reflecting changing learning style preferences/ Addressing & 4.03 & 1.12 \\
\hline learning style differences & & \\
\hline Making learning more enjoyable. & 4.17 & .80 \\
\hline Increasing student productivity in group work. & 4.24 & .83 \\
\hline Increasing student learning responsibility & 4.21 & .77 \\
\hline Being effective in giving timely feedback. & 4.21 & .86 \\
\hline Improving the quality of student-student interaction and student- & 4.34 & .67 \\
\hline
\end{tabular}

Table Continues 


\begin{tabular}{lcc}
\hline Item & M & SD \\
\hline Reflecting changing learning style preferences/addressing learning & 4.03 & 1.12 \\
style differences & & .80 \\
Making learning more enjoyable. & 4.17 & .76 \\
Fostering positive student attitudes towards learning. & 4.17 & .82 \\
Motivating students to actively and fairly participate in group & 4.21 & 1.00 \\
work. & & .92 \\
Minimizing, if not eliminating, travel costs for group work. & 3.83 & \\
Creating greater flexibility and engaging work-from-home & 4.14 & .82 \\
Increasing student engagement in an online course. & 4.41 & \\
\hline
\end{tabular}

In addition to the high level of endorsement on the survey statements regarding the influence of using collaborative technology tools in online learning, the follow-up interviews gave more details about the successful implementing of collaborative tools to support collaboration and student engagement. For instance, Samantha described the impact of offering opportunities for interaction in individual-driven online courses on student learning. She said:

I've taught one of the courses that we have for the Master's here, that's a little more just individual-driven. It was already created, I was just assigned to teach it, so I left it alone. And it doesn't have much interaction between the students. And I find the students, they can kind of just work through it at their own pace. They don't have to talk to each other particularly unless they want to. And that kind of stuff. And I find that the students that talk seems to get more out of it and they collaborate with each other clearly. That just 
make the effort to be like, "Hey, this is who I am." and, "Hey, have you thought about this?" and that kind of stuff. They seem to get more out of it. They just apply and stretch their knowledge more. Even when they just peer review each other's ideas, they get more out of it. So I need... I'm working to build even more into these kinds of already structured courses, that don't have really much collaboration at this point and how to kind of keep working them a little bit more and more."

Laura also shared a successful experience in developing collaborative learning activity using the collaborative technology tool, Google Slides, in an online course that continued to grow even after the course ended and expanded more to include two other universities. She said:

There are so many terms in e-Learning and in online education. Instead of just feeding them to them, or telling them to go out and find them, we decided to come up with something different. We used Google Slides. And we told them to make it an e-Learning encyclopedia. And we gave them a couple of examples. We each made a slide for a letter...we said we wanted media on it and not just text. And, if they could only think of a term, but nothing else, just build it out. And together they would build this out, so they could work on different slides.

Laura explained the purpose of using Google Slides for collaborative activities within the course and beyond. She said:

The reason we used slides was, so they could drag and drop it. then a document would be. And once we finished the class, and we let them know beforehand, "Once we finish this class, we're going to open this up." And other, like, sister universities, sister classes, we would open it up. And they would contribute. So, this is a living document. That will continue to grow even after you're finished with the class. And we thought that that gave 
it a sense of authenticity in contributing to the field. And it seemed to, they bought it. And by the end of the class, we had 120 slides. And they were all really built up. They were all unique. I think some were better than others. But it was just really fun to watch that thing grow. And they still have access to it. And I know that at least two universities joined in with us with their class. So, that was fun.

\section{Student perspectives.}

Student participants were asked to rate their levels of endorsement with twenty-one items included in the survey on a 5-point Likert scale with the following response metric: strongly disagree, disagree, neutral, agree, and strongly agree. Examining the mean response scores shown in Table 11, the majority of students agreed or strongly agreed with the importance of the twenty-one items as all means were above (3.53). The highest mean was 4.41 for the item Minimize, if not eliminate, travel costs for group work followed by the item Create greater flexibility and engaging work-from-home which had a mean of 4.35. The item that had the lowest mean (3.53) was Make learning more enjoyable. Comparing students and faculty responses, it was found that the item Minimize, if not eliminate, travel costs for group work had the highest mean score (4.41) in student responses while it had the lowest mean score (3.83) in the faculty responses. 
Table 11

Student Perceived Influence of Using Collaborative Technology Tools on Online Learning $(n=181)$

Item

Help students to understand the material.

Facilitate group work to become easier.

Minimize, if not eliminate, travel costs for group work.

Create greater flexibility and engaging work-from-home

Make group communication easier and more productive

Monitor the progress of group work.

Motivate students to actively and fairly participate in group work.

Increase student learning responsibility

Increase student productivity in group work.

Increase group performance.

Allow students to communicate and network)

Build necessary collaboration and communication skills

Develop 21st-century skills

Train students for post-educational work.

Prepare students for the real world and workplace

link students to help one another learn

M SD

3.96

4.27

4.41

4.35

4.08

4.25

3.78

3.87

1.01

3.77

1.08

3.88

.98

4.23

.75

3.83

1.01

4.30

.75

3.91

.98

3.89

1.00

3.88

1.01

Table Continues 


\begin{tabular}{lcc}
\hline Item & M SD & \\
\hline Create an online learning community. & 3.99 & .90 \\
Decrease the sense of isolation in an online course & 3.90 & 1.06 \\
Create interactive and engaging learning experiences & 3.86 & 1.04 \\
Improve the quality of student-student interaction and student-teacher & 3.76 & 1.06 \\
interaction. & & 1.23 \\
Make learning more enjoyable. & 3.53
\end{tabular}

Taken together, these results show a high level of endorsement on the survey items regarding the influence of using collaborative technology tools in online learning. Additionally, student participants were asked if they believe that the use of collaborative technology tools improves their collaborative eLearning. The answer choices were expanded to a 5-point Likert scale with the following response metric: definitely no, probably no, might yes or might no, probably yes, and definitely yes. The results presented in Table 12 reveal that $42 \%$ of student participants chose "probably yes" and 37\% "chose definitely yes," while 16\% chose "might yes or might no." Only $4 \%$ of respondents chose "probably no." 
Table 12

Student Perceived Impact of Collaborative Technology Tools in Collaborative Learning ( $n=178)$

Do you think using collaborative technology tools improve your group Number Percent work?

Definitely no

2

1

Probably no

6

4

Might yes or Might no

29

16

Probably yes

75

42

Definitely yes

66

37

Student participants were also asked if their experiences using collaborative technology tools for online collaborative activities were either positive or negative, and the answer choices were expanded to a 5-point Likert scale with the following response metric: extremely negative, somewhat negative, neither positive nor negative, somewhat positive, and extremely positive. From the data in Table 13, it is apparent that a high percentage of students who completed the survey reported that their experiences while participating in collaborative eLearning activities using collaborative technology tools were neither positive nor negative. Examining the percentage of responses in the table, $38 \%$ of students reported that their experiences were neither positive nor negative, $32 \%$ reported that their experiences were somewhat positive and $13 \%$ reported extremely positive experiences. However, 14\% of student participants reported that 
their experiences were somewhat negative and $3 \%$ of them reported extremely negative experiences.

Table 13

Student Perceived Experiences in Online Collaborative Learning $(n=179)$

Overall, how positive were your online collaborative learning

Number Percent experiences?

Extremely negative

Somewhat negative

Neither positive nor negative

Somewhat positive

Extremely positive
5

25

67

58

24
32

3

14

38

13

Comparing the two results from Tables 9 and 10, it can be seen that the majority of student participants believe that the use of collaborative technology tools improves their online collaborative learning; however, $38 \%$ of them reported that their experiences using these tools in online collaborative activities were neither positive nor negative. The data from the follow-up interviews helped gain a better understanding of the reasons behind the conflict between the two results. A follow-up interview with two graduate students revealed that there are some factors that negatively affect students' experiences using collaborative technology tools for online collaborative learning. One of these factors was the selection of a technology tool that has 
limited features to support online collaborative learning. One of the students interviewed in the study reported a negative experience due to the complication and inflexibility of a technology tool that had been selected for online collaborative activity in his online course. He said:

If you're going to promote collaborative tools in a learning environment, the collaborative tools should work $100 \%$. No questions. The tools have to be available to function correctly and effectively in collaborative learning. Especially in higher academics. Because, I mean, if you think about it, if you have three people that are putting a time into work on a collaborative project. And something happens. Well, where we all put in at least two hours into this project, saved it, and had nothing to show. You're talking six wasted hours, right there, alright? That we're never going to get back. We got our notes and other drafts and other things that we used to be able to put into that document, but everything that was put in there is wasted and gone, alright? And there's nothing more frustrating.

In addition, student participants expressed that the inadequate instructions and inaccurate information from the instructor about selected collaborative tools for online collaborative learning negatively affect their collaborative learning experiences. Students also raised an issue about the tool affordances, such as the accuracy of live updating in some collaborative tools and how the deficient of this feature can cause a writing conflict, which does not support online collaboration. Patrick said:

Working together live is a big thing. Because not all collaborative tools are built to work the same. The biggest thing that I found with Microsoft, especially Office 365 that we use here, is it says it's a live update, it's not a live update. You can't have three people working on the same document at the same time. It doesn't automatically update. It 
doesn't automatically continually update. With the group project I told you about, where I had to collaborate with three classmates to build a project, we started it in Office and all three of us were sitting there working, we all saved and lost everything. "I thought you were working on it." "I was, but I wasn't seeing what you were working on. I thought you were." "I was, but I couldn't see what anybody else was working on." And when all of us saved, it caused conflict somewhere to where it all got wiped out. So we went to Google Docs, opened up a document. I could see where this guy was, I could see where that guy was. He was green, typing right here. He's orange, typing right there. I'm red, typing right here, And we could make sure that we weren't typing over each other. It was automatically updated. That was just a comfort to me.

Patrick perceived collaborative technology tools as great instructional tools only when they have the key features that support collaborative learning; such as "Live updates. Live editing. Being able to support all people working on the same project at the same time, without wiping out any data."

Additionally, a common view amongst student interviewees was that using built-in links in the online course platform for a technical assistant is not always effective, and their needs to have human contact to help with any issue students face in an online course. In this regard, Patrick expressed his feeling about contacting the Help Desk for technological issues. He said: They [instructors] say, "If you have problems, contact the Help Desk." Well, if it's 3 o'clock in the morning and there's nobody at the Help Desk, and I've just lost a 12-page document that I'm working on, not only with myself but two other collaborators, and it's due in three days, I can't wait another 6 hours. Instructors have to embrace it, and when there are problems, it does not pass the buck and call the Help Desk ... It's one of those 
things where I've got to feel confident in the tools that I'm working with, to be able to use a tool effectively.

Abby expressed her need to have a human contact to help with any issue students face in an online course. She said:

Online learning is here to stay, online learning is great because it makes your life so much easy. But a fully $100 \%$ online-- there are things which I think has to be face-toface. There are times when you have to go and meet the faculties. I don't think a blackboard or something on the online can just teach you, there should be an option for at least having one human contact, like, “I'm stuck here. Now, who do I go to?” I mean, there should be an option that I can go to somebody.

Another issue not related to the use collaborative technology tools was particularly prominent in the interview data revealing that some instructors paid little attention to coordinating online discussion to assure that all students' posts received at least one response from their peers. A student interviewed in the study pointed out that the lack of coordination and the limited interaction between students in online discussion negatively affected her collaborative learning experience. She said:

There were times when I was posting and nobody responded to my post even when I was posting on time. That is something as an instructor will keep in mind because there are some people whose posts don't get any comments. Most instructors ask for two responses or at least one response. How about you just respond to all? That's a lot of work, but I think there has to be some way where I'll have to incorporate everybody. If it is collaborative learning, then there cannot be one person who is posting and nobody is responding to that post. Then why are people not responding?" So, going to that, 
sometimes it's because of contrarian views. You don't agree with the view, so you don't want to disagree. You just ignore it, and that cannot be done. That's something that I think we need to tell the students, even if you disagree, do that politely without disrespecting, but you must see that everybody is getting responses because that is part of your learning process because this is not an individual learning course. It's a collaboration. So, you all have the responsibility to collaborate.

Despite the mentioned factors that negatively affect students' experiences using collaborative technology tools for online collaborative learning, students interviewed in the study indicated that collaborative technology tools offer them the opportunity to demonstrate their understanding of content through communication, interaction and collaboration with each other in online courses. They identified some of the benefits of using collaborative technology tools in their online courses such as minimizing the sense of isolation in an online course, keeping students more connected to each other, and evoking real-time collaboration opportunities. 


\section{CHAPTER V: DISCUSSION AND IMPLICATIONS}

This chapter summarizes the major findings as interpreted in light of the research questions and discussed in conjunction with other related literature.

The chapter concludes with practical recommendations drawn from the results of the study for professional and meaningful practice, along with recommendations for future research. Accordingly, the chapter is organized into six sections as follows: (a) overview of the study, (b) summary of findings, (c) conclusions, (d) implications, and (e) recommendations

\section{Overview of Study}

The main goal of the current study was to better understand the potential and use of technology for enhancing collaboration and student engagement in online settings and the factors that influence the selection of collaborative technology tools for collaborative eLearning activities in online courses. Starting with an initial online survey, followed by a set of interviews, an explanatory sequential mixed methods approach was utilized to explore the experiences of faculty members integrating collaborative technology tools into online courses to support collaboration and student engagement and to obtain the perspectives of students toward their experiences while participating in these activities. Thus, the study was conducted in two phases: (a) an initial quantitative data collection and analyzing phase, followed by (b) a qualitative data

collection and analyzing phase. In this way, the quantitative results were explained in more detail through the use of qualitative data.

The instruments used to collect the quantitative data for this study were online surveys completed by a total of 210 participants who met the participation criteria and volunteered to participate in the study. Out of the 210 participants, 29 were faculty members and 181 were students. After analyzing and reviewing of the data obtained from the surveys, a total of six 
semi-structured interviews were conducted with four faculty members and two students to provide further information that supported and expanded the results obtained from the quantitative phase. Then, the data obtained from both quantitative and qualitative data were integrated, organized, and presented in light of the following research questions:

1. What collaborative technology tools do faculty use and how do they incorporate collaborative eLearning activities in their online courses using those tools?

2. What are the factors that faculty may consider when selecting collaborative technology tools for collaborative eLearning activities?

3. How do faculty and students perceive the influence of collaborative technology tools on online collaborative learning?

\section{Summary of Findings}

\section{Research Question 1}

What collaborative technology tools do faculty use and how do they incorporate collaborative eLearning activities in their online courses using those tools?

The most obvious finding to emerge from both the quantitative and qualitative data is that Google applications are the most commonly used collaborative technology tools to support collaboration and student engagement in online courses. The students interviewed in this study perceived Google applications as excellent collaborative tools because of their features that are mostly geared for collaboration, such as live updating, tracking changes, simultaneous editing by multiple and visible editors. Furthermore, the faculty members interviewed in this study declared the integration of a variety of collaborative technology tools into their online courses for collaborative eLearning activities and discussed some strategies for successful integration. 
While some of the collaborative technology tools mentioned in the study offer great opportunities for synchronous learning, the results showed that some faculty members demonstrated reluctance in providing synchronous activities in their online courses, considering that flexibility and convenience are positive elements for online learning. Other faculty members recognized the educational benefits of synchronous activities. They discussed their utilization of such tools to provide synchronous collaborative activities in their online course to increase online presence and provide real-time interaction. They also clarified their attempts to balance the use of synchronous and asynchronous activities in their online course in a way that is suitable for their students, providing clear instructions for these activities and allowing students to work together and schedule times during the semester that are appropriate for them to collaborate online in synchronous activities. Increasing the instructor's presence and providing synchronous and asynchronous activities are seen to be effective strategies to establish a sense of community within online courses.

Thus, the results show that faculty make significant use of collaborative technology tools for collaborative eLearning activities and they are aware of the benefits and challenges of integrating these tools into their online courses. It was found that incorporating collaborative activities into online courses using collaborative technology tools is critical and requires preparedness and proactive thinking. Faculty stated that it is essential to have an initial plan that identifies how to find the appropriate tool that supports the assigned collaborative activity, how to create students' groups based on their interests and schedules, and how to assign their roles in the groups on a rotating basis. In addition, the successful integration of collaborative technology tools for collaborative activities in online courses requires knowledge of a wide range of available technology tools. 
Some of the challenges related to interaction and student engagement in online environments discussed include importance of creating a sense of instructor presence, establishing a sense of community in online courses using collaborative technology tools to reduce the sense of isolation, and assisting students who lack technology skills or those who are unfamiliar with the tool selected for collaborative activities. Techniques to overcome these challenges include (a) using built-in links in the course platform to video tutorials or Help Desk, (b) providing step-by-step instructions, (c) making screenshots of the use of the tool, and (d) modeling. However, other faculty members stated that they don't intervene in this process allowing students to explore the tools, and some believe that their role should not be more than a facilitator

Practical guidelines to better support online collaboration found in this study include: (a) change habits, take the risk, and not be afraid to fail; (b) explore a wide range of collaborative technology tools to select the best tool for the assigned collaborative task; (c) be willing to learn the tool well to know how to use it, how to troubleshoot it, and how to explain it to students; (d) test the tool by creating multiple accounts to test the tool from both the instructor's and the student's standpoint; (e) be vividly clear on the expectations and have some flexibility in how students apply it.

\section{Research Question 2}

What are the factors that faculty may consider when selecting collaborative technology tools for collaborative eLearning activities?

The most important aspects to consider are user-friendliness (ease of use), effectiveness, ability to be integrated within the platform used, and features that support collaborative learning 
(communication-interaction-collaboration). Factors such as security features, being adopted by several instructors (user community), and receiving adequate training were found less important.

The follow-up interviews revealed additional factors that affect the tool selection process. Some of these factors are related to (a) faculty confidence in their technological abilities, (b) faculty ability to identify the instructional purpose for integrating technology tools, and (c) faculty knowledge of a wide range of tools available and the ability to keep up with new technology trends. The faculty members participated in the follow-up interviews described ways and methods they used for integrating new tools into their online courses. The survey data showed that a large percentage of faculty participants received technology-related training. However, the follow-up interviews revealed that most faculty participants felt that most of the training sessions that their institution offered were insufficient and not pedagogically focused.

Faculty voiced concerns about the quality of the technology-related training workshops they received and discussed the need for professional development and training that intensively focus on integrating collaborative technology tools into online courses for collaborative eLearning activities. In this vein, they expressed pursuing their own professional development through exchanging ideas, expressing opinions, sharing concerns, and benefiting from each other's expertise. They explained their efforts to create and involve in a professional learning community, either within their departments or university-wide to enhance faculty expertise in integrating collaborative technology tools into their online courses to enhance collaboration and student engagement.

The findings also reveal that some faculty perceived the students' familiarity with the tool as an important factor to consider within the tool selection process, with regard to the fact that most students have previous experience using some of these tools for collaboration, especially 
student teachers who integrate these tools in their classrooms. They explained that students' familiarity with the selected tool can help avoid being overwhelmed by unfamiliar technology tools, which can result in fostering collaborative learning. Another factor mentioned in the findings is the institution's technology license which was perceived by some faculty as a fundamental factor to consider when selecting collaborative technology tools for collaborative activities, with the aim to secure students' information and privacy.

\section{Research Question 3}

How do faculty and students perceive the influence of using collaborative technology tools on online learning?

Overall, faculty and students expressed positive perspectives toward the integration of collaborative technology tools into online courses to facilitate communication, interaction, and collaboration. The three most influential items were (a) promoting interactive and engaging learning, (b) allowing students to communicate and network, and (c) minimizing, if not eliminating, travel costs for group work. However, faculty and students pointed out various challenges and obstacles that online instructors need to overcome in order to successfully integrate collaborative technology tools into online courses to support collaboration and student engagement. These challenges and obstacles included: lack of awareness of collaborative technology tools available, lack of understanding of the effective use of tools, and lack of training and support needed for successful implementation of collaborative technology tools for collaborative eLearning activities in online courses.

The findings demonstrate that students value the integration of collaborative technology tools in their online courses, which positively impact their online learning experiences. The students participated in the study perceived using collaborative technology tools for collaborative 
eLearning activities in online courses as positive experiences that resulted in enhanced experiences with online learning in general, and with online collaborative learning in particular. However, the findings reveal that when there is a lack of clarity regarding the use of technology tools for collaborative activities, it negatively affects students' online collaborative learning experiences. The student participants claimed that the collaborative features of some of the selected tools are limited which may prevent or limit collaboration and student engagement. It was found that students desire that tools used for collaborative writing have features that include synchronous, confusion-free collaboration where multiple students can write or edit a single document at the same time without editing conflicts. They believed that instructors' limited knowledge of and experiences with collaborative technology tools also contribute to this problem.

\section{Discussion}

The main goal of the current study was to better understand the potential and use of technology for enhancing collaboration and student engagement in online settings and the factors that influence the selection of collaborative technology tools for collaborative eLearning activities in online courses. The findings of the study confirm that technology has the potential to enhance collaboration and student engagement in online settings by offering opportunities for collaboration and enable students who are spread geographically to engage in collaborative eLearning activities, which could never be achieved without the use of collaborative technology tools. Despite the instructional and technical challenges, the study shows that collaborative technology tools can have a positive impact on student engagement by offering opportunities for communication, interaction, and collaboration in online learning. This finding is consistent with that of Revere and Kovach (2011) who found that instructors can appropriately use technology 
tools to build a learner-centered environment and foster student engagement. The major findings of this study include the following: collaboration tools, the instructional influence of integrating collaborative technology tools, and factors influence the tool selection process. Each finding was discussed along with related literature.

\section{Collaboration Tools}

Technology tools that can be used for collaborative eLearning activities are vast and varied. However not all tools have the required set of features that effectively support collaboration and student engagement in online learning and positively impact student learning experiences. The perfect collaborative technology tool should be capable enough to add more motivation to online collaborative learning, rather than being frustrating for students. Unsurprisingly, the data shows that Google applications were seen as the most popular collaborative tools because their features are mostly geared for collaboration. This finding supports evidence from previous observations (Brodahl, Hadjerrouit, \& Hansen, 2011; Parra, 2013; Reyna, 2010). These results reflect those of Cheung and Vogel (2013) who also found that Google Applications have significant contributions for enhancing collaborative learning environments. In accordance with the present findings, previous studies have demonstrated that Google applications and other collaborative tools support collaborative learning and help overcome students' sense of isolation (Brodahl, Hadjerrouit, \& Hansen, 2011; Justus, 2017; Parra, 2013; Reyna, 2010).

It is clear from the findings that the availability of various collaborative technology tools helps instructors create a variety of collaborative learning opportunities in online courses. These tools provide a common place for students to communicate, interact, and collaborate on a common task, as well as for instructors to monitor their work. This finding further supports the 
idea of Severance and Teasley (2010) who stated that "the most exciting aspect of enabling teachers to build, exchange, and use thousands or even hundreds of thousands of new tools is how we enable the exploration of an increasingly wide range of new ways to teach" (p. 758). These technological advances increase the opportunities to create synchronous learning activities in online courses and subsequently foster collaborative learning. The findings of the study show that some of the collaborative technology tools mentioned in the present study enable the instructor to create synchronous learning activities in online courses, providing real-time exchanging ideas and prompt feedback. These tools include Zoom Video Conferencing, Google Hangouts, Adobe Connect, and Blackboard Collaborate, which have effective features to support synchronous collaborative eLearning activities such as academic meetings and webinars. These features include audio/video calling, screen sharing, file sharing, whiteboard sharing, and messaging.

\section{Instructional Influence of Technology Integration}

The findings of this study highlight the instructional influence of using collaborative technology tools on online learning such as minimizing sense of isolation felt by students in online courses, keeping students more connected to the instructor and to each other, and evoking real-time collaboration opportunities. The findings show a response to the argument of O'Neill, Scott, and Conboy (2011) who stated, "if these technologies are to be fully optimized as an enabling factor in collaborative distance education then their educational benefits need to be more strongly highlighted to practitioners" (p. 945). Therefore, the present study suggests that the educational benefits and positive influence of collaborative technology tools on online learning include (a) fostering student engagement, (b) demonstrating and building knowledge, 
(c) promoting collaborative authoring, (d) increasing online presence, (e) establishing a sense of learning community, and (f) instructing 21 st-century skills.

\section{Fostering student engagement.}

The most obvious finding to emerge from the present study is that the successful integration of collaborative technology tools into online courses can support collaboration and foster student engagement. It is encouraging that this is similar to what was found by Rees (2010) that technology can improve student engagement in ingenious ways. This also confirms the findings of Simonson et al. (2014) who declared that technologies can foster student engagement and improve learning outcomes. By creating greater flexibility and engaging collaborative work-from-home, collaborative technology tools can keep students engaged and motivated to participate in collaborative eLearning activities. Furthermore, the finding of this study also supports evidence from Daher and Lazarevic (2014) who reported a statistical significance for student engagement and motivation when using Web 2.0 tools for instruction.

\section{Demonstrating and building knowledge.}

Another important finding is that collaborative technology tools offer flexible opportunities for students to work together toward a common learning goal, while they learn from the experiences of one another and support each other during this process. It is clear from the research findings that the use of collaborative technology tools helps students demonstrate knowledge through exchanging ideas, expressing opinions, sharing information, and evoking experiences, which create a meaningful learning experience for students. This finding is consistent with that of Justus (2017) who found that "technology can have a positive impact on student learning by introducing new methods to support a demonstration of knowledge" (p. 508). The use of collaborative technology tools offers students great opportunities to demonstrate their 
understanding of content through communication, interaction, and collaboration with each other in online courses. This finding confirms the role of social interaction in the process of constructing knowledge and understanding. This finding aligns with the social-constructivist principles of constructing knowledge through active interaction and collaboration in a single web, program, or file with more capable peers to accomplish a common learning goal. This corresponds with Vygotsky theory (1978), specifically the "zone of proximal development."

\section{Promoting collaborative authoring.}

Findings of the study aligned with the literature that collaborative technology tools offer excellent opportunities for students to write collaboratively where students brainstorm ideas and document their work, which is seen as common use of these tools. This finding is in agreement with that of Green and Ruane (2011) who noted that the use of technology tools for collaborative writing increases creativity level and efficiency. The findings of this study show that collaborative technology tools provide an authoring environment in which two or more students from varied locations can edit a document concurrently. More specifically, these tools allow students to collaborate on a shared document where they can view, edit, suggest changes, track changes, and communicate in real-time. Having the peer-editing capabilities, Google Documents is seen to be an excellent collaborative technology tool for collaborative authoring, allowing students to work together synchronously or asynchronously on a shared document. These findings also support evidence from previous observations (Brodahl, Hadjerrouit, \& Hansen, 2011; Parra, 2013; Reyna, 2010).

\section{Increasing online presence.}

The findings of the study highlighted the importance of the instructor's presence and availability in online courses to student success. This finding is in accord with the previous study 
of Palloff and Pratt (2011) indicating that establishing a presence is the "first order of business" for online instructors. This finding further supports the ideas of den Exter, Rowe, Boyd, and Lloyd (2012), who assert that instructors need to be present throughout the journey. According to Velasquez, Graham, and Osguthorpe (2013),

When teachers communicated that they were accessible to students, students felt respected and acknowledged. Communicating accessibility demonstrated to students that the teacher was willing to be receptive to them. Accessibility was also communicated through the teachers' attitudes. Students explained that their teachers were nonjudgmental, willing to give them the benefit of the doubt, polite, and eager to connect. This attitude communicated accessibility to students and a willingness of the teacher to receive them (p. 16).

With the support of technology, instructors can increase visibility, connection, and interaction in online learning, allowing students to feel their presence and support. These findings corroborate the ideas of Brady, Holcomb, and Smith (2010), who suggested that using technology tools for communication with students in online courses can address issues inherent in online learning such as social presence and interaction.

\section{Establishing a sense of learning community.}

Findings of this study reveal that using collaborative technology tools for online collaborative activities enable the instructor to establish a sense of community within online courses, resulting in helping students reduce feelings of isolation, which is often cited as one of the challenges that students experience in the online learning environment. More specifically, collaborative technology tools, such as Google Applications, offer students flexible opportunities to learn from each other from anywhere and at any time where they can work on one shared 
document to edit, suggest improvements, share ideas and information, or exchange comments, resulting in creating an excellent learning community. This finding supports evidence from previous observations (Abdelmalak, 2015; Reyna, 2010; Scott \& Liu, 2011) that Google Documents help promote students' sense of learning communities in online classes. Wikis also are perceived as effective collaborative technology tools to establish a learning community, allowing multiple students to collaborate in real-time where they can create multiple pages, and directly add or modify content. This finding was also reported by (Abdelmalak, 2015; Scott \& Liu, 2011).

\section{Instructing 21st-century skills.}

Another potential benefit of using collaborative technology tools in online courses is to create a sharable environment for students to communicate and collaborate on a common task with a sense of commitment and trust in each other, which are the building blocks for the 21 stcentury learner. In this vein, Hsu and Shiue (2017) stated that "the ability of individuals to work together productively and creatively is highly desirable by the employers, and is regarded as a pre-condition for employment” (p. 935). Reviewing data reported by a large number of established institutions, Eisner (2010) found that the most important skills that students need to possess in the workplace are: (a) oral communication, (b) teamwork/collaboration, (c) professionalism/work ethic, (d) written communication, and (e) critical thinking/problem solving. With the support of collaborative technology tools, students can learn collaboration, communication, and technology skills to be better prepared for the $21^{\text {st }}$ century workplace. Technologies like multi-user environments, group conferencing, and social networks are perceived to be alternatively predicted to have a profound impact on education for future learners (Moore \& Kearsley, 2012). 
To prepare students for professional life, Larson and Miller (2011) emphasized the importance of instructing 21 st-century skills to be regularly incorporated in the curriculum, including teaching collaboration, communication, and technology skills. Students need to be shown the necessary and required interpersonal skills in the $21^{\text {st }}$ century workplace. Learning the 21 st-century skills can be facilitated through collaborative technology tools. Collaboration is a major factor in successful learning outcomes (Martinez-Caro, 2011). The ability to collaborate with others in online settings through the use of technology tools is a unique skill for today's students. Online instructors need to integrate technology to empower students to communicate, interact, and collaborate in online learning. Students as digital citizens need to be prepared to collaborate with people across the world and to be ready for that contemporary professional life.

\section{Factors Influence the Tool Selection Process}

The continuous advancement and development of technology have created a wide range of collaborative technology tools available, and new ones are created continuously. Each tool has different affordances. Perhaps as a consequence, it becomes very difficult for instructors to make decisions on the tool selection. Accordingly, the present study attempts to determine the factors that influence faculty when selecting technology tools for collaborative eLearning activities in their online courses. Faculty demonstrate that one of the critical decisions that have to be made when designing an online course is to select appropriate technology tool that supports and facilitates online collaborative learning. The findings indicate that the selected technology tool for online collaborative activities directly affects students' collaborative learning experiences. These findings were in line with those reported by Paechter, Maier, and Macher (2010) who stated that "when designing an e-learning course, instructors are faced with many considerations 
and decisions that consequently affect how students experience instruction, construct and process knowledge" (p. 223).

Consistent with the literature, this study has identified the ease of use and familiarity with the tool as major factors that faculty may consider when selecting technology tools for collaborative eLearning activities. This finding supports evidence from previous observations that the ease of use and usefulness were major factors influencing the acceptance of collaborative technologies (Cheung \& Vogel, 2013; den Exter, Rowe, Boyd, and Lloyd, 2012; Justus, 2017) Furthermore, den Exter, Rowe, Boyd, and Lloyd (2012) suggested that the flexibility and ease of use of such tools presents almost unlimited opportunities to facilitate collaboration in online learning.

However, the findings of this study emphasized that the instructor's knowledge and experience with technology in general, and collaborative technology tools in particular, contribute to the successful selection and implementation of these tools to support collaboration and student engagement in online learning. Yet, there are many online instructors who are not sufficiently skilled and have little prior experience with integrating technology into online courses for collaborative eLearning activities. Indeed, teaching in the $21^{\text {st }}$ century requires instructors to be skilled and committed to the technology. Instructors must be familiar with the selected technology tool to effectively facilitate student collaborative learning. The inadequate instructions and inaccurate information from the instructor about the selected collaborative technology tools for online collaborative learning are seen as the biggest frustration for students, which may result in preventing or limiting the desired collaboration and student engagement. These findings match those observed in earlier studies regarding the impact of the instructor's 
familiarity with the technology tool in facilitating effective learning environments (Bower, 2011; Falloon, 2011).

\section{Faculty roles and responsibilities.}

According to Keengwe and Georgina (2012), "the pathway of course migration to online environments often begins with the assumption that instructional designs, grading procedures and other methods that typically work in the traditional classroom would remain the same in online settings however, this is not usually the case" (p. 366). This approach was also described by Meier (2015) who discussed "codifying past educational practice in a digital form - merely digitizing the status quo" (p. 5). That being the case, it is important to note that teaching and learning in an online environment requires a new set of teaching methods and a redefinition of the instructor's roles and responsibilities. In online learning, the roles of instructors transformed from subject matter experts to mentors and facilitators of learning. The findings of this study suggest that instructors need to incorporate a variety of instructional strategies in order to improve the quality of online learning. The suggested instructional strategies include increasing instructor's presence, establishing a sense of community, monitoring student learning, providing clear instructions and feedback, and incorporating collaborative eLearning activities.

The advanced technology has the potential to foster different forms of interaction and collaboration, which affects the role of the instructor. These technology tools afford new learning opportunities along with new responsibilities. With the emerging technology tools that support interaction and collaboration, the responsibility of online instructors increased to include incorporating the technology tools into their teaching practices and providing students with the guidance and resources needed to facilitate their interaction and collaboration in an online environment. This finding supports evidence from previous observations (Handayani, 2012; Hew 
\& Cheung, 2013; Jaggars, 2014; Johnson, 2013; Kuo, et al., 2014). The findings of this study revealed that student engagement in online learning could be negatively affected by the limited capabilities of the tool selected for collaboration. One of the student participants argued that if the goal for incorporating collaborative activities in online learning is to develop both cognitive and collaborative skills for students, the selected collaborative technology tools must support this goal. It is the instructor's responsibility to ensure that the selected tool has all the features that facilitate collaborative eLearning activities in an effective manner.

\section{Faculty professional development.}

The data from this study indicated that faculty value support from their institution. The faculty, however, believe that training and professional development initiatives offered by their institution appear ineffective in supporting the successful integration of collaborative technology tools into online courses to enhance collaboration and student engagement. These findings are in accord with those of Mbuva (2015) and Nayan et al. (2010) who reported faculty's reluctance to implement collaborative eLearning activities because of lack of adequate training in collaborative learning methods. Yet, designing eLearning activities that engage students and foster interaction and collaboration is still one of the many challenges that instructors face while creating online courses. The findings of this study reveal that incorporating collaborative activities into online courses using collaborative technology tools is critical and requires preparedness and proactive thinking. According to the literature and the findings of this study, more emphasis should be placed on the need for a practical and research-based training and purposeful pedagogical instructional professional development to help online instructors update their teaching practices and learn how to meaningfully integrate collaborative technology tools 
into online courses (Crawford-Ferre \& Wiest, 2012; Justus, 2017; Mbuva, 2015; Nayan et al.; Sun \& Chen, 2016)

Findings also align with the literature that faculty struggling with some challenges related to exploring, learning, and keeping up with technology (Justus, 2017; Marzilli et al., 2014). It is clear from the findings that exploring a variety of collaborative technology tools expands the options for instructors to select the appropriate tool that effectively supports collaboration and student engagement, which is seen to be a life-long exploration of knowledge. Through the implementation of this study, it was discovered that faculty pursue their professional development through exchanging ideas, sharing concerns, and gaining knowledge from each other's expertise. Therefore, the findings of the study reported an increased need for the formal or informal professional learning community to help online instructors work as a team to reflect, collaborate, and discuss challenges they experienced while incorporating collaborative technology tools into their online courses to facilitate collaborative eLearning activities and increase student engagement. Such a community may help faculty see the utility, value, and feasibility of using a particular collaborative technology tool in their online courses. These findings further support the idea of Justus (2017) who reported: "an increased need for faculty to have not only professional development opportunities but also opportunities to become involved with the community of full-time faculty" (p. 515). The findings also support those of Swan et al. (2014) who suggested creating "a collaborative community of educators to share responsibility for ongoing course improvement and redesign" (p. 79).

Various studies have assessed the efficacy of informal professional development and have found that many professionals and educators have turned to informal professional learning with the aim of learning and connecting with peers about related work (Campana, 2014; de Laat 
\& Schreurs, 2013; Eraut, 2011; Macià \& García, 2016). According to Macià and García (2016), "informal online communities and networks offer teachers the possibility of voluntarily engaging in shared learning, reflecting about teaching practice and receiving emotional support" (p. 291). Lieberman and Mace (2010) indicated that such communities are effective ways to enable instructors to connect with others who can help them to resolve particular problems.

The findings of the study raise intriguing questions regarding the nature and extent of faculty professional development community. In this regard, Thoma, Hutchison, Johnson, Johnson, and Stromer (2017) recognized five common characteristics of an effective professional learning community: "(a) share a common view of the mission, (b) reflect on practice, (c) participate in reflective discourse, (d) offer feedback to one another on instruction, and (e) keep student learning the central focus" (p. 168). Instructors should have the opportunity to join a professional learning community that inspires confidence and willingness to take risks around technology when making decisions related to the integration of collaborative technology tools into online courses. For faculty who cannot meet regularly, an online faculty professional development community is seen to be a feasible way that allows faculty to have access to the information and support they need at their convenience. Such an online community offers educators the opportunity to share knowledge and learn with other peers who are geographically separated (Ravenscroft, Schmidt, Cook, \& Bradley, 2012). This method is a cost-effective and appropriate for faculty who may be unable to attend training sessions. Indeed, technology has empowered informal professional communities to meet educators' needs (Lieberman \& Mace, 2010). The digital informal professional communities provide new opportunities for learning and knowledge creation (Macià \& García, 2016). Thus, collaborative technology tools presented in the study have the potential to support professional development communities by enriching and 
transforming the structure and processes of these communities and encouraging effective participation. These tools can offer appropriate opportunities for instructors to discuss their concerns and share their strategies for successful integration of collaborative technology tools. The online instructor can use collaborative technology tools to connect and work collaboratively with other educators to gain new ideas and inspiration. In this regard, Katz (2010) noted:

Ideas move through the cloud at the speed of light. They are mashed together with other ideas, commented on, transmuted, embedded, enlivened, debased as they circle the globe. Unbundling, in this regard, in its most positive light, presents the academic with unprecedented access to other interested scholars - and amateurs. (p. 37)

Taken together, these results suggest that there is a need to build and sustain an interactive collaborative learning community within the institution for online instructors who have a common sense of purpose and a real need to acquire the knowledge from each other's expertise.

\section{Implications and Contributions}

Earlier findings from the literature showed that very few studies had been conducted to explore the experiences and perspectives of both faculty and students regarding the implementation of collaborative technology tools to support collaboration and student engagement in online learning. The current study appears to be the first study to offer valuable insights into the experiences of faculty using collaborative technology tools to design, develop, and implement collaborative eLearning activities to enhance collaboration and student engagement in their online courses, along with the perspectives of students toward their experiences while participating in these activities. The findings of the study provide insights into the practical implications for implementing collaborative technology tools to design and facilitate collaborative eLearning activities by informing instructors and instructional designers 
of the perceptions of both students and instructors. This study contributed a more detailed understanding on how to implement collaborative technology tools to support communication, interaction and collaboration and positively impact student engagement in online courses. Understanding the perspectives of faculty and students regarding the used of technology tools for online collaboration is influential and critical to the success of the integration of collaborative technology tools in higher education settings. Hence, outcomes from this study have significant implications for online instructors, educational institutions, and online education.

The insights gained from this study may be of assistance to online instructors who are seeking methods and instructional strategies to engage students and provide opportunities for interaction and collaboration in online courses. This study provides the first comprehensive assessment of the lived experiences of faculty using collaborative technology tools to design, develop, and implement collaborative eLearning activities in their online courses, which may be useful for informing online instructors of the design, development, and implementation of collaborative eLearning activities. This new understanding should be of interest to online instructors who seek to better design their online courses, shape their instructional practices, and refine their teaching approaches to meet students' learning needs. The findings from this study provide guidance and practical suggestions for online instructors as they make informed decisions in the development of collaborative learning in their online courses. Exploring the ideal use of advanced collaborative technology tools to promote interaction and collaboration in online courses is of great significance to online instructors who are concerned about designing effective collaborative eLearning activities.

Insights gained from this study may be useful for informing instructional designers and administrators in educational institutions of the key features and success factors in existing 
collaborative technology tools that effectively support online collaborative learning, which may be useful in planning for faculty training as well as technology procurement. Findings from this study may be beneficial in guiding administrators during the process of designing and developing training workshops and professional development programs for online instructors who had little prior experience with relevant technologies, in order to offer the support needed and help them see the value of using collaborative technology tools in online learning. The evidence from this study suggests creating an online professional learning community where online instructors can share, examine, reflect on their experiences incorporating technology tools into their online courses and transform the new knowledge to their teaching practices making changes to the curriculum and the design of their online courses. The findings reported here shed new light on the possibility that the collaborative technology tools can be used to create professional learning communities that enable online instructors to connect and work collaboratively with other educators to gain new ideas and inspiration regarding the implementation of such tools in their online courses.

More broadly, this study has the potential to add to the rapidly expanding field of online education by providing a new understanding of instructional methods and strategies that have the potential to prompt persistence of students in online learning contexts. This new understanding should help to improve predictions of the impact of the use of technology to improve the quality of the teaching and learning in an online environment. This work can help improve the quality of online education in higher education by offering insights gained from faculty about their experiences in incorporating collaborative technology tools in their online courses to support collaboration and student engagement, resulting in increasing student enrollment and retention. 
Lastly, this study contributes to the body of knowledge regarding collaborative learning, student engagement, and technology integration in online learning.

\section{Recommendations for Future Practice}

Based on the findings of this study and the literature review, the following are recommended for the meaningful integration of collaborative technology tools to support collaboration and student engagement in online settings:

\section{Practical Recommendation for Faculty}

Faculty are at the frontline in the integration of technology in teaching and learning. Therefore, the study offers practical recommendations for faculty to better implement collaborative technology tools in online courses to support collaboration and student engagement. The following practical recommendations referred to the need to:

- Explore a wide variety of collaborative technology tools and keep up with new technology trends, taking into consideration that it could be a life-long exploration of knowledge.

- Use the collaborative technology tools for personal and professional use before implementing them in the classroom.

- Seek out professional development opportunities that intensively focus on how collaborative technology tools could be incorporated into online courses for collaborative eLearning activities.

- Join the available professional learning communities to share, develop, critique learning resources, enabling critical thought about technology integration.

- Determine the specific needs and purpose of using collaborative technology tools before making a decision of using a certain tool. 
- Be willing to learn the tool and how to effectively use that particular tool in a particular activity and model troubleshooting.

- Select technology tools that have the specific features required for the assigned collaborative task, considering the positive impact to include and champion the student voice in the decision-making process of selecting the collaborative technology tool and how they apply it for collaborative eLearning.

- Provide clear instructions and guidance on how to use the tools for collaborative learning. Model how to participate in the assigned collaborative activities and provide exemplars.

- Create small groups, with only three to four students per group and enable students to manage the group work at their own pace.

- Increase online presence, considering the use of short instructional videos and some form of synchronous learning activities, such as synchronous online meetings that improve real-time communications in online courses.

- Establish a sense of community to encourage connections and interactions among students.

- Be clear on the expectations. Students do not know implicitly what the instructor's expectations. Therefore, it is important that instructors clarify expectations before the incorporation of collaborative eLearning activities. Make students aware of the value of their collaborative learning.

- Learn from experience through trial and error. 


\section{Practical Recommendation for Educational Institutions}

In order to make progress in the area of technology integration for enhancing collaborative learning, it is important that the perspectives of faculty and students are taken into consideration. Based on the findings of this study and the literature review, the following recommendations for future practice would be for instructional designers, and administrators to consider the need for better selection of technology tools that support communication, interaction, and collaboration in online courses:

- Listen carefully to online instructors' concerns and suggestions to best offer assistance to those who are seeking methods and instructional strategies to engage students and provide opportunities for interaction and collaboration in online courses.

- Include faculty in selecting the technology tools necessary to support online programs in higher education, considering conducting a university-wide survey to agree upon a single tool perceived as an effective tool to support collaborative learning in online courses based on certain criteria.

- Provide funds and personnel for training that intensively focus on how collaborative technology tools could be incorporated into online courses for collaborative eLearning activities.

- Establish and sustain formal and informal faculty professional development communities within the institution that allow online instructors to reflect and discuss challenges they experienced while incorporating collaborative technology tools into their online courses to facilitate collaborative eLearning activities and enhance student engagement. 


\section{Recommendation for Future Research}

The mixed methods approach used in this study proved to be beneficial to better understand the experiences of faculty members regarding using collaborative technology tools to design, develop, and implement collaborative eLearning activities in online courses, along with the perspectives of students toward their experiences while participating in these activities. Although this mixed methods study is useful in its own right, empirically examining the impact of implementation of collaborative technology tools on online collaborative learning and student learning outcomes, would be a fruitful area for further research.

Furthermore, a number of opportunities exist for replicating this study. Firstly, it is recommended to replicate the study with a large sample of students to obtain a broad picture of their perspectives toward the utilization of collaborative technology tools to support their online collaborative learning. Secondly, it is recommended to replicate the study to examine the effective utilization of collaborative technology tools to support collaboration and student engagement at a different institution or a number of institutions. Lastly, researchers may consider replicating this study using a different approach, relying more on a qualitative approach to better understand the role that technology can play in student success in collaborative learning in online settings.

An additional recommendation for research is on the support, training, and professional development needed for online instructors and guidance on how to integrate tools in online courses to support collaboration and student engagement. As most of the tools mentioned in the study have been widely employed as collaborative technology tools, more research is needed to provide reliable findings that can be generalized to the best practices of using such tools to support student collaborative learning in online learning. This would be a fruitful area for further 
work. Though there is a wide range of collaborative technology tools available, many of them are not widely utilized in education, especially in online education. That being said, a pilot implementation of tools that have not been examined is recommended to determine their potential impact on online collaborative learning and student engagement in online settings. Further investigation into the impact of incorporating synchronous activities into online courses on student engagement is strongly recommended.

\section{Conclusion}

According to Gerdy (1998), "learning is enhanced when it is more like a team effort than a solo race. Good learning, like good work, is collaborative and social, not competitive and isolated. Sharing one's ideas, expressing opinions, and responding to others improves thinking and deepens understanding" (p. 4). Collaborative learning in online settings needs to be mediated by some forms of technology that affords communication, interaction, and collaboration. The new trends of pedagogy in higher education aim to merge with the advanced technologies that enhance collaboration and student engagement (Aboul-Enein, 2017). Collaborative technology tools have the potential to create an environment that embodies Vygotsky's (1978) socialconstructivist principles, allowing a group of students to connect, collaborate, and engage in collaborative eLearning activities with capable peers to construct their knowledge. The findings of this study confirmed that collaborative technology tools have the potential to create a virtual collaborative environment that enables instructors to establish a learning community within online courses where students can synchronously or asynchronously work together toward a common task, in which each student adds to an emerging pool of knowledge of the group. The potential inherent in such tools lies in their abilities to facilitate meaningful interaction and collaboration in online learning environments. 
Collaborative technology tools have been widely adopted to support collaboration and student engagement in online courses. These tools offer new solutions to some of the challenges associated with online education such as the sense of isolation as such tools support establishing and maintaining a social presence throughout the duration of the online course. In considering this in relation to Moore's theory, it appears that collaborative technology tools have the potentials to facilitate meaningful dialogue and evoke real-time and two-way interaction and collaboration opportunities. This study provides evidence that the use of collaborative technology tools improves collaborative eLearning and positively affects students' experiences with online learning. However, the success of integrating collaborative technology tools into online settings to design eLearning activities that engage students and foster interaction and collaboration largely depends on well-prepared and fully-supported instructors. More specifically, findings indicate that faculty must be capable of selecting appropriate technology tools that support and facilitate online collaborative learning, which can be a key contributor to student engagement in online learning. In sum, a better selection of technology tools will result in a better incorporation of collaborative eLearning activities into online courses and, in the long run, a better offering of online education. 


\section{REFERENCES}

Abdelmalak, M. M. M. (2015). Web 2.0 Technologies and Building Online Learning Communities: Students' Perspectives. Online Learning, 19(2), 1-20.

Aboul-Enein, B. H. (2017). Online collaborative learning: Opportunities for interprofessional education. Computers \& Education, 54, 1137-1144.

Akhter, N. (2015). Perceptions of academicians regarding assessment process of distance teacher education courses in Pakistan. Pakistan Journal of Commerce \& Social Sciences, 9(1), $248-260$.

Alahmari, A. (2017). The state of distance education in Saudi Arabia. Quarterly Review of Distance Education, 18(2), 91-98.

Alahmari, A., \& Amirault, R. J. (2017). The use of e-learning in highly domain-specific settings: Perceptions of female students and faculty in Saudi Arabia. Quarterly Review Of Distance Education, 18(4), 37-56.

Alahmari, A., \& Kyei-Blankson, L. (2016). Adopting and implementing an e-learning system for teaching and learning in Saudi public K-12 schools: Benefits, challenges, and concerns. World Journal of Educational Research, 3 (1), 11-32. DOI: http://dx.doi.org/10.22158/ wjer.v3n1p11

Alahmari, A. \& Kyei-Blankson, L. (2018). Comparing teacher experiences using a learning management system in K-12 schools in Saudi Arabia. In J. Keengwe (Ed.). Handbook of research on pedagogical models for next-generation teaching and learning (pp. 345360). Hershey, PA: IGI Global.

Allen, I. E., \& Seaman, J. (2010). Class differences: Online education in the United States. Needham, MA: Sloan Consortium. 
Allen, I. E. and Seaman, J. (2013) Changing course: Ten years of tracking online education in the United States. Babson Park, MA: Babson Survey Research Group Report. Retrieved from http://sloanconsortium.org/publications/survey/changing_course_2012

Allen, E., \& Seaman, J. (2014). Grade change: Tracking online education in the United States. Wellesley, MA: Babson Survey Research Group Report. Retrieved from http://sloanconsortium.org/publications/survey/grade-change-2013

Allen, I. E., \& Seaman, J. (2015). Grade level: Tracking online education in the United States. Babson Park, MA: Babson Survey Research Group and Quahog Research Group, LLC. Retrieved from http://www.onlinelearningsurvey.com/reports/gradelevel.pdf

Allen, I. E., \& Seaman, J. (2017). Digital learning compass: Distance education enrollment report 2017. Retrieved from https://onlinelearningsurvey.com/reports/digtiallearningcompassenrollment2017.pdf

Alshenqeeti, H. (2014). Interviewing as a data collection method: A critical review. English Linguistics Research, 3(1), 39-45.

Anderson, T. \& Dron, J. (2011). Three generations of distance education pedagogy. The International Review of Research in Open and Distance Learning, 12(3), 80-97.

Barkley, E. F., Major, C. H., \& Cross K. P. (2014). Collaborative learning techniques: A handbook for college faculty. San Francisco, CA: Jossey-Bass.

Barry, M. (2012). What skills will you need to succeed in the future? Phoenix Forward (online). Tempe, AZ, University of Phoenix.

Bell, B. S., \& Fedeman, J. E. (2013). E-learning in postsecondary education. The Future of Children, 23(1), 165-185.

Blair, N. (2012). Technology integration for the new 21st-century learner. Principal, 91(3), 8-13. 
Blue, E. \& Tirotta, R. (2012). The benefits and drawbacks of integrating cloud computing and interactive whiteboards in teacher preparation. TechTrends, 55(3), 31-41.

Bowen, W. G. (2012, October 10 \& 11). The 'Cost Disease' in Higher Education: Is Technology the Answer? The Tanner Lectures (1 and 11), 1-49.

Bower, M. (2011). Synchronous collaboration competencies in web-conferencing environments - their impact on the learning process. Distance Education, 32(1), 63-83. doi: $10.1080 / 01587919.2011 .565502$

Bowers, J., \& Kumar, P. (2015). Students' perceptions of teaching and social presence: A comparative analysis of face-to-face and online learning environments. International Journal of Web-Based Learning and Teaching Technologies, 10(1), 27-44.

Brady, K., Holcomb, L., \& Smith, B. (2010). The use of alternative social networking sites in higher educational settings: A case study of the e-learning benefits of Ning in education. Journal of Interactive Online Learning, 9(2), 151-170.

Brannagan, K. B. (2012). Enhancing online finance education for non-financial managers. Journal of Online Learning and Teaching, 8(1), 79.

Brindley, J. E., Walti, C., \& Blaschke, L. M. (2009). Creating effective collaborative learning groups in an online environment. International Review of Research in Open and Distance Learning, 10(3), 1-18.

Brinkman, S., \& Kvale, S. (2015). Interviews: Learning the craft of qualitative research interviewing. Thousand Oaks, CA: Sage

Brodahl, C., Hadjerrouit, S., \& Hansen, N. (2011). Collaborative writing with Web 2.0 technologies: Education students' perceptions. Journal of Information Technology Education: Innovations in Practice, 10, 73-103. 
Bruner, J. S. (1961). The act of discovery. Harvard Educational Review, 31, 21-32.

Brutus, S., \& Donia, M. B. (2010). Improving the effectiveness of students in groups with a centralized peer evaluation system. Academy of Management Learning \& Education, 9(4), 652-662.

Campana, J. (2014). Learning for work and professional development: The significance of informal learning networks of digital media industry professionals. International Journal of Training Research, 12(3), 213-226.

Capo, B. H., \& Orellana, A. (2011). Web 2.0 technologies for classroom instruction: High school teachers' perceptions and adoption factors. The Quarterly Review of Distance Education. $12(4), 235-253$.

Carrol, N., \& Burke, M. (2010). Learning effectiveness using different teaching modalities. Journal of Business \& Economics Research, 8(12), 65-76

Caruth, G. D., \& Caruth, D. L. (2013). Distance education in the United States: From correspondence courses to the internet. Turkish Online Journal of Distance Education, $14(2), 141-149$.

Cheung, R., \& Vogel, D. (2013). Predicting user acceptance of collaborative technologies: An extension of the technology acceptance model for e-learning. Computers \& Education, 63, 160-175. doi:10.1016/j.compedu.2012.12.003

Chiong, R., Jovanovic, J., \& Gill, T. G. (2012). Collaborative learning in online study groups: An evolutionary game theory perspective. Journal of Information Technology Education, $11,81-101$ 
Choi, I., \& Lee, K. (2009). Designing and implementing a case-based learning environment for enhancing ill-structured problem solving: Classroom management problems for prospective teachers. Educational Technology Research and Development, 57(1), 99-129.

Chou, P. (2012). Teaching strategies in online discussion board: A framework in higher education. Higher Education Studies, 2(2), 25-30.

Cicconi, M. (2014). Vygotsky meets technology: A reinvention of collaboration in the early childhood mathematics classroom. Early Childhood Education Journal, 42(1), 57-65.

Cole, M. T., Shelley, D. J., \& Swartz, L. B. (2014). Online instruction, E-learning, and student satisfaction: A three year study. The International Review of Research in Open and Distance Learning, 15(6), 111- 131.

Crawford-Ferre, H. G., \& Wiest, L. R. (2012). Effective online instruction in higher education. The Quarterly Review of Distance Education, 13(1), 11-14.

Creswell,J. W. (2013). Research design: Qualitative, quantitative, and mixed methods approaches $\left(4^{\text {th }}\right.$ ed.). Thousand Oaks, CA: Sage.

Creswell, J. W., \& Plano Clark, V. L. (2011). Designing and conducting mixed methods research ( $2^{\text {nd }}$ ed.). Thousand Oaks, CA: Sage.

Cutler, R.H. (1995). Distributed presence and community in cyberspace, interpersonal communication and technology. A Journal for the 21st Century, 1(2), 12-32

Daher, T., \& Lazarevic, B. (2014). Emerging instructional technologies: Exploring the extent of faculty use of web 2.0 tools at a Midwestern community college. Tech Trends, 58(6), 4250. 
Dahlberg, B., Wittink, M. N., \& Gallo, J. J. (2010). Funding and publishing integrated studies: Writing effective mixed methods manuscripts and grant proposals. In A. Tashakkori \& C. Teddlie (Eds.), Handbook of mixed methods in social and behavioral science (2nd ed.). Thousand Oaks, CA: SAGE.

Dahlberg, B., Wittink, M. N., \& Gallo, J. J. (2010). Funding and publishing integrated studies: Writing effective mixed methods manuscripts and grant proposals. In A. Tashakkori \& C. Teddlie (Eds.), Handbook of mixed methods in social and behavioral science (2nd ed.).

Daniel, J. (2012). Making sense of MOOCs: Musings in a maze of myth, paradox and possibility. Journal of Interactive Media in Education, 2012(3), 1-20.

de Laat, M., \& Schreurs, B. (2013). Visualizing informal professional development networks: Building a case for learning analytics in the workplace. American Behavioral Scientist, 57(10), 1421-1438.

den Exter, K., Rowe, S., Boyd, W., \& Lloyd, D. (2012). Using Web 2.0 Technologies for Collaborative Learning in Distance Education—Case Studies from an Australian University. Future Internet, 4(1), 216-237. doi:10.3390/fi4010216

Dewey, J. (1916). Democracy and education. New York, NY: The Free Press.

Dorner, H., \& Kumar, S. (2016). Online collaborative mentoring for technology integration in pre-service teacher education. Techtrends: Linking Research \& Practice to Improve Learning, 60(1), 48-55. doi:10.1007/s11528-015-0016-1

Driscoll, M. P. (2005). Psychology of learning for instruction. Boston, MA: Pearson.

Eisner, S. (2010). Grave new world? Workplace skills for today's college graduates. American Journal of Business Education, 3(9), 27-50. 
Eraut, M. (2011). Informal learning in the workplace: Evidence on the real value of work-based learning (WBL). Development and Learning in Organizations: An International Journal, $25(5), 8-12$.

Etikan, I., Musa, S. A., \& Alkassim, R. S. (2016). Comparison of convenience sampling and purposive sampling. American Journal of Theoretical and Applied Statistics, 5(1), 1-4.

Falloon, G. (2011). Making the connection: Moore's theory of transactional distance and its relevance to the use of a virtual classroom in postgraduate online teacher education. Journal of Research on Technology in Education, 43(3), 187-209.

Fennema, J. (2010). Constructivism: A critique from a biblical worldview. In H. Lee (Ed.), Faith-based education that constructs: A creative dialogue between constructivism and faith-based education (pp. 23-36). Eugene, OR: Wipf and Stock.

Foote, M., Q and T. Bartell, Gau (2011). Pathways to equity in mathematics education: How life experiences impact researcher positionality. Educational Studies in Mathematics, 78(1), 45-68.

Fox-Turnbull, W., \& Snape, P. (2011). Technology teacher education through a constructivist approach. Design and Technology Education, 16(2), 45-56.

Gan, B., Menkhoff, T., \& Smith, R. (2015). Enhancing students' learning process through interactive digital media: New opportunities for collaborative learning. Computers in Human Behavior, 51, 652-663.

Gerdy, K. B. (1998, July). If Socrates only knew: Expanding law class discourse. S. 9. Lawyer skills. Paper presented at the meeting CALI Conference on Law School Computing, Chicago, IL. 
Gravetter, F. J. \& Wallnau, L. B. (2012). Statistics for the behavioral sciences $\left(9^{\text {th }}\right.$ ed.). Belmont, CA: Thomson Wadsworth.

Green, C. \& Ruane, E. (2011). Collaboration in the cloud: Untethered technology for scholarly pursuits. College \& Research Libraries News, 72(8), 454-460.

Guasch, T., Espasa, A., Alvarez, I. M., \& Kirschner, P. A. (2013). Effects of feedback on collaborative writing in an online learning environment. Distance Education, 34(3), 324338.

Gunawardena, C. N. (1995). Social presence theory and implications for interaction and collaborative learning in computer conferences. International Journal of Educational Telecommunications, 1(2/3), 147-166.

Hämäläinen, R., \& Vähäsantanen, K. (2011). Theoretical and pedagogical perspectives on orchestrating creativity and collaborative learning. Educational Research Review, 6(3), 169-184.

Handayani, N. S. (2012). Emerging roles in scripted online collaborative writing in higher education context. Procedia - Social and Behavioral Sciences, 67, 370-379. doi:10.1016/j.sbspro.2012.11.340

Hew, K. F. (2011). Students' and teachers' use of Facebook. Computers in Human Behavior, 27(2), 662-676.

Hew, K. F., \& Cheung, W. S. (2013). Use of Web 2.0 technologies in K-12 and higher education: The search for evidence-based practice. Educational Research Review, 9, 4764. doi:10.1016/j.edurev.2012.08.001

Hocutt, D. L., \& Brown, M. E. (2018). Crossing wires with Google Apps: Jumpstarting collaborative composing. In C. E. Ball, C. Chen, K. Purzycki, \& L. Wilkes (Eds.), 
Proceedings of the Annual Computers \& Writing Conference: Vol. 1. 2016-2017 (pp. 5257). Ft. Collins, CO: WAC Clearinghouse.

Hoic-Bozic, N. (2009). A blended learning approach to course design and implementation. IEEE transactions on education, 52(1), 19-30.

Horzum, M. B. (2015). Interaction, structure, social presence, and satisfaction in online learning. Eurasia Journal of Mathematics, Science \& Technology Education, 11(3), 505-512. doi:10.12973/eurasia.2014.1324a

Hsu, Y. C., \& Shiue, Y. M. (2017). Exploring the Influence of Using Collaborative Tools on the Community of Inquiry in an Interdisciplinary Project-Based Learning Context. Eurasia Journal of Mathematics, Science and Technology Education, 14(3), 933-945.

Huynh, K. P., Jacho-Chávez, D. T., \& Self, J. K. (2010). The efficacy of collaborative learning recitation sessions on student outcomes. American Economic Review, 100(2), 287-291.

Irwin, C., Ball, L., Desbrow, B., \& Leveritt, M. (2012). Students' perceptions of using Facebook as an interactive learning resource at university. Australasian Journal of Educational Technology, 28(7), 1221-1232.

Jacobs, P. (2013). The challenges of online courses for the instructor. Research in Higher Education Journal, 21, 1-18.

Jaggars, S. S. (2014). Choosing between online and face-to-face courses: Community college student voices. American Journal of Distance Education, 28(1), 27-38.

Jaggars, S. S., \& Bailey, T. (2010). Effectiveness of fully online courses for college students: Response to a department of education meta-analysis. Community College Research Center, Columbia University. 
Jain, S., \& Jain, P. (2015). Designing interactive online nursing courses. Education, 136(2), 179191.

Janssen, J., Kirschner, F., Erkens, G., Kirschner, P. A., \& Paas, F. (2010). Making the black box of collaborative learning transparent: Combining process-oriented and cognitive load approaches. Educational Psychology Review, 22(2), 139-154.

Johnson, L., Adams, S., and Cummins, M. (2012). The NMC Horizon Report: 2012 Higher Education Edition. Austin, TX: The New Media Consortium.

Johnson, R.B. \& Onwuegbuzie, A.J. (2004), Mixed methods research: A research paradigm whose time has come. Educational Researcher, 33(7), 12-26.

Justus, M. (2017). The role of pedagogical beliefs in emerging technology integration: An exploratory case study of faculty perspectives. The Qualitative Report, 22(2), 499-526.

Katz, R. N. (2010). The tower and the cloud: Higher education in the age of cloud computing. Washington, DC: Educause.

Kelly, D., \& Thorn, K. (2013). Should instructional designers care about the Tin Can API? eLearn, (3), 1. doi:10.1145/2446514.2446579

Kelly, D., \& Thorn, K. (2013). Should Instructional Designers care about the Tin Can API? Elearn, 2013(3), 1. Retrieved from http://libproxy.lib.ilstu.edu/login?url=https://search.ebscohost.com/login.aspx?direct=true $\& \mathrm{db}=\mathrm{edb} \& \mathrm{AN}=103010025 \&$ site $=$ eds-live $\&$ scope $=$ site

Keengwe, J. \& Georgina, D. (2012). The digital course training workshop for online learning and teaching. Education and Information Technologies, 17(4), 354-379.

Keengwe, J., \& Kidd, T. T. (2010). Towards best practices in online learning and teaching in higher education. MERLOT Journal of Online Learning and Teaching, 6(2), 533-541. 
Kimmerle, J., Moskaliuk, J., \& Cress, U. (2011). Using wikis for learning and knowledge building: Results of an experimental study. Educational Technology \& Society, 14(4), $138-148$.

Ku, H. Y., Tseng, H. W., \& Akarasriworn, C. (2013). Collaboration factors, teamwork satisfaction, and student attitudes toward online collaborative learning. Computers in Human Behavior, 29(3), 922-929.

Kuo, Y. C., Walker, A. E., Schroder, K. E., \& Belland, B. R. (2014). Interaction, Internet selfefficacy, and self-regulated learning as predictors of student satisfaction in online education courses. The Internet and Higher Education, 20, 35-50.

Lalonde, C. (2011). Courses that deliver: Reflecting on constructivist critical pedagogical approaches to teaching online and on-site foundations courses. International Journal of Teaching and Learning in Higher Education, 23(3), 408-423.

Leafman, J. (2015). Online instructor perceptions of social presence and educational use of social media. Advances in Social Sciences Research Journal, 2(11), 85-96.

Leedy, P.D. \& Ormrod, J. E. (2010) Practical Research: Planning and Design, Ninth Edition. NYC: Merril.

Lee, H. J., \& Lim, C. (2012). Peer evaluation in blended team project-based learning: What do students find important? Educational Technology \& Society, 15(4), 214-224.

Lee, J. \& Spires, H. (2009). What students think about technology and academic engagement in school: Implications for middle grades teaching and learning. AACE Journal, 17(2), 6181.

Lee, L. (2016). Autonomous learning through task-based instruction in fully online language courses. Language Learning \& Technology, 20(2), 81-97. 
Lei, S. A., \& Gupta, R. K. (2010). College distance education courses: Evaluating benefits and costs from institutional, faculty and students' perspectives. Education, 130(4), 616-631.

Lieberman, A., \& Mace, D. P. (2010). Making practice public: Teacher learning in the 21st century. Journal of Teacher Education, 61(1-2), 77-88.

Liu, S. H. J., \& Lan, Y. J. (2016). Social Constructivist Approach to Web-Based EFL Learning: Collaboration, Motivation, and Perception on the Use of Google Docs. Educational Technology \& Society, 19 (1), 171-186.

Lowenthal, P. R. (2010). The evolution and influence of social presence theory on online learning. In S. Dasgupta (Ed.), Social computing: Concepts, methodologies, tools, and applications (pp. 113-128). Hershey, PA: IGI Global.

Luna Scott, C. (2015). The futures of learning 2: What kind of learning for the $21^{\text {st }}$ century. Education Research and Foresight Working Papers. Paris, France: The United Nations Educational, Scientific and Cultural Organization.

Macià, M., \& García, I. (2016). Informal online communities and networks as a source of teacher professional development: A review. Teaching and Teacher Education, 55, 291-307.

Mafenya, P. N. (2014). A South African distance learning case study: Reducing distance through mobile technology. Mediterranean Journal of Social Sciences, 5(14), 276

Martinez-Caro, E. (2011). Factors affecting effectiveness in e-learning: An analysis in production management courses. Computer Applications in Engineering Education, 19(3), 572-581.

Marzilli, C., Delello, J., Marmion, S., McWhorter, R., Roberts, P., \& Marzilli, T. S. (2014). Faculty attitudes towards integrating technology and innovation. International Journal on Integrating Technology in Education, 3(1), 1-20. doi :10.5121/ijite.2014.3101 
Marshall, C , \& Rossman, G. B. (2011). Designing qualitative research (5th ed.). Thousand Oaks, CA: SAGE.

Mashaw, B. (2012). A model for measuring effectiveness of an online course. Decision Sciences Journal of Innovative Education, 10(2), 189-221. doi:10.1111/j.1540- 4609.2011.00340.x

Mbuva, J. M. (2015). Examining the effectiveness of online educational technological tools for teaching and learning and the challenges ahead. Journal of Higher Education Theory and Practice, 15(2), 113-127.

Meier, E. (2015). Beyond a digital status quo: Re-conceptualizing online learning opportunities. Bank street Occasional Paper Series, 2015 (34), 5-19. Retrieved from https://educate.bankstreet.edu/occasional-paper-series/vol2015/iss34/2

Merriam, S. B., \& Tisdell, E. J. (2015). Qualitative research: A guide to design and implementation. City: ST: John Wiley \& Sons.

McCarthy, J. (2010). Blended learning environments: Using social networking sites to enhance the first year experience. Australasian Journal of Educational Technology, 26(6), 729740.

Milman, N. B. (2010). Online education and the wild, wild, web. Distance Learning, 7(4), 95-97. Molina-Azorín, J. F., \& Font, X. (2016). Mixed methods in sustainable tourism research: an analysis of prevalence, designs and application in JOST (2005-2014). Journal of Sustainable Tourism, 24(4), 549-573

Moore, M. G. (1973). Towards a theory of independent learning and teaching. Journal of Higher Education, 44(12), 661-679.

Moore, M. G. (1997). Theory of transactional distance. In D. Keegan (Ed.), Theoretical principles of distance education. p 22-38. New York: Routledge. 
Moore, M. G. (2006). Theory and theorists: Evolution of theory of transactional distance. European Distance and E-Learning Network. Retrieved from https://www.slideshare.net/guest2c679db/michael-moore-distance-education-presentation

Moore, M. G. (2007). The theory of transactional distance. In M. G. Moore (ed.), The handbook of distance education (2nd ed.) (pp. 89-108). Mahwah, NJ: Lawrence Erlbaum Associates.

Moore, M., \& Kearsley, G. (2011). Distance education: A systems view of online learning ( $3^{\text {rd }}$ ed.). Belmont, CA: Wadsworth.

Nayan, S., Shafie, L. A., Mansor, M., Maesin, A., \& Osman, N. (2010). The practice of collaborative learning among lecturers in Malaysia. Management Science and Engineering, 4(1), 62-70.

Nookhong, J., \& Wannapiroon, P. (2015). Development of collaborative learning using casebased learning via cloud technology and social media for enhancing problem-solving skills and ICT literacy within undergraduate students. Procedia-Social and Behavioral Sciences, 174, 2096-2101. doi:10.1016/j.sbspro.2015.02.007

O’Neill, S., Scott, M., \& Conboy, K. (2011). A Delphi study on collaborative learning in distance education: The faculty perspective. British Journal of Educational Technology, 42(6), 939-949.

Onwuegbuzie, A. J., \& Combs, J. P. (2010). Emergent data analysis techniques in mixed methods research: a synthesis. In A. Tashakkori \& C. Teddlie (Eds.), Handbook of mixed 
methods in social and behavioral research (2nd ed., pp. 397-430). Thousand Oaks, CA: Sage.

Onwuegbuzie, A. J., \& Teddlie, C. (2003). A framework for analyzing data in mixed methods research. In A. Tashakkori \& C. Teddlie (Eds.), Handbook of mixed methods in social and behavioral research (pp. 351-383). Thousand Oaks, CA: Sage.

Oteng-Ababio, M. (2011). Door of hope or despair: Students' perception of distance education at University of Ghana. Turkish Online Journal of Distance Education, 12(3) 241-258.

Özek, Y. H., Edgren, G., \& Jandér, K. (2012). Implementing the critical friend method for peer feedback among teaching librarians in an academic setting. Evidence Based Library \& Information Practice, 7(4), 68-81.

Paechter, M., Maier, B., \& Macher, D. (2010). Students' expectations of, and experiences in elearning: Their relation to learning achievements and course satisfaction. Computers \& Education, 54(1), 222-229.

Palloff, R. M., \& Pratt, K. (2011). The excellent online instructor: Strategies for professional development. San Francisco, CA: Jossey-Bass.

Panitz, T. (1996). Collaborative versus cooperative learning: Comparing the two definitions helps understand the nature of interactive learning. Cooperative Learning and College Teaching, 8(2), 1-9.

Parra, J. (2013). Developing technology and collaborative group work skills: Supporting student and group success in online and blended courses. In C. Wankel \& P. Blessinger (Eds.), Cutting-edge technologies in higher education: Vol. 6. Increasing student engagement and retention in e- learning environments: Web 2.0 and blended learning technologies (pp. 287-337). Emerald Group Publishing Limited. 
Piaget, J. (1971). Biology and knowledge. Chicago, IL: University of Chicago Press.

Picciano, A. (2002). Beyond student perceptions: issues of interaction, presence, and performance in an online course. Journal of Asynchronous Learning Networks, 6(1), 2140.

Plano-Clark, V., \& Creswell, J. W. (2015). Understanding research: A consumer's guide $\left(^{\text {nd }}\right.$ ed.). Upper Saddle, NJ: Pearson.

Popescu, E. (2014). Using wikis to support project-based learning: A case study. In Proceedings of ICALT 2014 (pp. 305-309). Athens, Greece: IEEE Computer Society Press.

Powell, K. C., \& Kalina, C. J. (2009). Cognitive and social constructivism: Developing tools for an effective classroom. Education, 130(2), 241-250.

Pritchard, A. \& Woollard, J. (2010). Psychology for the classroom: constructivism and social learning. New York, NY: Routledge

Rao, K., \& Tanners, A. (2011). Curb cuts in cyberspace: Universal instructional design for online courses. Journal of Postsecondary Education and Disability, 24(3), 211-229.

Ravenscroft, A., Schmidt, A., Cook, J., \& Bradley, C. (2012). Designing social media for informal learning and knowledge maturing in the digital workplace. Journal of Computer Assisted Learning, 28(3), 235-249.

Razali, S. N., Shahbodin, F., Hussin, H., \& Bakar, N. (2015). Factors affecting the effective online collaborative learning environment. Pattern Analysis, Intelligent Security \& the Internet of Things, 215-224. doi:10.1007/978-3-319-17398-6_20

Reilly, J. R., Vandenhouten, C., Gallagher-Lepak, S., \& Ralston-Berg, P. (2012). Faculty development for e-learning: A multi-campus community of practice (COP) approach. Journal of Asynchronous Learning Networks, 16(2), 99-110. 
Revere, L. R., \& Kovach, J. V. (2011). Online technologies for engaged learning: A meaningful synthesis for educators. Quarterly Review of Distance Education, 12(2), 113-124.

Reyna, J. (2010). Google Docs in higher education settings: A preliminary report. Proceedings of World Conference on Educational Multimedia, Hypermedia and Telecommunications (pp. 1566-1572). Chesapeake, VA: AACE.

Roberts, C. M. (2010). The dissertation journey: A practical and comprehensive guide to planning, writing, and defending your dissertation. Thousand Oaks, CA: Corwin Press.

Roblyer, M. D., McDaniel, M., Webb, M., Herman, J. \& Witty, J. V. (2010). Findings on Facebook in higher education: A comparison of college faculty and student uses and perceptions of social networking sites. Internet and Higher Education, 13(3), 134-140.

Rodrigues, J. J. P. C., Sabino, F. M. R., \& Zhou, L. (2010). Enhancing e-learning experience with online social networks. IET Communications, 5(8): 1147-1154.

Schlosser, L. A., \& Simonson, M. (2009). Distance education: Definition and glossary of terms ( $3^{\text {rd }}$ ed.). Charlotte, NC: Information Age.

Scott, C., \& Liu, Y. (2011). Using Wiki tools to promote community learning. In M. Koehler \& P. Mishra (Eds.), Proceedings of Society for Information Technology \& Teacher Education International Conference (1671-1674). Chesapeake, VA: AACE.

Severance, C., \& Teasley, S. (2010). Preparing for the long tail of teaching and learning tools. In K. Gomez, L. Lyons, \& J. Radinsky (Eds.), Learning in the Disciplines: Proceedings of the 9th International Conference of the Learning Sciences (ICLS 2010) - Volume 1 (Vol. 1, pp. 758-764). Retrieved from https://dl.acm.org/citation.cfm?id=1854457

Short, J., Williams, E., \& Christie, B. (1976). The social psychology of telecommunications. London: John Wiley \& Sons. 
Sills, S. J., \& Song, C. (2002). Innovations in survey research: An application of web-based surveys. Social Science Computer Review, 20(1), 22.

Simon, M. K. (2011). Dissertation and scholarly research: Recipes for success. Seattle, WA: Dissertation Success, LLC.

Simonson, M., Smaldino, S., Albright, M., \& Zvacek, S. (2014). Teaching and learning at a distance: Foundations of distance education. ( $6^{\text {th }}$ ed.). Greenwich: CT: Information Age.

So, H.-J., \& Bonk, C. J. (2010). Examining the roles of blended learning approaches in computer-supported collaborative learning (CSCL) environments: A Delphi study. Educational Technology \& Society, 13(3), 189-200.

Stenhouse, L. (1975). An introduction to curriculum research and development. London, England: Heinemann.

Subedi, D. (2016). Explanatory sequential mixed method design as the third research community of knowledge claim. usdoi:10.12691/education-4-7-10

Sun, A., \& Chen, X. (2016). Online education and its effective practice: A research review. Journal of Information Technology Education: Research, 15, 157-190.

Swan, K., Day, S. L., Bogle, L. R., \& Matthews, D. B. (2014). A collaborative, design-based approach to improving an online program. The Internet and Higher Education, 21, 74-81. doi:10.1016/j.iheduc.2013.10.006

Tamin, R., Bernard, R., Borokhovski, E., Abrami, P., \& Schmid, R., (2011). What forty years of research says about the impact of technology on learning: A second-order meta-analysis and validation study. Review of Educational Research, 81(1), 4-28.

Tashakkori, A., \& Teddlie, C. (1998). Mixed methodology: combining qualitative and quantitative approaches. Thousand Oaks, CA: Sage. 
Thabane, L., Ma, J., Chu, R., Cheng, J., Ismaila, A., Rios, L., Robson, R., Thabane, M., Giangregorio, L., \& Goldsmith C. (2010). A tutorial on pilot studies: The what, why and how. BMC Medical Research Methodology, 10(11), 1-10. doi: 10.1186/1471-2288- 10-1

Thoma, J., Hutchison, A., Johnson, D., Johnson, K., \& Stromer, E.(2017). Planning for Technology Integration in a Professional Learning Community. Reading Teacher, 71(2), $167-175$

Tsai, C. (2013). How to involve students in an online course: A redesigned online pedagogy of collaborative learning and self-regulated learning. International Journal of Distance Education Technologies, 11(3), 47-57. doi:10.4018/jdet.2013070104

Tu, C. H., \& McIsaac, M. (2002). The relationship of social presence and interaction in online classes. The American journal of distance education, 16(3), 131-150.

U.S. Department of Education, Office of Planning, Evaluation, and Policy Development. (2009). Evaluation of evidence-based practices in online learning: A meta- analysis and review of online learning studies. Washington, DC: Author. Retrieved from https://www2.ed.gov/rschstat/eval/tech/evidence-based-practices/finalreport.pdf

Velasquez, A., Graham, C. R., \& Osguthorpe, R. D. (2013). Caring in a technology- mediated online high school context. Distance Education, 34(1), 97-118. doi:10.1080/01587919.2013.770435

Ventayen, R. J. M., Estira, K. L. A., De Guzman, M. J., Cabaluna, C. M., \& Espinosa, N. N. (2018). Usability evaluation of google classroom: Basis for the adaptation of gsuite elearning platform. Asia Pacific Journal of Education, Arts and Sciences, 5(1), 47-51.

Vogt, W. P., Gardner, D. C., \& Haeffele, L. M., (2012). When to use what research design. New York, NY: Guilford Press. 
Vygotsky, L. (1978). Mind in society. Cambridge, MA: Harvard University Press.

Wang, J. (2011). Work in progress - A feedback system for peer evaluation of engineering student teams to enhance team effectiveness. Proceedings of Frontiers in Education Conference (FIE), pp. S4C-1-S4C-5.

Wang, Q. (2010). Using online shared workspaces to support group collaborative learning. Computers \& Education, 55(3), 1270-1276.

Ward, M. E., Peters, G., \& Shelley, K. (2010). Student and faculty perceptions of the quality of online learning experiences. International Review of Research in Open \& Distance Learning, 11(3), 57-77.

Weidman, R., \& Bishop, M. J. (2009). Using the jigsaw model to facilitate cooperative learning in an online course. Quarterly Review of Distance Education, 10(1), 51-64.

Wever B. D., Keer, H. V., Schellens, T., \& Valcke, M. (2011). Assessing collaboration in a wiki: The reliability of university students' peer assessment. The Internet and Higher Education, 14(4), 201-206.

Yates, S., Thorn, M., Han, A., \& Deacon, M. (2018). Building an online copyright module: A case study in collaborative learning. In Collaboration and the academic library (pp. 97104). Chandos Publishing.

Yin, R. (2014). Case study research: Design and methods (5th ed.). Thousand Oaks, CA: Sage. Yuan, J., \& Kim, C. (2014). Guidelines for facilitating the development of learning communities in online courses. Journal of Computer Assisted Learning, 30, 220-232.

Zhou, W., Simpson, E., \& Domizi, D. P. (2012). Google Docs in an out-of-class collaborative writing activity. International Journal of Teaching and Learning in Higher Education, 24(3), 359-375. 
Zhu, C. (2012). Student satisfaction, performance, and knowledge construction in online collaborative learning. Educational Technology \& Society, 15(1), 127-136.

Zygouris-Coe, V. (2012). Collaborative learning in an online teacher education course: Lessons learned. ICICTE 2012 Proceedings, 332-342. 


\section{APPENDIX A: PILOT STUDY RECRUITMENT EMAIL}

Subject: [Research] Using Collaborative Technologies in Online Learning Environments.

Dear Student/Faculty member,

You are invited to participate in a pilot research study. The purpose of the main study is to explore the experiences of faculty members using collaborative technologies to enhance collaborative learning and student engagement in their online courses as well as obtain the perspectives of students about their experiences in these activities. Your responses to this pilot study will help to the feasibility, reliability, and validity of the main study.

The survey is very brief and should take no longer than 15 minutes to complete. To participate in this survey, please click the link below to be redirected to a website for the survey or copy and paste the link into your Internet browser.

Survey link: https://illinoisstate.az1.qualtrics.com/jfe/form/SV_cHISkFxGcOc7bWB

If you have any comments or questions, please feel free to contact me at aalahma@ilstu.edu or 309-433-6679. You may contact my advisor Dr. Ryan A. Brown at rbrown@ilstu.edu_or (309) 438-3964.

Thank you very much for your time and cooperation. Your feedback is very important to us. 
Sincerely,

Ayshah Alahmari

Doctoral Candidate, School of Teaching and Learning

Illinois State University, Normal, IL

(309) 433-6679

Email: aalahma@ilstu.edu 


\section{APPENDIX B: E-MAIL INVITATION TO PARTICIPATE IN A SURVEY}

From:

To:

Subject:

If you have taught or taken an online course, I would like to invite you to participate in a brief survey. I would like to better understand your perspective about collaboration and student engagement in online learning environments. Your responses to this survey will help gain useful knowledge about the best practices of using collaborative technology tools to enhance collaborative learning in online learning environments.

The survey is very brief and will only take about 15-20 minutes to complete. Please click the link below to go to the survey website or copy and paste the link into your Internet browser.

Survey link: https://illinoisstate.az1.qualtrics.com/jfe/form/SV_eFp9yq9iaPwul8N

Your participation in the survey is completely voluntary and all of your individual responses will be kept confidential. No personally identifiable information will be reported in any uses of these data. The study is confidential and conducted through a secure website, however, any online activity such as surveys involves the potential breach of data. More information about the study and its risks are listed at the beginning of the study. The Institutional Review Board has 
approved this survey. If you have any comments or questions, please feel free to contact me at aalahma@ilstu.edu or 309-433-6679.

Thank you very much for your time and cooperation. Your feedback is very important to us.

Sincerely,

Ayshah Alahmari

Doctoral Candidate, School of Teaching and Learning

Illinois State University, Normal, IL

(309) 433-6679

Email: aalahma@ilistu.edu 


\section{APPENDIX C: INFORMED CONSENT FOR THE SURVEY}

\section{Dear student/faculty member:}

You are invited to participate in a research study that explores collaboration in online courses. This study aims to develop a more complete understanding of the effective use of collaborative technology tools to support collaboration experiences and student engagement in online learning.

If you choose to take part in this research study, you will be asked to complete a short survey. This survey will take approximately 15-20 minutes of your time. By responding to and submitting the survey you will be providing consent to participate in the survey. An additional option to participate in a follow-up interview is asked at the end of the survey. Your participation in the study is strictly voluntary. You have the right to refuse to participate or discontinue participation at any time without penalty or loss of benefits. There are no direct benefits to participants. However, your participation will help gain useful knowledge about the best practices of using collaborative technology tools to enhance collaborative learning in online learning environments.

The risks associated with this research are no greater than those encountered in everyday life. However, participants that are faculty members could feel that they are sharing information that could increase employment risks by making statements that are unfavorable toward the University. To minimize this risk, your responses to this survey will be confidential and will only be reported as group data with no identifying information. Data gathered by way of the survey will be aggregated and reported in a research study. If you have any questions regarding this 
study, please feel free to contact me at aalahma@ilstu.edu or (309) 433-6679. You may contact my advisor Dr. Ryan A. Brown at rbrown@ilstu.edu or (309) 438-3964. If you have any questions about your rights as a participant in this research, you may contact the Research Ethics \& Compliance Office at Illinois State University at (309) 438- 2529 or via email at rec@ilstu.edu.

Sincerely,

Ayshah Alahmari

Doctoral Candidate, School of Teaching and Learning

Illinois State University, Normal, IL

(309) 433-6679

Email: aalahma@ilstu.edu

\section{Consent:}

Yes, Clicking Yes indicates that you consent to participate in the survey and will allow you to proceed to the survey.

If you are not interested in participating in the study, please exit the browser. 


\section{APPENDIX D: FACULTY SURVEY}

\section{Gender}

Male

Female

Other

2 Age

25 and below

$26-35$

$36-45$

46 and above

\section{Years of teaching experience}

\footnotetext{
Less than a year

$1-5$ years

6- 10 years

$11+$ years
} 
4 What is your current position/title?

Instructional Assistant Professor/NTT

Assistant professor

Associate Professor

Professor

Other

\section{School/Department:}

Department of Agriculture

Department of Chemistry

Department of Communication Sciences and Disorder

Department of Criminal Justice Sciences

Department of Economics

Department of Educational Administration and Foundation

Department of English

Department of Family and Consumer Sciences 
Department of Geography-Geology

Department of History

Department of Languages, Literatures and Cultures

Department of Mathematics

Mennonite College of Nursing

Department of Politics and Government

Department of Psychology

Department of Sociology and Anthropology

Department of Special Education

Department of Technology

School of Art

School of Biological Sciences

School of Communication

School of Information Technology

School of Kinesiology and Recreation 
School of Music

School of Social Work

School of Teaching and Learning

School of Theatre and Dance

Other

6 Please rate your comfort/confidence using technology:

Very comfortable

Comfortable

Neither comfortable nor uncomfortable

Uncomfortable

Very uncomfortable 
*Online Course: A courses where all or at least 80 percent of the content is delivered online.

7 Have you ever taken an online course as a student?

Yes

No

8 If yes, what was the format of the online courses participated in as a student? (Please check all that apply)

$100 \%$ online

Blended/hybrid

9 Have you taught an online course?

Yes

No 
10 If yes, what was the format of the online courses you taught? (Please check all that apply)

$100 \%$ online

Blended/hybrid

11 Number of years you have been teaching online courses?

Less than a year

$1-5$ years

6- 10 years

$11+$ years

12 What course level you taught?

Undergraduate

Graduate

Both 
*Collaborative learning: An educational approach of learning through a coordinated and shared environment where groups of students work together toward a common task.

13 Have you ever developed collaborative eLearning activities in your online course?

Yes

No

14 Number of years you have been developing and implementing collaborative learning into your online courses?

Less than a year

$1-5$ years

6- 10 years

$11+$ years 
*Collaborative technology tools: The technology tools that enable individuals and groups to communicate, collaborate, and interact in online environments in order to accomplish a common task, share or exchange information, and construct knowledge without the use of face-to-face interaction.

15 Please rate your comfort/confidence using collaborative technology tools:

Very comfortable

Comfortable

Neither comfortable nor uncomfortable

Uncomfortable

Very uncomfortable

16 Have you received any faculty training session about collaborative technology tools?

Yes

No 
17 Do you use collaborative technology tools in your online courses?

Yes

No

18 If yes, what are the most commonly used collaborative technology tools you integrate into your pedagogy for collaborative learning in your online courses? Please select all that apply.

Google Applications (Google Drive: Docs, Sheets, Slides, Draw)

Microsoft Applications/Microsoft Office 365 (OneNote Class Notebook)

Social Networking Tools (Facebook, Linked-in, Skype, Twitter, WhatsApp, SnapChat)

Wikis

Blogs

Microblogging

Web Conferencing

Presentation \& Slide Sharing

Blackboard Collaborate 
Discussion Forms

Other 
19 Have you received any training on how to use those tools?

Yes

No

20 Please rate your comfort/confidence implementing new collaborative technology tools to support collaborative learning into your online course on a scale of 1 to 5

[with $1=$ very uncomfortable and $5=$ very comfortable].

Very comfortable

Comfortable

Neither comfortable nor uncomfortable

Uncomfortable

Very uncomfortable

21 Do you use collaborative technology tools other than in online course?

Yes

No

22 If yes, for what do you use collaborative technology tools? Please select all that apply.

Communication

To share documents 
To schedule or assign work

To work with a colleague or a team

To build or participate in an online community

Other

23 Factors to consider when selecting collaborative technology tools for collaborative learning

Please select your level of agreement with the following statements: 


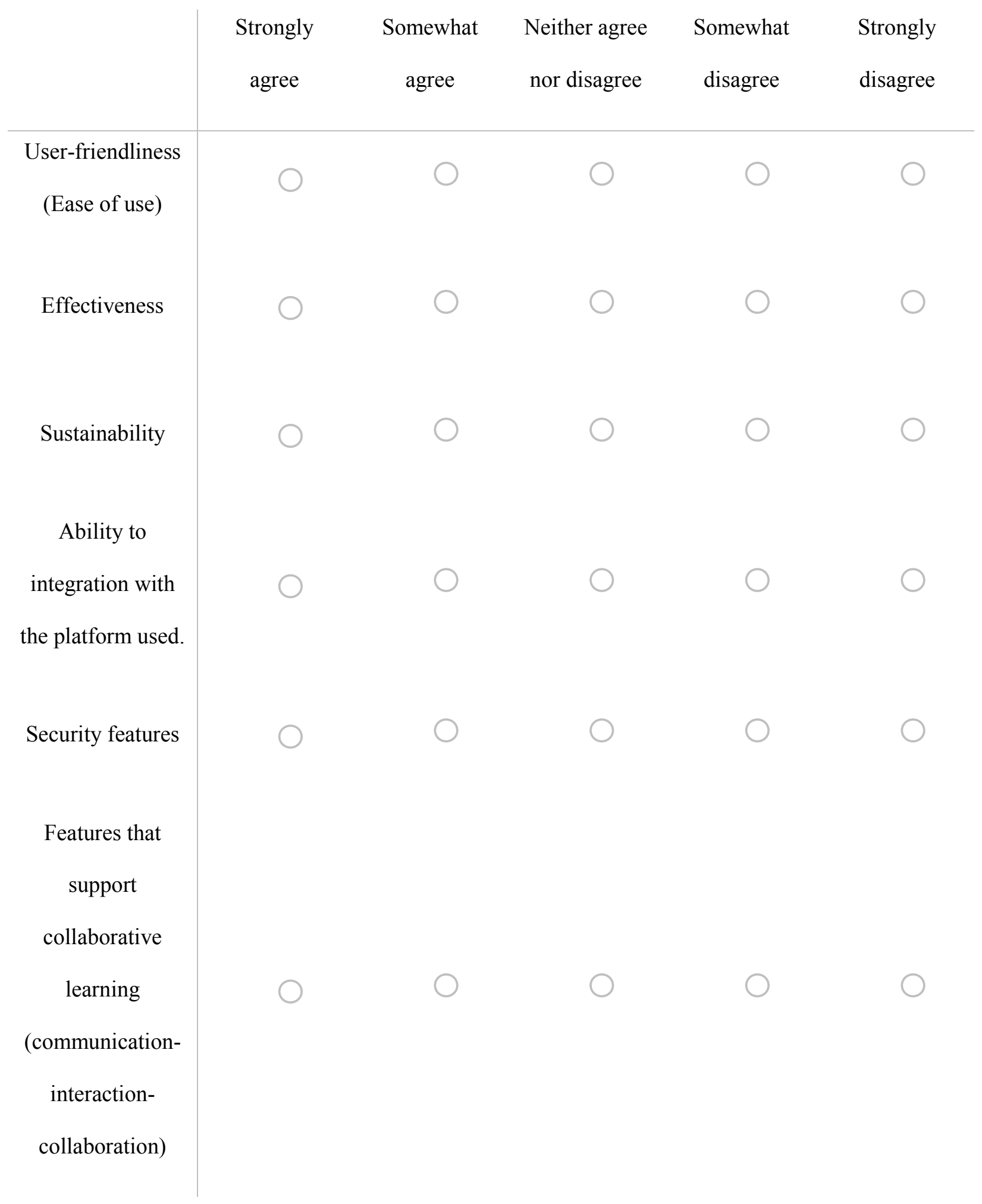




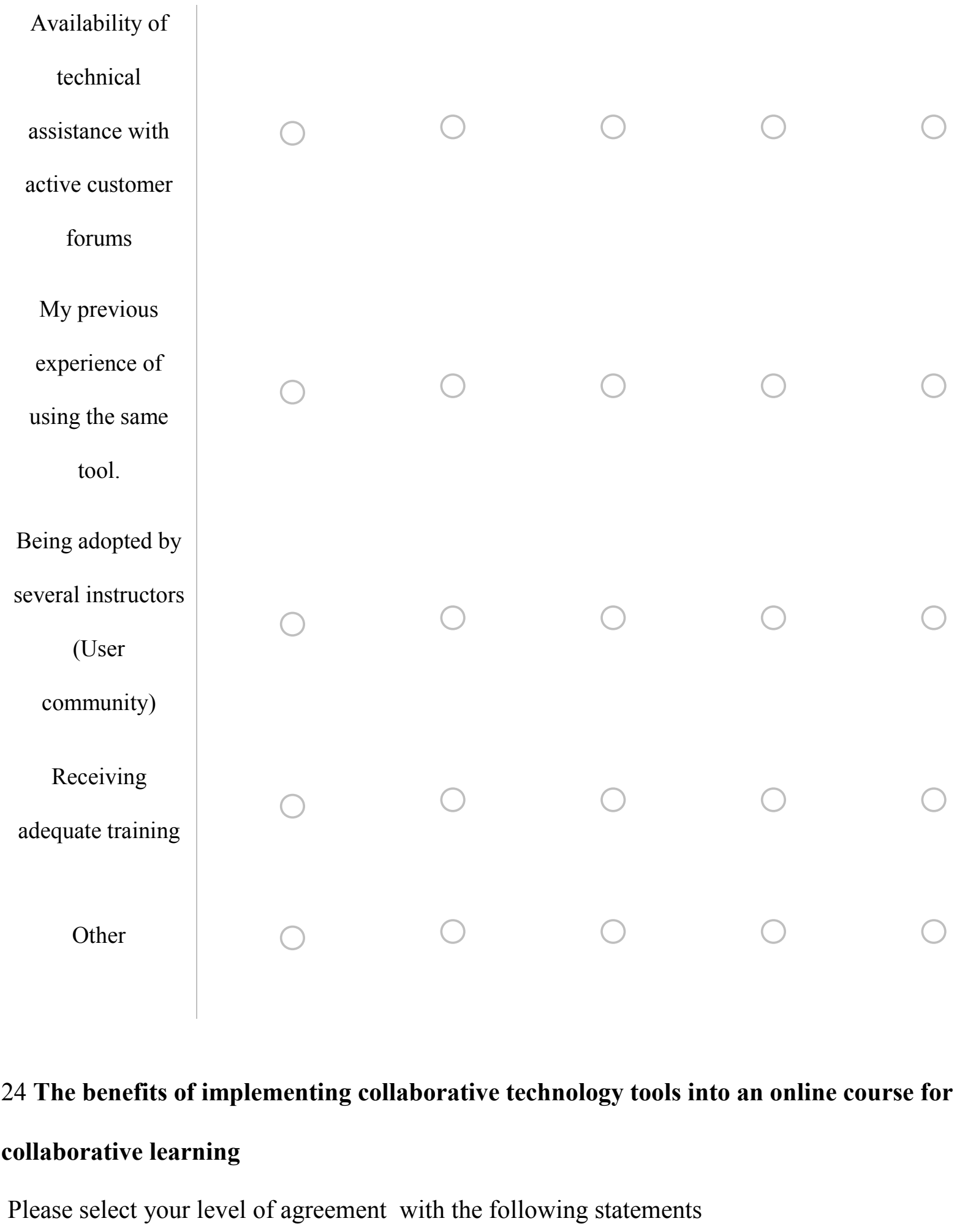




\begin{tabular}{|c|ccccr} 
Strongly & Somewhat & Neither & & Somewhat & Strongly \\
agree & agree & agree nor & disagree & disagree
\end{tabular}

Facilitating collaborative learning to become easier.

Promoting collaboration and team work.

Making communication easier and more productive.

Helping students obtain a deeper understanding of the material.

Decreasing student resistance to group work Increasing group performance.

Monitoring the progress of group work. 


Building necessary
collaboration and
communication skills

Developing higher level thinking skills

Fostering critical
thinking.

Developing 21st-century skills
Training for post-
educational work.
Preparing students for the
real world and workplace
Increasing interaction and
connection

\footnotetext{
Allowing students to communicate and network.

linking students to help one another learn
} 


Enhancing collaborative
learning experience
Expanding educational
options for students
Promoting interactive and
engaging learning
teacher interaction.
Creating online learning
community.
student-student
timely feedback.
Increasing student
learning responsibility
isolation in online course
Increasing student
productivity in group




Reflecting changing
learning style
preferences/ Addressing
learning style differences
Making learning more
enjoyable.
Fostering positive student
attitudes towards
learning.
course.
Motivating students to
actively and fairly
flexibility and engaging
participate in group work.
Minimizing, if not
eliminating, travel costs


Other

25 Do you have any additional information, comments, thoughts, or suggestions to better use collaborative tools for collaborative learning?

26 If you are willing to participate in a follow-up interview, please click here to provide your name and email address. 


\section{APPENDIX E: STUDENT SURVEY}

\section{$\underline{\text { Student Survey }}$}

\section{Gender}

Male

Female

Other

2 Age

20 and below

$21-25$

26-30

31 and above

3 Educational level

Undergraduate

Graduate

4 Degree

Associate's

Bachelor's 
Master's

Doctorate

Non-Degree Courses.

\section{School/Department}

Department of Agriculture

Department of Chemistry

Department of Communication Sciences and Disorder

Department of Criminal Justice Sciences

Department of Economics

Department of Educational Administration and Foundation

Department of English

Department of Family and Consumer Sciences

Department of Geography-Geology

Department of History

Department of Languages, Literatures and Cultures 
Department of Mathematics

Mennonite College of Nursing

Department of Politics and Government

Department of Psychology

Department of Sociology and Anthropology

Department of Special Education

Department of Technology

School of Art

School of Biological Sciences

School of Communication

School of Information Technology

School of Kinesiology and Recreation

School of Music

School of Social Work

School of Teaching and Learning 
School of Theatre and Dance

Other

6 Please rate your comfort/confidence using technology:

Very comfortable

Comfortable

Neither comfortable nor uncomfortable

Uncomfortable

Very uncomfortable

*Online Course: A courses where all or at least 80 percent of the content is delivered online. 
7 Have you ever had experience taking an online course?

Yes

No

8 If yes, what was the format of the online courses you participated in?

$100 \%$ online

Blended/hybrid

Student Experience in Collaborative Learning in Online Courses

*Collaborative learning: An educational approach of learning through a coordinated and shared environment where groups of students work together toward a common task. 
9 How many times have you been involved in a collaborative learning or group work required for an online course?

$1-3$ times

4- 10 times

11-20 times

more than 20 times

Student Experience in Using Collaborative Techmology Tools

*Collaborative technology tools: The technology tools that enable individuals and groups to communicate, collaborate, and interact in online environments in order to accomplish a common task, share or exchange information, and construct knowledge without the use of face-to-face interaction. 
10 Have you used any of collaborative technology tools for technical communication or collaboration prior to taking your online course?

Yes

No

11 Have you used any collaborative technology tool in your online courses?

Yes

No 
12 What collaborative technology tools being integrated into your online course?

Google Applications (Google Drive: Docs, Sheets, Slides, Draw)

Microsoft Applications/Microsoft Office 365 (OneNote Class Notebook)

Social Networking Tools (Facebook, Linked-in, Skype, Twitter, WhatsApp, SnapChat)

Wikis

Blogs

Microblogging

Web Conferencing

Presentation \& Slide Sharing

Blackboard Collaborate

Discussion Forms

Other

13 Do you think the use of collaborative technology tools improve your group work?

Definitely yes 
Probably yes

Might or might not

Probably not

Definitely not

14 Overall, how positive were your online collaborative learning experiences?

Extremely positive

Somewhat positive

Neither positive nor negative

Somewhat negative

Extremely negative

15 Please select your level of agreement with the following statements:

Using collaborative technology tools for group work in an online course can... 


$\begin{array}{ccccc}\text { Strongly } & \text { Somewhat } & \text { Neither agree } & \text { Somewhat } & \text { Strongly } \\ \text { agree } & \text { agree } & \text { nor disagree } & \text { disagree } & \text { disagree }\end{array}$

Help students to
understand the
material.
Facilitate group
work to become
easier.
Minimize, if not
eliminate, travel
costs for group
work.
wonork.
productive
Make group
communication
flexibility and
engaging work-
from-home




Motivate students to
actively and fairly
participate in group
work.
Increase student
learning
responsibility
Increase student
productivity in
group work.
century skills
Increase group
collaboration and
performance.
Allow students to
communicate and




Train students for
post-educational
work.
Prepare students for
the real world and
workplace
link students to help
one another learn
Create online
learning community.

Decrease the sense

of isolation in online course

Create interactive
and engaging
learning experiences
Improve the quality
of student-student
interaction and
student-teacher
interaction.


Make learning more enjoyable.

Other

16 Do you have any additional information, comments, thoughts, or suggestions to better use collaborative tools for collaborative learning?

17 If you are willing to participate in a follow-up interview, please click here to provide your name and email address. 
APPENDIX F: E-MAIL INVITATION TO PARTICIPATE IN A FOLLOW-UP INTERVIEW

\section{Dear student/faculty member:}

Thank you for taking the time to participate in the survey COLLABORATIVE TECHNOLOGY TOOLS IN ONLINE LEARNING ENVIRONMENTS. You have been selected to participate in a follow-up interview. This interview will take approximately 20-40 minutes of your time. The interview will take place at a mutually agreed upon time and location.

Your participation in the study is strictly voluntary. You have the right to refuse to participate or discontinue participation at any time without penalty or loss of benefits. There are no direct benefits to participants. However, your participation will help gain useful knowledge about the best practices of using collaborative technology tools to support collaboration experiences and student engagement in online learning.

The risks associated with this research are no greater than those encountered in everyday life. However, participants that are faculty members could feel that they are sharing information that could increase employment risks by making statements that are unfavorable toward the University. To minimize this risk, your responses to this survey will be confidential and will only be reported as group data with no identifying information. The interviews will be audio recorded, with your consent. The audio files will be used to be sure that the research does not miss any important information and will not be shared with anyone other than the research team. If you have any questions regarding this study, please feel free to contact me at aalahma@,ilstu.edu or 
(309) 433-6679. You may contact my advisor Dr. Ryan A. Brown at rbrown@ilstu.edu or (309) 438-3964. If you have any questions about your rights as a participant in this research, you may contact the Research Ethics \& Compliance Office at Illinois State University at (309) 438- 2529 or via email at rec@ilstu.edu.

Please click $\underline{\text { Here }}$ to select a suitable date and time:

Sincerely,

Ayshah Alahmari

Doctoral Candidate, School of Teaching and Learning

Illinois State University, Normal, IL

(309) 433-6679

Email: aalahma@ilstu.edu 


\section{APPENDIX G: INFORMED CONSENT FOR THE INTERVIEW}

\section{Dear student/faculty member:}

You are invited to participate in a research study that explores collaboration in online courses. This study aims to develop a more complete understanding of the effective use of collaborative technology tools to support collaboration experiences and student engagement in online learning.

If you choose to take part in this portion of the research study, you will be asked to complete an interview. This interview will take approximately 20-40 minutes of your time. The interview will take place at a mutually agreed upon time and location. Your participation in the study is strictly voluntary. You have the right to refuse to participate or discontinue participation at any time without penalty or loss of benefits. There are no direct benefits to participants. However, your participation will help gain useful knowledge about the best practices of using collaborative technology tools to enhance collaborative learning in online learning environments.

The risks associated with this research are no greater than those encountered in everyday life. However, participants that are faculty members could feel that they are sharing information that could increase employment risks by making statements that are unfavorable toward the University. To minimize this risk, your responses to this survey will be confidential and will only be reported as group data with no identifying information. The interviews will be audio recorded, with your consent. The audio files will be used to be sure that the research does not miss any important information and will not be shared with anyone other than the research team. If you 
have any questions regarding this study, please feel free to contact me at aalahma@ilstu.edu or (309) 433-6679. You may contact my advisor Dr. Ryan A. Brown at rbrown@ilstu.edu or (309) 438-3964. If you have any questions about your rights as a participant in this research, you may contact the Research Ethics \& Compliance Office at Illinois State University at (309) 438- 2529 or via email at rec@ilstu.edu.

Sincerely,

Ayshah Alahmari

Doctoral Candidate, School of Teaching and Learning

Illinois State University, Normal, IL

(309) 433-6679

Email: aalahma@ilstu.edu

\section{Consent:}

Signing below indicates that I am 18 years or older and give my consent to participate.

Name Signature Date

Signing below indicates that I give my consent to be audio recorded for this study.

Name Signature Date




\section{APPENDIX H: FACULTY INTERVIEW PROTOCOL}

\section{Introductory Protocol}

To facilitate our note-taking, we would like to audio tape our conversations today. Please sign the release form. For your information, only the researcher on the project will be privy to the tape which will be eventually destroyed after it is transcribed. In addition, you must sign a form devised to meet our human subject requirements. Essentially, this document states that: (1) all information will be held confidential, (2) your participation is voluntary and you may stop at any time if you feel uncomfortable, and (3) we do not intend to inflict any harm. Thank you for agreeing to participate.

We have planned this interview to last no longer than one hour. During this time, we have several questions that we would like to cover. If time begins to run short, it may be necessary to interrupt you in order to push ahead and complete this line of questioning.

\section{Introduction}

You have been selected to speak with us today because you have been identified as someone who has a great deal to share about online learning and the use of collaborative technologies. Our research project as a whole focuses on examining the impact of the use of collaborative technologies on collaboration experiences in online learning environments, with a particular interest in understanding how faculty incorporate collaborative eLearning activities in their online courses, and what factors hinder faculty when developing and implementing collaborative learning into their online courses. Our study does not aim to evaluate your techniques or 
experiences. Rather, we are trying to learn more about online learning, and hopefully learn about faculty practices that help improve collaborative learning.

\section{A. Interviewee Background}

1. What is your highest degree?

2. What is your field of study?

3. How long have you been teaching online courses?

\section{B. Interviewee Perspective About Collaborative eLearning}

4. Do you incorporate collaborative eLearning activities in your online courses? How?

5. What factors hinder you when developing and implementing collaborative learning into your online courses?

6. What do you view as benefits and challenges associated with collaborative learning?

\section{Interviewee Perspective About the use of Collaborative Technology Tools}

7. What are the collaborative technology tools you integrate into your online course for collaborative learning? how do you use them?

8. Which types of collaborative tools do you consider effective for collaborative learning?

9. What motivates you to use collaborative tools in your online course?

10. Do you think the use of these tools impact collaboration experiences in your online course? How?

11. What do you do to help your students succeed in using these tools for collaboration?

12. What do you do to keep teamwork alive, motivated, and enthused? What do you do to address student resistance of participation in groups? 
13. How are students performing in using these tools for collaboration?

14. In which ways do you think collaborative technology tools can improve the quality of online learning?

15. What challenges do you face when using these tools for collaborative learning in your online course?

16. What type of assistance do you need to integrate these tools into your online course?

17. Do you feel you are supported by your institute?

18. Describe the quality of the support (professional development or training) that you have received on the use of technology for collaborative activities in online learning?

19. What professional development or training is needed to improve the use of collaborative technology tools?

20. What tips do you give for successfully adopting collaborative technology tools in an online course?

21. Is there anything else you would like to mention about the use of collaborative tools in online learning?

\section{Thank you for your time.}




\section{APPENDIX I: STUDENT INTERVIEW PROTOCOL}

\section{Introductory Protocol}

To facilitate our note-taking, we would like to audio tape our conversations today. Please sign the release form. For your information, only the researcher on the project will be privy to the tape which will be eventually destroyed after it is transcribed. In addition, you must sign a form devised to meet our human subject requirements. Essentially, this document states that: (1) all information will be held confidential, (2) your participation is voluntary and you may stop at any time if you feel uncomfortable, and (3) we do not intend to inflict any harm. Thank you for agreeing to participate.

We have planned this interview to last no longer than one hour. During this time, we have several questions that we would like to cover. If time begins to run short, it may be necessary to interrupt you in order to push ahead and complete this line of questioning.

\section{Introduction}

You have been selected to speak with us today because you have been identified as someone who has a great deal to share about online learning and the use of collaborative technologies. Our research project as a whole focuses on examining the impact of the use of collaborative technologies on collaboration experiences in online learning environments. Our study does not aim to evaluate your experiences. Rather, we are trying to learn more about online learning, and hopefully learn about best practices that help improve collaborative learning. 


\section{A. Interviewee Background}

1. Are you a graduate or an undergraduate student?

2. Are you a Full-Time or a Part-Time student?

\section{B. Interviewee Perspective About Collaborative eLearning}

3. What is your opinion about learning collaborative technology skills?

4. How was your experience in collaborative learning?

5. How well did your instructor facilitate collaborative learning in the online course?

\section{Interviewee Perspective About Collaborative Technology Tools}

6. What are the collaborative technology tools being used in your online course?

7. Have you used any of these tools for technical communication or collaboration prior to taking your online course?

8. Have you been taught to effectively collaborate using these tools?

9. What is your opinion about the use of these tools in your online collaboration experience?

10. What do you view as the pros and cons of using these tools for collaborative learning?

11. What were some of the challenges you faced in using those tools?

12. What tips do you give for successfully adopting collaborative technology tools in an online course?

13. Do you have any additional information, comments, or questions?

\section{Thank you for your time.}

